\title{
Aplicação de Texturas em Visualização Científica
}

\author{
Marcelo de Barros Mendonça \\ Prof. Dr.: João do Espírito Santo Batista Neto
}

Monografia apresentada ao Instituto de Ciências Matemáticas e Computação de São Carlos - USP, para obtenção do título de Mestre em Ciências - Área de Ciências de Computação e Matemática Computacional.

Instituto de Ciências Matemáticas e Computação

Universidade de São Paulo - São Carlos

Outubro de 2001 
A Deus pela vida e Aos meus pais Marcelino e Izilda pelo amor, carinho, e apoio 


\section{Agradecimentos}

A Ana Paula Guasi pelo amor, compreensão e apoio.

Aos orientadores Dr. João do E. S. Batista e Dra.Maria Cristina F. de Oliveira por toda paciência e empenho ao longo deste trabalho.

A CNPq pelo fomento deste trabalho.

Ao professor Dr. Antônio Castelo Filho pelos dados vetoriais fornecidos a este trabalho.

A professora Dra. Rosane Minghim por toda ajuda.

Aos meus irmãos Vinicius e Raphael pela ajuda e incetivo.

Aos amigos Rodrigo, Kleber, Reginaldo pela ajuda e apoio.

A Beth, Marília e Laura da Secretaria de Pós-graduação por todo empenho.

A todos que cooperaram e apoiaram este trabalho. 


\section{Resumo}

A crescente disponibilidade de recursos computacionais para o cálculo, simulação e aquisição de dados permite que cientistas e engenheiros produzam enormes conjuntos de dados, bi ou tridimensionais, em geral multivariados. A aplicação de técnicas de Computação Gráfica com o objetivo de ganhar compreensão desses dados compreende o objeto de estudo da área conhecida por Visualização Científica .

Texturização é uma forma de variar as propriedades de uma superfície ponto a ponto de forma que esta simule detalhes que não estão de fato presentes na sua geometria. A texturização pode ser aplicada usando as técnicas de mapeamento de textura, e a textura procedimental .

Conjuntos de dados vetoriais tridimensionais necessitam de técnicas complexas e computacionalmente caras para que sejam visualizadas com sucesso. No caso de dados vetoriais densos, a visualização torna-se mais difícil, uma vez que as técnicas convencionais não produzem uma visualização adequada desse dados.

A técnica conhecida por Line Integral Convolution (LIC) produz bons resultados para conjunto de dados vetoriais densos a um custo computacional aceitável. Esta técnica utiliza uma textura de ruído branco e o cálculo de streamlines como base para a geração da imagem LIC. Esta técnica produz assim uma imagem bidimensional de uma fatia selecionada desse conjunto de dados, interpolando a textura ruído segundo o campo vetorial a ser visualizado.

Este trabalho propõe-se a invertigar a técnica LIC e sua relevância no contexto de visualização científica, através da implementação da classe vtkImageLIC. Esta classe segue os princípios de orientação a objetos podendo, assim, ser integrada à biblioteca de visualização VTK, conferindo-lhe portabilidade e capacidade de extensão. 


\section{Abstract}

The increasing availability of computational resources for calculus, simulation and data acquisition allow scientists and engineers to generate enormous datasets, bi or tridimensional, generally, multi-varied. The application of Computer Graphics techniques aiming at gathering a better understanding of these data is the target of an area known as Scientific Visualization (ViSC).

Texturing is a means of changing the surface's properties step by step in such a way that it simulates details which are not present in the surface's geometry. Texturing can be applied through texturing mapping and procedural techniques.

Tridimensional vectorial datasets require complex and computer-demanding techniques to be successfully visualized. For dense vectorial dataset, the visualization becomes more difficult, since conventional techniques do not generated an adequate visualization of data.

The technique known as Line Integral Convolution (LIC) produces better results for dense vectorial dataset within acceptable computational costs. This technique uses a white noise texture and streamline calculus as the foundation for LIC image generation. As a result, the technique produces a bidimensional image of a selected slice of the dataset, by interpolating the white noise texture according to the vector field to be visualized.

This work aims to investigate the LIC technique and its relevance in the context of Scientific Visualization, culminating with the implementation of the vtkImageLIC class. This class is bound to object oriented programming principles and can be integrated with the VTK visualization Library, allowing it to be portable and easily extensible. 


\section{Sumário}

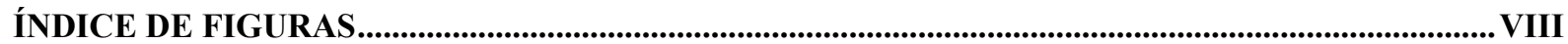

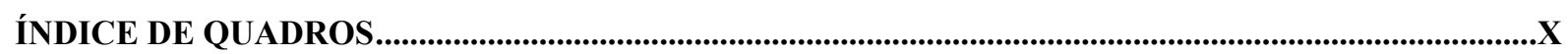

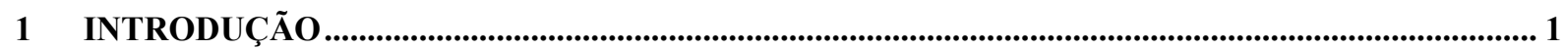

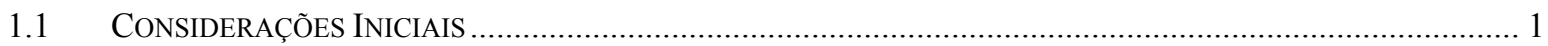

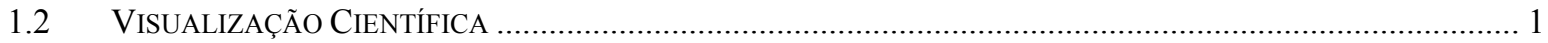

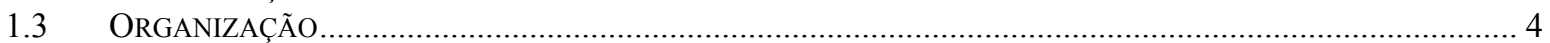

2 TEXTURAS

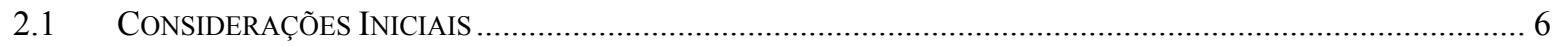

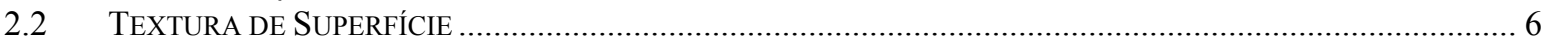

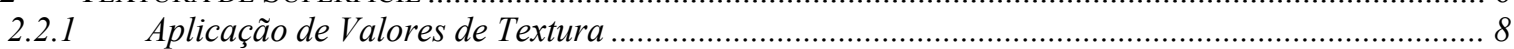

2.2.2 Mapeamento da Textura Sobre Superficies Poligonais ............................................................... 11

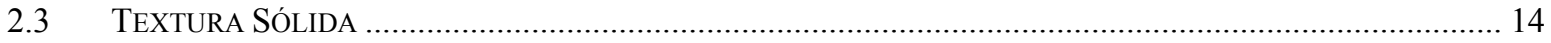

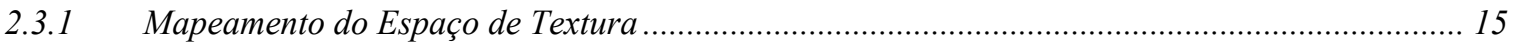

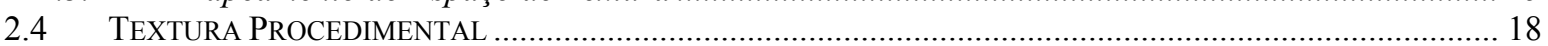

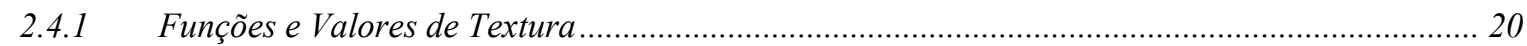

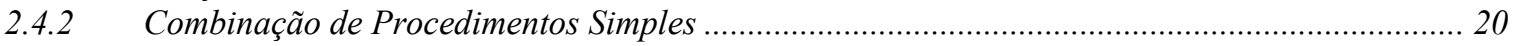

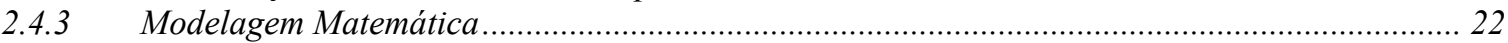

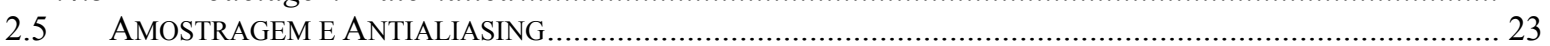

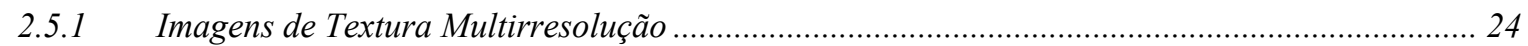

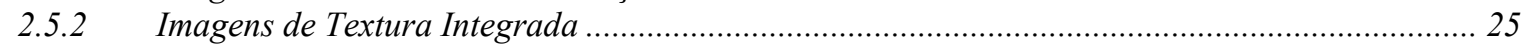

3 TÉCNICAS DE VISUALIZAÇÃO BASEADAS EM TEXTURAS ................................................. 27

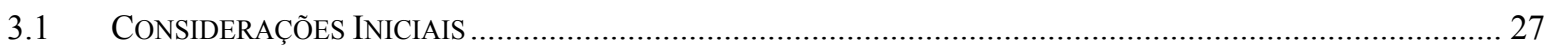

3.2 TEXTURA COMO Alternativa Para MAPEAMENTO POR Cores, Isolinhas, ReCORTE E Filtragem.

\begin{tabular}{|c|c|}
\hline 3.2 .1 & Mapeamento por Cores....... \\
\hline 3.2 .2 & Isolinhas sobre Superficies.. \\
\hline 3.2 .3 & Filtragem de Informação .... \\
\hline 3.2 .4 & Recorte de Superficies Arbitrárias........ \\
\hline & ITURA COMO ALTERNATIVA EFICIENTE PARA RENDERING VOLUMÉTRICO DIRETO ............................. 34 \\
\hline 3.3.1 & 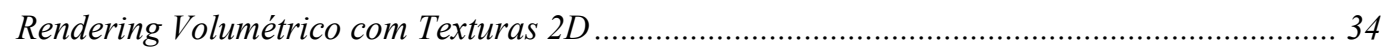 \\
\hline 3.3 .2 & 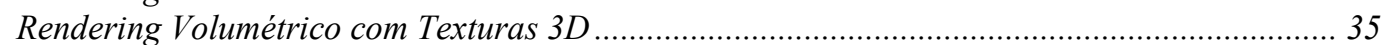 \\
\hline & 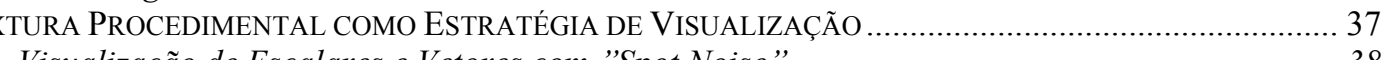 \\
\hline
\end{tabular}

4 VISUALIZAÇÃO DE DADOS VETORIAIS USANDO "LINE INTEGRAL CONVOLUTION"

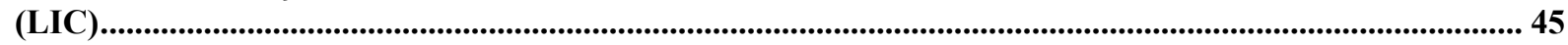

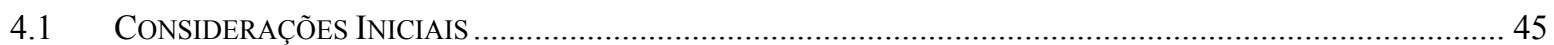

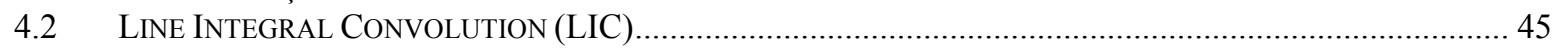

4.3 InTERPolaÇ̃̃o Usando AlgoritMo DDA (Digital DifFERENTIAL ANALYSER) …........................... 46

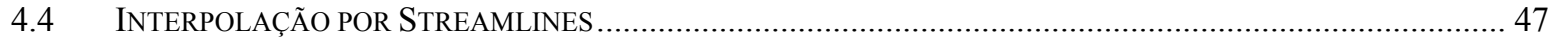

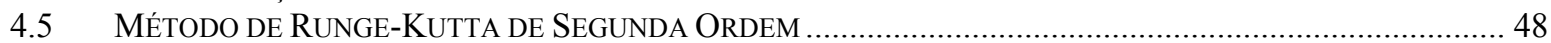

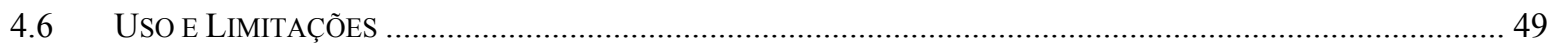

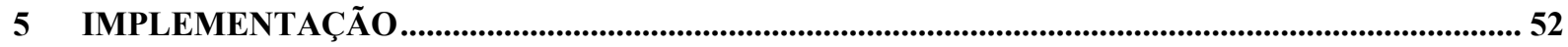

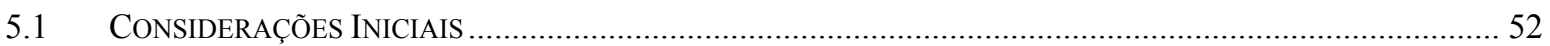




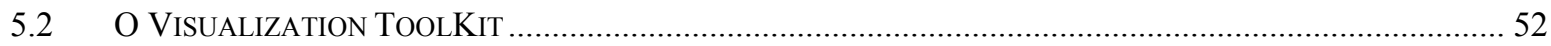

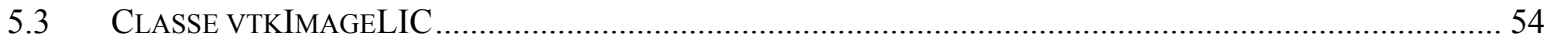

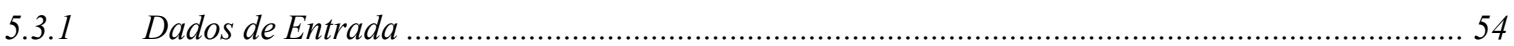

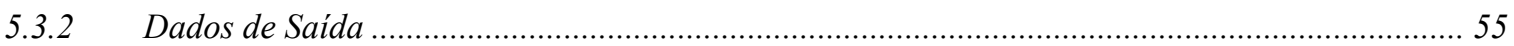

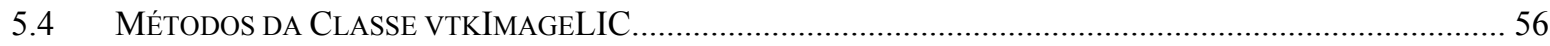

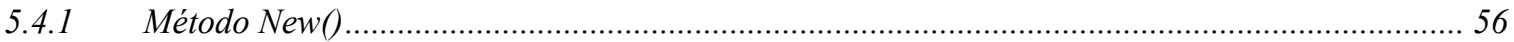

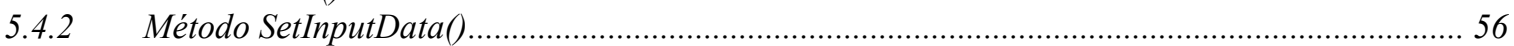

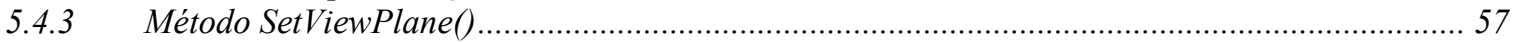

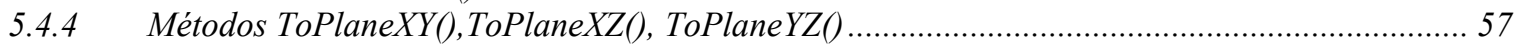

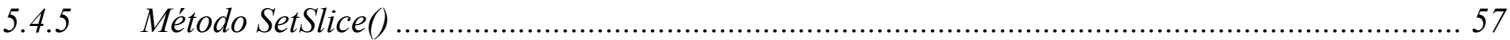

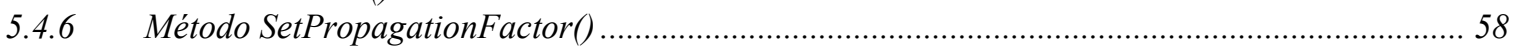

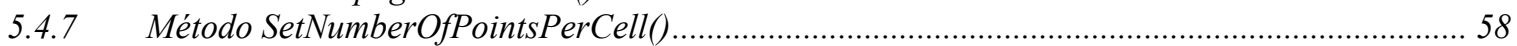

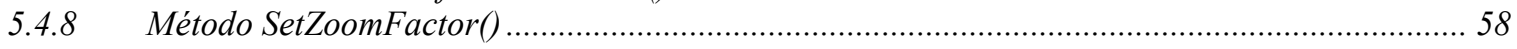

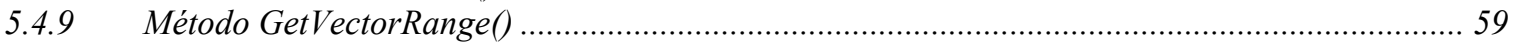

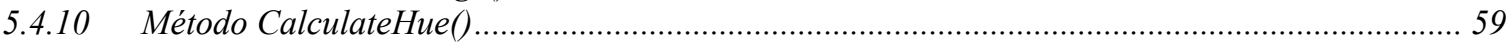

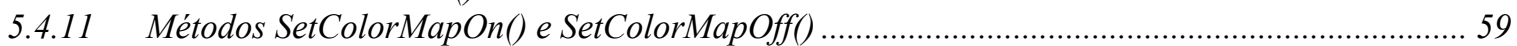

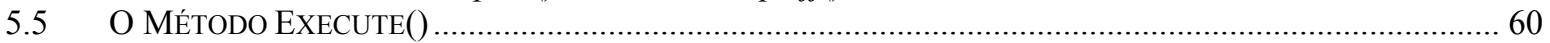

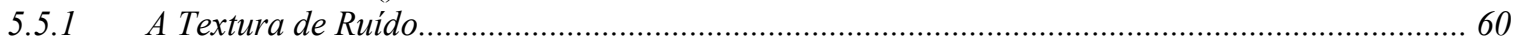

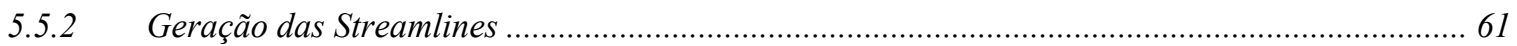

5.5.3 A Interpolação entre a Textura e as Streamlines ...................................................................6. 62

5.5.4 Mapeamento por Cores da Magnitude Vetorial................................................................... 63

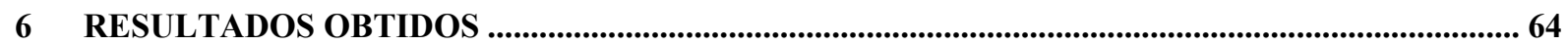

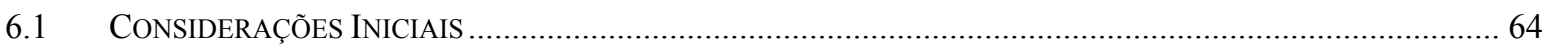

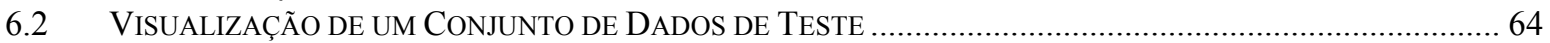

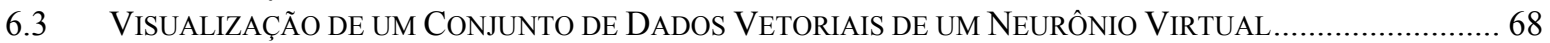

6.4 VISUALIZAÇÃO DE UM CONJUNTO DE DADOS ESPARSOS ............................................................... 70

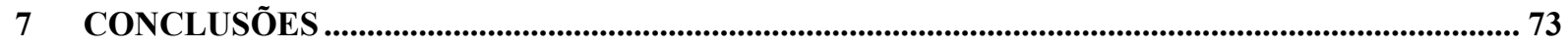

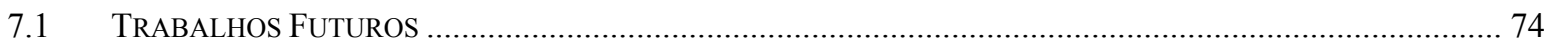

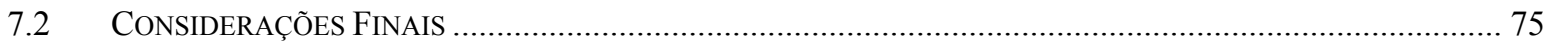

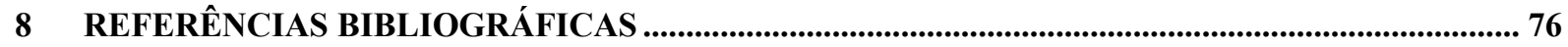

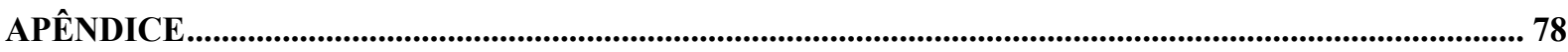

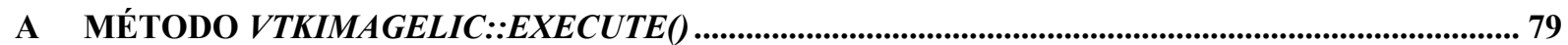




\section{Índice de Figuras}

Figura 2.1 - Textura com intensidade (ovo) e transparência (copo) [CRO90] .................................................. 9

Figura 2.2 - Fotografia e coloração de vértices como textura [CRO90] ...................................................... 10

Figura 2.3 - Textura como coeficiente de reflexão [CRO90] ................................................................... 10

Figura 2.4 - Texturas geradas com mapeamento bump (a esquerda) e com mapeamento de intensidades (a

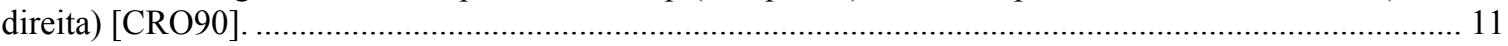

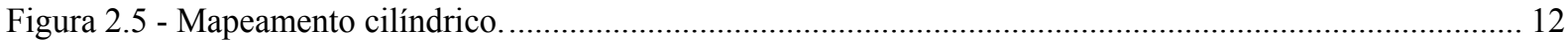

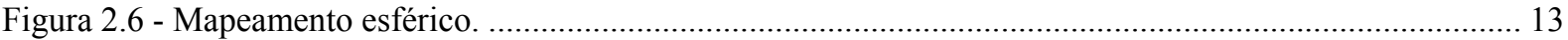

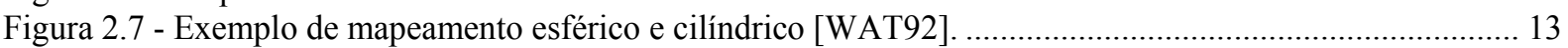

Figura 2.8 - Nuvem criada usando textura sólida e função de ruídos [EBE98] .............................................. 14

Figura 2.9 - Aplicação de uma função simples para preenchimento do espaço de textura [CRO90] .................. 17

Figura 2.10 - Chaleira usando um textura sólida pseudonatural [CRO90] ................................................. 18

Figura 2.11 - Exemplo de uma textura multirressolução [WAT92] ............................................................ 25

Figura 2.12 - Textura de tabuleiro. Com aliasing (a), multirresolução (b) e integrada (c) [CRO90]. ................. 26

Figura 3.1 - Interpolação RGB (esquerda) e mapeamento de textura (direita) [TES98] ...................................28

Figura 3.2 - Molécula de etanol, usando interpolação RGB (esquerda) e mapeamento de textura (direita)

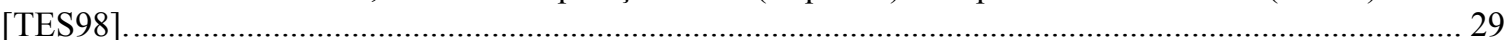

Figura 3.3 - Isolinhas na superfície, mostrando a escala no espaço de textura. Textura original à esquerda e

textura escalada à direita. [TES98]. ........................................................................................ 30

Figura 3.4 - Mostra a métrica na superfície molecular do zeolítio com uma textura 2D [TES98] ..................... 31

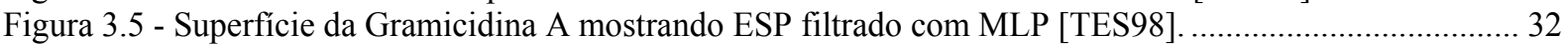

Figura 3.6 - Recorte da superfície da Gramicidina A de acordo com MLP [TES98].................................... 33

Figura 3.7 - Plano de corte dentro da densidade da água que cerca a molécula de açúcar [TES98]................... 36

Figura 3.8 - Rendering Volumétrico de dados de Ressonância Magnética usando pilha de fatias paralelas à tela

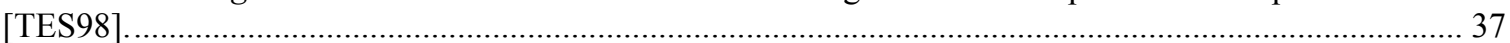

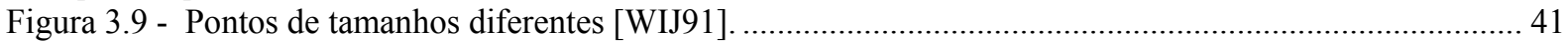

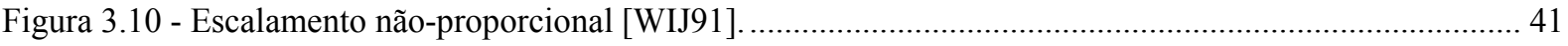

Figura 3.11 - Padrões Regulares na Textura [WIJ91] ......................................................................... 42

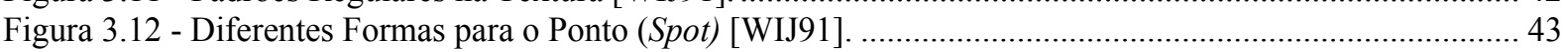

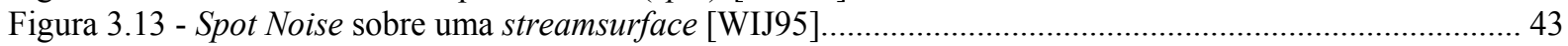

Figura 3.14 - Cor mostrando pressão, utilizando spot noise [WIJ95] ......................................................... 44

Figura 3.15 - Visualização da fricção do vento sobre uma superfície em simulador de túnel de vento [WIJ95].. 44

Figura 4.1 - (a) Ruído branco, (b) campo vetorial 2D, (c) textura de ruído branco filtrada com o campo vetorial [GRÖ99].

Figura 4.2 - Mapeamento do vetor por convolução DDA gerando a imagem de saída.....................................46

Figura 4.3 - Ponto calculados através do método de Euler. A imprecisão é claramente notada. ........................ 49

Figura 4.4 - Método de Runge-Kutta de Segunda Ordem. Pontos intermediários $(2,4)$ melhoram a precisão em relação ao método de Euler.

Figura 4.5 - OLIC: LIC com textura esparsa e função kernel tipo rampa....................................................50

Figura 4.6- (a) Imagem LIC de um fluxo circular, (b) Imagem OLIC com fluxo horário, (c) Imagem OLIC com

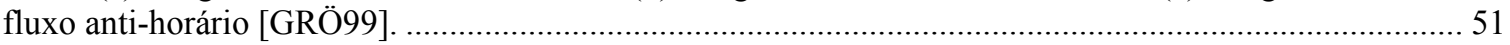

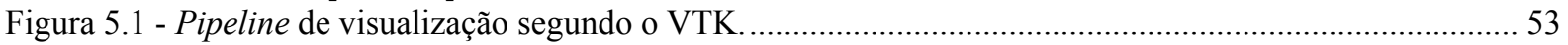

Figura 6.1 - Imagens LIC relativas às fatias 5, 15, 25, 35, 45 e 55 do conjunto de dados. ..............................6 65

Figura 6.2 - Imagens LIC com fator de ampliação (ZoomFactor) igual a 2.0, 3.0 e 4.0 respectivamente............66

Figura 6.3 - Imagens LIC representando os planos XY, XZ, YZ respectivamente...........................................6 66

Figura 6.4 - Comparativo entre uma imagem LIC mapeada por cores e em tons de cinzas..............................67

Figura 6.5 - Comparativo entre visualização por streamline (a esquerda) e uma imagem LIC (a direita)...........6 67

Figura 6.6 - Fatias de número 24, 26, 28, 30, 32, 34, 36 e 38 do conjunto de dados vetoriais de um neurônio virtual.

Figura 6.7 - Imagens LIC dos dados vetoriais de um neurônio virtual pelo planos XY, XZ, YZ, respectivamente.

Figura 6.8 - Comparativo entre imagens LIC colorida e em tons de cinzas do campo vetorial de um neurônio virtual.

Figura 6.9 - Comparativo entre uma visualização por streamline e uma imagem LIC.................................... 70 
Figura 6.10 - Fatias de número 8.0, 8.2, 8.4, 8.5, 8.7, 8.9 do conjunto de dados esparsos de um fluido gerado por

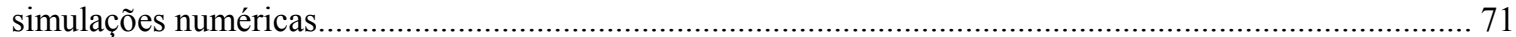

Figura 6.11 - Comparativo entre visualização por streamlines e imagem LIC . ............................................. 71

Figura 6.12 - Comparativo entre imagens com mapeamento por cores e em tons de cinzas. ............................ 72 


\section{Índice de Quadros}

Quadro 2.1 - Código usado para texturizar o ovo da figura 2.2. ................................................................... 16

Quadro 2.2 - Código usado para texturizar o ovo da figura 2.9. .................................................................... 16

Quadro 2.3 - Código usado para gerar a transparência no copo da figura 2.1 ……............................................ 17

Quadro 5.1 - Trecho de código usado para gerar a textura de ruído através da classe vtkImageNoiseSource ...... 61

Quadro 5.2 - Trecho de código usado para gerar uma streamline a partir do ponto $(x, y, z)$................................ 62

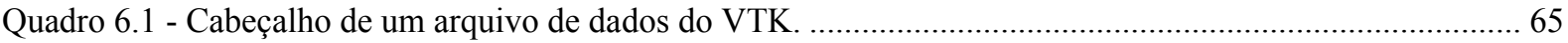




\section{Introdução}

\subsection{Considerações Iniciais}

A incorporação de "realismo" em imagens sintetizadas em computador foi fortemente auxiliada pela introdução da textura de superfície, em meados de 1970. Técnicas de texturização de superficie permitiram criar imagens visualmente interessantes e ricas sem a necessidade de produzir descrições complexas das superfícies dos objetos. Desde então, muitas técnicas de texturização foram criadas e exploradas, e a textura passou a ser uma característica essencial na qualidade de uma imagem sintética.

As primeiras técnicas utilizavam o mapeamento de uma imagem, muitas vezes obtida de uma fotografia, ou uma imagem sintética, para aumentar o realismo do objeto. Uma alternativa em situações em que imagens bidimensionais (2D) não produzem resultados satisfatórios consiste em usar textura sólida, uma abordagem tridimensional (3D) que em alguns casos produz resultados melhores do que o mapeamento de textura convencional. No entanto, esta abordagem necessita de uma grande quantidade de memória para armazenar as texturas. Visando contornar este problema surgem funções para a geração de uma textura com características semelhantes àquela que seria armazenada. Para isso, existe uma grande variedade de funções que simulam efeitos naturais, como a textura de mármore ou de madeira.

\subsection{Visualização Científica}

Existem várias definições para Visualização. No seu sentido amplo, a palavra significa a geração de imagens mentais para a organização e entendimento de um conceito, idéia ou informação. Formulações alternativas relacionam essa definição a um contexto computacional. Uma definição que trata especificamente de Visualização Científica (ViSC), é: "Visualização é mais do que um método de computação. Visualização é o processo de transformar informação para uma forma visual, permitindo aos usuários observar a informação. A apresentação visual resultante permite ao cientista ou engenheiro perceber 
visualmente características que estão escondidas nos dados, mas que são necessárias para tarefas de exploração e análise" [GER94].

Os dados em ViSC podem estar definidos sobre domínios 1D, 2D, 3D e, genericamente multidimensionais. Em geral, eles estão organizados em uma malha (regular ou irregular), mas podem se constituir de um conjunto de pontos esparsos. As informações associadas a cada ponto podem ser um ou mais valores escalares, vetoriais ou tensoriais, e os dados podem ser estáticos ou variantes no tempo. Geralmente, em visualização de dados escalares definidos em domínios 1D usam-se gráficos de barra ou histogramas. Essas técnicas também podem ser estendidas para o domínio 2D.

Uma técnica bastante comum para visualização de escalares consiste em associar uma tabela de cores usando os valores escalares como índice para a tabela. A tabela é um vetor de cores na forma RGB, e está associada a um intervalo de variação (scalar range) definido por um valor mínimo e um valor máximo. A questão chave para a geração de boas visualizações é escolher cuidadosamente as entradas na tabela de cores, uma tarefa nem sempre simples [BRO92; MIN97a].

Outra técnica usada para visualizar escalares são as isolinhas ou mapas de contornos. Esta técnica consiste em traçar isolinhas de valor constante sobre uma superfície. Os parâmetros para essa técnica são os valores de interesse. A geração de isolinhas requer alguma técnica de interpolação, a qual depende da organização dos dados. No caso de domínios 3D estende-se essa técnica de forma a gerar isosuperfícies, aplicando um detector de superfícies ao volume de pontos amostrados e, em seguida, ajustando primitivas geométricas sobre as superfícies detectadas [MIN97a].

Uma vantagem das isosuperfícies é a possibilidade de identificação de estruturas nas medições ou simulações. Elas também permitem análise em tempo real, pois, apesar do processo de extração das superfícies ser lento, a renderização das superfícies resultantes pode ser muito rápida, principalmente se feita por hardware. Entre as desvantagens, tem-se a perda da informação relativa ao conteúdo do conjunto de dados fora dos valores selecionados para 
traçado. Além disso, nem sempre os dados podem ser descritos em termos de superfície, como é o caso de objetos amorfos como nuvens ou fumaça.

Para solucionar o problema da perda da informação na técnica de isosuperfícies criou-se técnicas de rendering volumétrico direto ou DVR (Direct Volume Rendering). As técnicas de DVR permitem a renderização direta de conjuntos de dados $3 \mathrm{D}$, sem a geração de primitivas geométricas intermediárias, pois não trabalham com superfícies, mas com voxels do volume. Elas permitem ao usuário enxergar "dentro" ou "através" do volume de dados. Uma das técnicas mais usadas para DVR é o Ray Casting. Nela são disparados raios que atravessam o volume de dados em linha reta coletando informações como cor e opacidade. Esse raio pára quando atinge o fundo do volume de dados, ou quando a opacidade acumulada atinge o valor máximo (1), sendo que não são geradas reflexões desses raios.

Uma vantagem desta técnica é que objetos pequenos ou pouco definidos são mostrados. Além disso, o processo não envolve uma classificação binária de "dentro" ou "fora" como no caso das isosuperfícies. As imagens mostram o conteúdo do volume todo, e não apenas uma superfície em particular. Outro ponto é que o traçado de cada raio é independente, o que torna o algoritmo facilmente paralelizável. O custo computacional dessa técnica é alto, porém pode ser reduzido utilizando placas gráficas que suportam DVR por hardware como, por exemplo, a placa VolumePro VG500.

No caso de dados vetoriais, outras estratégias podem ser usadas. Uma delas consiste em utilizar ícones puntuais (glyphs ou hedgehogs), que são segmentos de reta orientados segundo a direção e sentido, e em geral de comprimento proporcional à magnitude do dado a ser visualizado. Um glyph é um "objeto" cuja aparência é afetada por atributos de um dado de entrada ao qual está associado. No caso dos hedgehogs, o glyph é uma seta, mas outra representação poderia ser adotada. O principal problema desta técnica deve-se à ambigüidade da projeção final dos glyphs, pois, em geral, um segmento de reta projetado num plano pode corresponder a várias posições no espaço, gerando problemas de orientação [BRO92; MIN97a]. 
Outra técnica usada para visualizar vetores consiste em conectar a posição do ponto $x(t)$, em vários instantes de tempo. O resultado é uma aproximação numérica para a trajetória de uma partícula, representada por uma linha. Esta técnica é conhecida como linhas de escoamento. As linhas de escoamento são mais eficientes do que ícones puntuais para transmitir características gerais do escoamento, pois geram representações com menor congestionamento visual. Entretanto esquemas de interpolação e de integração numéricas adotados são sérias fontes de erros de visualização. Processos numéricos elevam o custo da visualização de linhas de escoamento consideravelmente em relação a ícones puntuais, principalmente no caso 3D [MIN97a].

Uma extensão natural da técnica de linhas de escoamento consiste em criar uma fita gerando duas linhas de escoamento adjacentes e conectando-as através de uma malha poligonal. Esta técnica funciona bem desde que as linhas originais permaneçam relativamente próximas entre si. Se elas divergem, a fita resultante não é uma boa representação do fluxo, pois a superfície da fita deve ser tangente ao campo vetorial em cada ponto [BRO92; MIN97a].

Há aproximadamente cinco anos, o mapeamento de textura não era usado em visualização técnica ou científica, porque os métodos de simulação visual mencionados direcionavam o uso de mapeamento de textura para representar superfícies de madeira ou mármore que definem objetos sólidos, ou padrões estocásticos para visualizar nuvens. Atualmente algumas técnicas de visualização já fazem uso do mapeamento de textura como, por exemplo, Spot Noise [WIJ91; WIJ95] e o LIC [KIU96; GRÖ99]. Além disso, o mapeamento de textura implementado em hardware pode ser aplicado em uma grande variedade de áreas. Para isso muda-se a definição formal de mapeamento de textura para um repositório geral de informações de cor baseadas em pixels mapeados em uma geometria 3D arbitrária. Isto cria uma base poderosa e elegante para mostrar e analisar as informações técnicas ou científicas obtidas por meio de medições ou simulações.

\subsection{Organização}

Nesta monografia será apresentada uma visão geral sobre texturas, sua definição e seus diversos tipos e seu uso em Visualização. O Capítulo 2 aborda a textura de superfície, sua 
definição e aplicações envolvendo texturas. Neste capítulo ainda serão brevemente descritas funções de textura. O Capítulo 2 também apresenta uma descrição de textura sólida e aplicações, além de textura procedimental e tratamento anti-aliasing. Já o Capítulo 3 aborda o uso de técnicas de textura de superfície e textura procedimental no contexto de Visualização. O Capítulo 4 descreve a técnica de LIC (Line Integral Convolution). No Capítulo 5 encontram-se os detalhes da implementação da técnica em questão. Finalmente no Capítulo 6 mostram-se os resultados obtidos, assim como sua relevância no contexto de visualização. 


\section{Texturas}

\subsection{Considerações Iniciais}

O mapeamento de textura tem sido tradicionalmente usado para adicionar realismo em imagens geradas por computador. Recentemente esta técnica saiu dos sistemas de rendering baseados em software para sistemas baseados em hardware gráfico das estações de trabalho e até de computadores pessoais. Isso tem motivado o desenvolvimento de simulações visuais e animações computadorizadas que utilizam o mapeamento de textura para projetar imagens sobre uma superfície poligonal que define um objeto 3D. Deste modo, o mapeamento de textura é uma ferramenta poderosa para adicionar realismo em imagens geradas por computador, sem aumentar drasticamente a complexidade geométrica da cena criada. Isto é muito importante em simuladores visuais que precisam manter uma taxa constante de quadros.

A seção 2.2 deste capítulo trata da aplicação da textura em uma superfície. Ela descreve o uso da textura com informações diferentes de uma imagem, como, por exemplo, opacidade, brilho ou coeficiente de deslocamento da normal [CRO90]. A seção 2.3 trata de textura sólida, e algumas considerações sobre o mapeamento da textura. A seção 2.4 aborda textura procedimental, e a geração de uma textura procedimental complexa a partir de primitivas simples, além do uso de modelagem matemática. Finalmente, a seção 2.5 trata dos problemas de amostragem e aliasing (serrilhado) e aborda algumas soluções para estes problemas.

\subsection{Textura de Superfície}

A textura de superfície baseia-se no armazenamento de valores de textura em uma tabela (que pode ser uma imagem digital) e sua aplicação sobre uma superfície. É mais fácil produzir imagens 2D para serem usadas como textura do que construir funções que produzam resultados satisfatórios quando se quer replicar uma certa textura "real", por exemplo [CRO90]. No caso de modelos paramétricos, esta estratégia utiliza a relação natural que existe 
entre o espaço de endereçamento da imagem de textura e o espaço paramétrico usado para criar e posicionar os objetos. Para isso, existem diversos métodos de mapeamento. $\mathrm{Na}$ verdade, este é o problema inverso ao dos cartógrafos que necessitam colocar uma determinada superfície sobre um pedaço de papel (plano). Aqui se deseja colocar o papel (imagem plana) sobre a superfície.

Há muitas maneiras de obter uma textura 2D. Uma alternativa é usar a abordagem procedimental, discutida na seção 2.3, para gerar a textura sobre uma superfície, com resultados satisfatórios na maioria dos casos. Porém, há casos em que a textura não é definida por uma imagem e sim por informações e coeficientes como opacidade, valor da normal e outros [CRO90; GEL96; TES98].

Hoje em dia, o mapeamento de textura está presente em um grande número de placas gráficas, possibilitando a modificação das informações do pixel durante o procedimento de rendering, mesmo após o término do processo de tonalização. O tempo de rendering de imagens em Computação Gráfica depende especialmente do hardware e de como ele é utilizado: o nível de entrada e interação do usuário podem reduzir significativamente o desempenho do sistema. Assim a utilização de hardware gráfico para mapeamento de textura pode ajudar a maximizar o desempenho. Os três componentes básicos necessários a um procedimento de mapeamento de textura são: (1) a textura, definida em um espaço de textura, (2) a geometria 3D, em geral definida por uma malha de vértices e (3) uma função de mapeamento que associa a textura ao objeto geométrico 3D.

O espaço de textura é um espaço de coordenadas paramétricas que pode ser definido sobre um domínio de uma, duas ou três dimensões. Análogo ao pixel (picture element) no espaço da tela, cada elemento no espaço de textura é chamado de texel (texture element). As placas gráficas atuais oferecem flexibilidade para a interpretação das informações armazenadas em cada texel. Múltiplos canais de cores, intensidades, transparência ou índices para tabela de cores são implementados em hardware.

Em uma concepção mais abstrata, o espaço de textura é mais do que apenas uma imagem definida em um sistema de coordenadas paramétricas: ele pode ser visto como um segmento 
especial de memória na qual uma variedade de valores pode ser armazenada para serem conectados à representação no espaço 3D. Esta informação pode ser utilizada eficientemente para representar qualquer propriedade paramétrica que necessite ser visualizada [TES98].

A natureza baseada em vértices da geometria 3D está, geralmente, associada a primitivas como pontos ou linhas. No entanto, o mapeamento de textura torna-se mais eficiente se tomarmos triângulos e polígonos de ordem mais alta como primitivas, porque os algoritmos de iluminação trabalham com triângulos, ou quadriláteros.

O procedimento de mapeamento associa uma coordenada do espaço da textura a cada vértice do objeto 3D. É importante lembrar que a dimensão do espaço da textura é independente da dimensão do espaço do objeto a ser mostrado. Por exemplo, uma textura 1D pode ser usada para gerar isolinhas sobre uma superfície 3D arbitrária [TES98]. Esta estratégia será discutida na seção 3.2.2.

\subsubsection{Aplicação de Valores de Textura}

A textura é, geralmente, aplicada por uma função de textura calculada para cada pixel exibido que pertence à superfície a ser texturizada. $\mathrm{O}$ valor da textura pode ser usado para modificar a iluminação da superfície de diferentes maneiras. Um uso comum do valor da textura é como uma intensidade da superfície, indo de zero (0) até um (1). Nos pontos em que o valor da textura é um (1), a superfície mantém sua cor. Naqueles em que o valor da textura é zero (0) a cor da superfície é zero (preta). Nos valores intermediários, a cor da superfície é escurecida proporcionalmente. A figura 2.1 mostra um ovo ao qual foi aplicado esta técnica de texturização de superfície. 


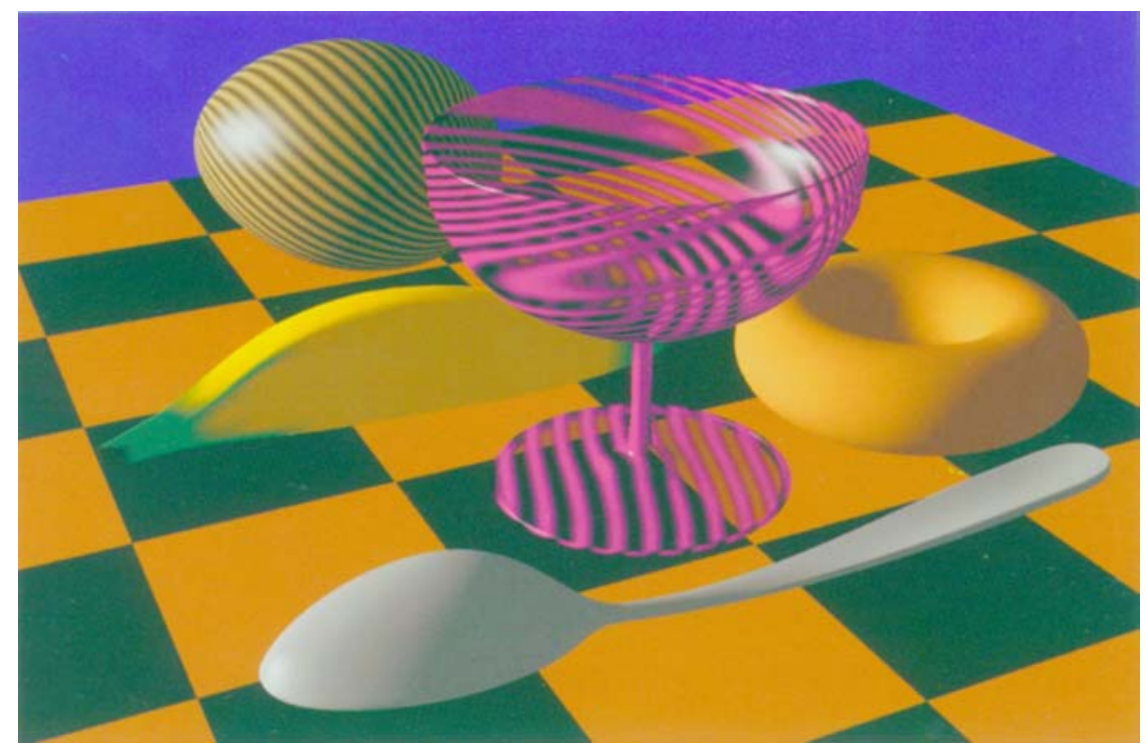

Figura 2.1 - Textura com intensidade (ovo) e transparência (copo) [CRO90].

Se três valores são retornados pela função de textura (por exemplo, uma tripla de intensidades vermelha, verde, azul), esses valores podem ser usados como a cor da superfície. Esta abordagem é particularmente apropriada se uma fotografia é usada para prover uma textura 'natural', como na esfera da figura 2.2. Uma grande porcentagem de objetos manufaturados tem pinturas ou padrões impressos em sua superfície. Desta maneira, muitos objetos são bem representados apenas variando-se suavemente suas cores ao longo da superfície, como foi feito, por exemplo, com a banana da figura 2.1. Objetos como metal e plástico apresentam padrões de reflexão suaves.

Por outro lado, objetos naturais, como madeira, exibem variações de reflexão ao longo de toda a superfície, além das variações de cor. Analogamente, padrões pintados ou impressos podem apresentar padrões resultantes de diferentes processos (pincéis, jatos) com diferentes propriedades de reflexão. Geralmente, a reflexão varia juntamente com as cores. Em funções de iluminação que incluem um componente de brilho especular, a contribuição de brilho pode ser modificada pelo valor de textura antes de ser combinada com as demais componentes da função de iluminação para implementar as variações de reflexão. A figura 2.3 mostra uma imagem a qual foi aplicada esta técnica. 


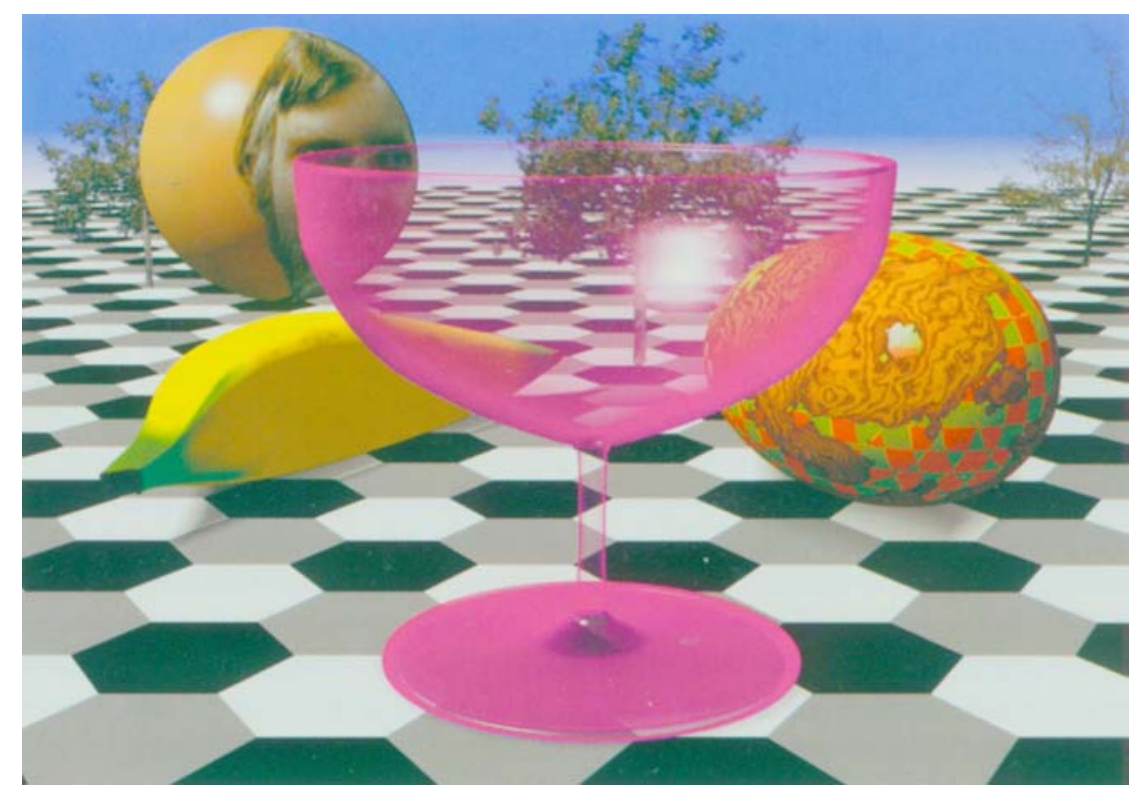

Figura 2.2 - Fotografia e coloração de vértices como textura [CRO90].

Vidros transparentes e objetos plásticos freqüentemente são exibidos com variações de transparência que podem ser produzidas por pinturas ou pela impressão de padrões na superfície, ou pela utilização de materiais com diferentes propriedades. Um valor de textura pode ser usado para variar o coeficiente de transmissão da luz na superfície de forma a obter efeitos visuais melhores. Um exemplo de aplicação dessa técnica pode ser visto no copo da figura 2.1.

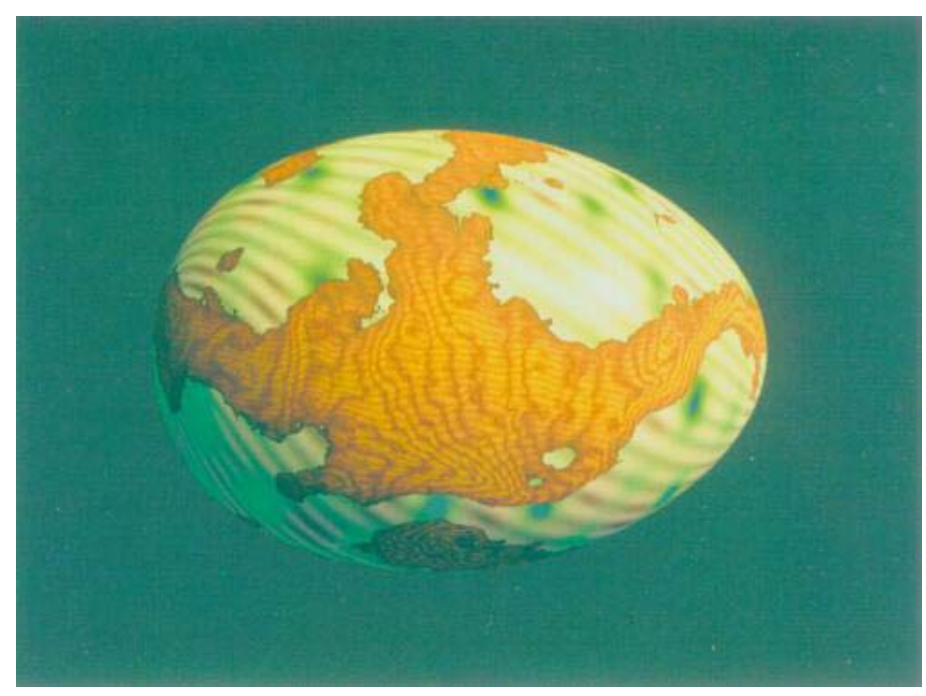

Figura 2.3 - Textura como coeficiente de reflexão [CRO90]. 
Muitos objetos manufaturados exibem uma textura de baixo relevo. Uma superfície pode ficar mais realística, por exemplo, com a adição de irregularidades ou rugosidades. Em outros casos, as texturas de baixo relevo podem ser um artefato introduzido pelo processo de manufatura, como um muro com sulcos entre os tijolos ou um carpete trançado. Este tipo de superfície pode ser simulado usando os valores de textura para perturbar a orientação local da superfície antes de calcular a função de iluminação. Assim, a superfície parece distorcida, sem que tenha sido alterada geometricamente [CRO90; FOL90; HEA94]. Um exemplo de aplicação desta técnica é mostrado na figura 2.4 .

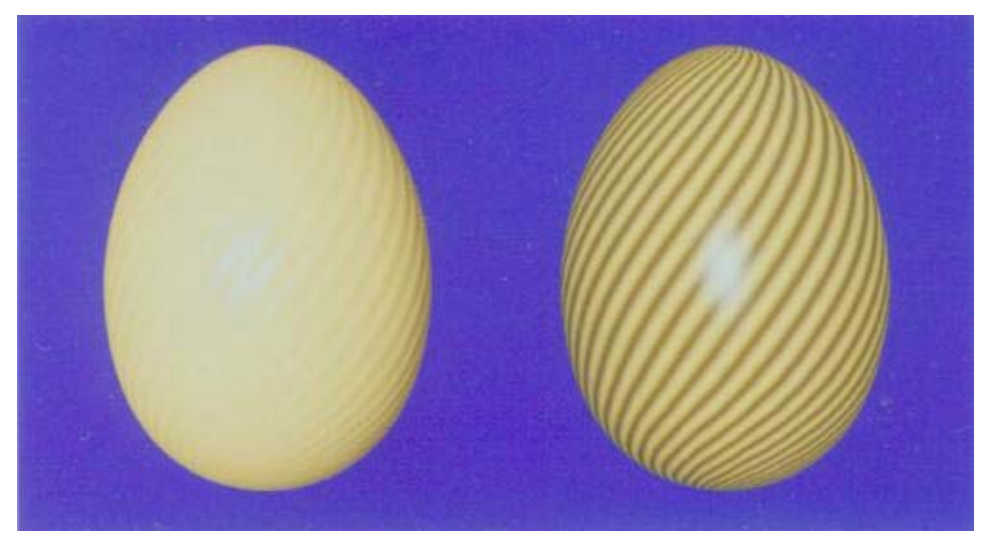

Figura 2.4 - Texturas geradas com mapeamento bump (a esquerda) e com mapeamento de intensidades (a direita) [CRO90].

É necessário deslocar a superfície na região onde se deseja representar alto relevo. Isto pode ser feito usando valores armazenados na textura como um coeficiente de deslocamento da normal. Uma textura pode ser usada para modular qualquer parâmetro que pode variar sobre a superfície, por exemplo, a presença ou ausência da superfície. Árvores, por exemplo, podem ser representadas por polígonos muito simples usando-se mapas de texturas bivalorados que determinam a presença ou ausência de folhas [CRO90].

\subsubsection{Mapeamento da Textura Sobre Superfícies Poligonais}

Antes de a textura ser aplicada à superfície do objeto, deve-se determinar como ela preencherá a superfície, e isso depende da superfície a ser texturizada. Mapear uma textura sobre uma superfície arbitrária não é tarefa trivial e, em alguns casos, pode ser muito complexa. Porém, para superfícies bem comportadas como cubos, cilindros e esferas, o mapeamento é simples. 
Considerando primeiro o mapeamento cilíndrico, dada uma definição paramétrica do cilindro $(\theta, z)$, a função de projeção que obtém as coordenadas de textura é trivial (Figura 2.5). Qualquer ponto $\mathrm{C}$ sobre a superfície do cilindro de raio $r$ e altura $h$ é representado como:

$$
C(\theta, \mathrm{z})=(r \cos \theta, r \sin \theta, h z), \text { onde } 0<\theta<2 \pi \text { e } 0<z<1 \text {. }
$$

Pode-se, assim, associar valores de textura $(u, v)$ a um ponto do cilindro pela equação:

$$
(u, v)=(\theta / 2 \pi, z) \quad u, v \in[0,1]
$$

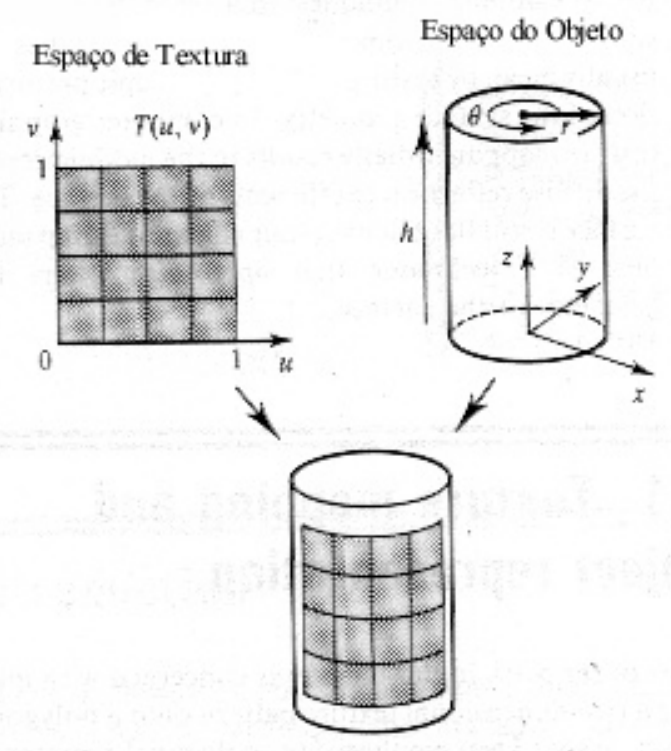

Figura 2.5 - Mapeamento cilíndrico.

O mapeamento esférico, porém, apresenta alguns problemas, pois mapear um plano sobre uma esfera produz distorções da textura próximas aos pólos da esfera. Assim sendo, considera-se o mapeamento de uma textura sobre parte de uma esfera, como na figura 2.6. A parametrização da esfera é dada por:

$C(\theta, \phi)=(r \cos \theta \sin \phi, r \sin \theta \sin \phi, r \cos \phi)$, onde $0 \leq \theta \leq \pi / 2$ e $\pi / 4 \leq \phi \leq \pi / 2$. 
A função de mapeamento é definida da mesma forma que para o cilindro:

$$
(u, v)=\left(\frac{\theta}{\pi / 2}, \frac{(\pi / 2)-\phi}{(\pi / 4)}\right) \quad u, v \in[0,1]
$$

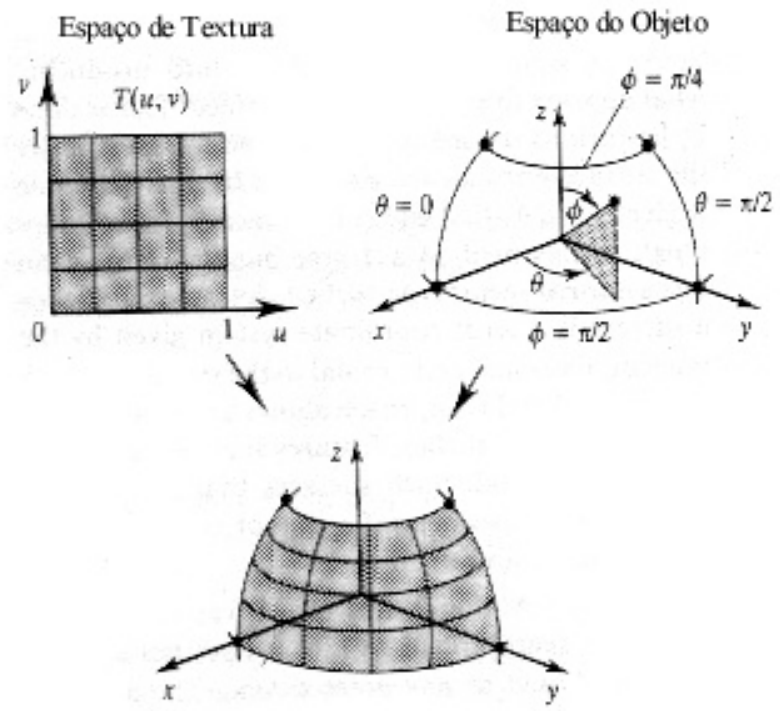

Figura 2.6 - Mapeamento esférico.

Note que ambas as definições são transformações canônicas, mapeando unidades do domínio da textura no espaço do objeto. Todas as transformações 2D padrão, como escala, rotação e translação, dentre outras, podem ser aplicadas ao espaço da textura. No caso do mapeamento sobre um cubo, a textura plana é aplicada a cada face do mesmo sendo o mapeamento trivial. A figura 2.7 mostra exemplos dos mapeamentos citados acima.

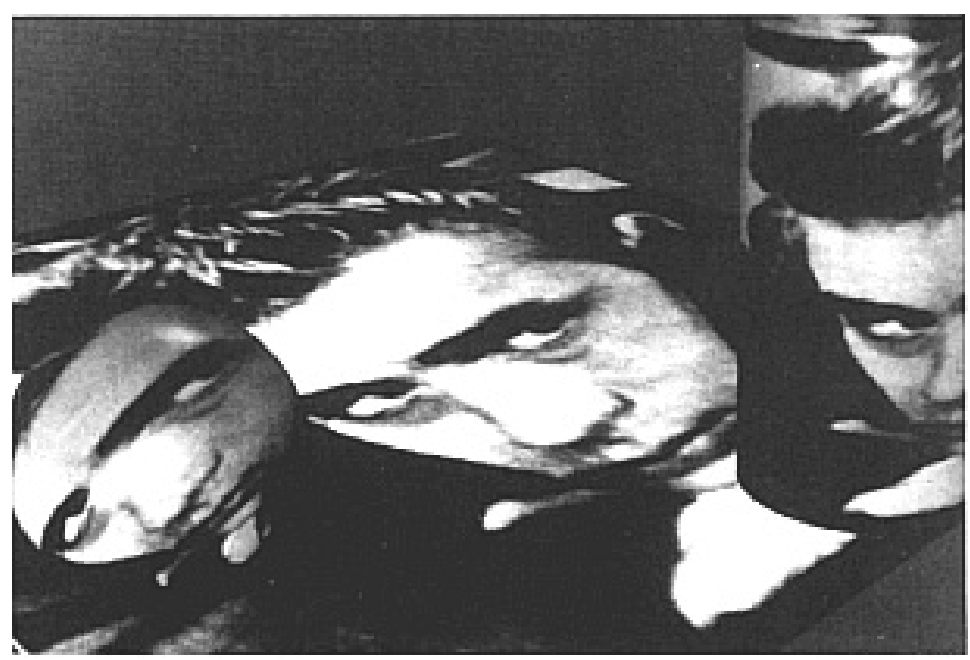

Figura 2.7 - Exemplo de mapeamento esférico e cilíndrico [WAT92]. 


\section{$2.3 \quad$ Textura Sólida}

A textura sólida pode ser imaginada como um espaço 3D de cores que envolve o objeto. Quando essa textura é aplicada ao objeto, é como se a superfície definida por ele estivesse sendo esculpida no material representado pela textura. Um bom exemplo disso é o uso da textura sólida para a criação de objetos feitos de mármore ou madeira. $\mathrm{O}$ espaço da textura sólida define um volume 3D de madeira ou mármore, no qual o objeto é colocado. Funções de ruído e turbulência podem ser empregadas para produzir efeitos de gases, possibilitando a criação de objetos dispersos, como nuvens. A figura 2.8 mostra uma nuvem criada usando textura sólida e função de ruídos [EBE98].

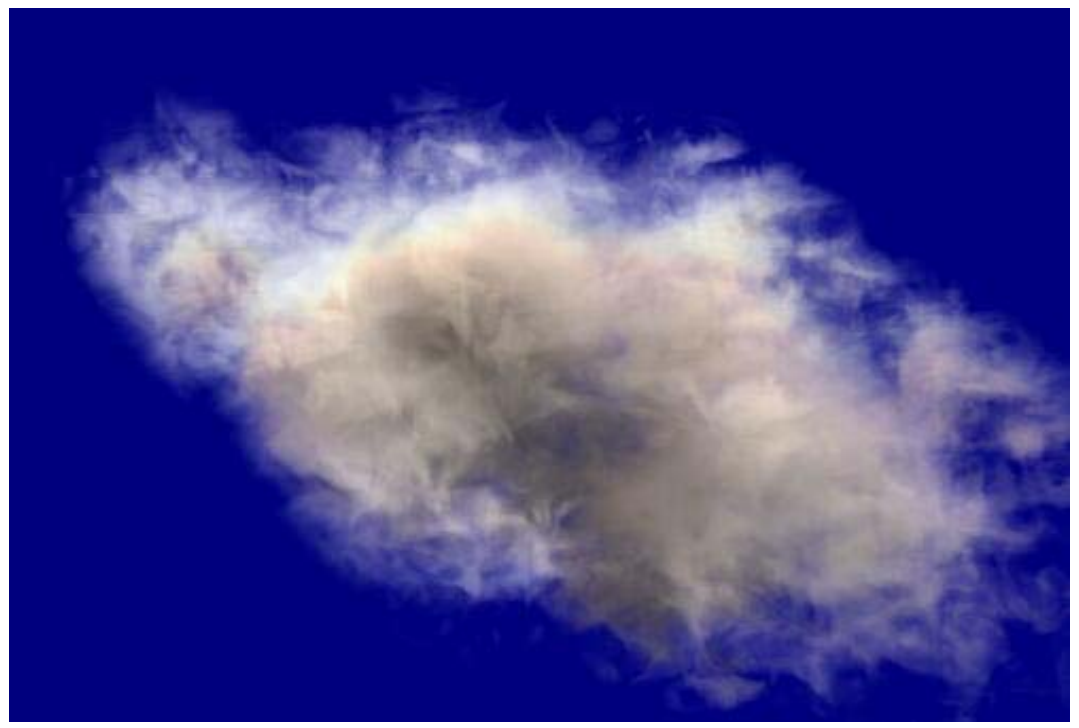

Figura 2.8 - Nuvem criada usando textura sólida e função de ruídos [EBE98].

A geração de uma textura sólida requer o cálculo da interseção da função de preenchimento do espaço com a superfície visível selecionada na cena. Isto causa dois problemas básicos: (a) as coordenadas 3D devem ser recuperadas para cada pixel da superfície representada; (b) as funções de preenchimento devem ser definidas. Funções interessantes não são encontradas facilmente. As coordenadas tridimensionais podem ser recuperadas aplicando-se as 
transformações inversas às aplicadas ao longo do pipeline de visualização ${ }^{1}$, recuperando a descrição da superfície no espaço do mundo a partir de sua descrição no espaço da imagem. As coordenadas do espaço de textura podem ser obtidas aplicando transformações no espaço de textura. Entretanto, é freqüentemente mais eficiente armazenar as coordenadas do espaço de textura junto com as da superfície, interpolando se necessário [EBE98].

Quando uma superfície é aproximada por polígonos, sua cor e outras características podem ser determinadas por interpolação bilinear a partir de seus valores nos vértices dos polígonos, como na tonalização por Gouraud [FOL90; HEA94]. Portanto, o custo adicional para obter estes valores do espaço de textura é muito pequeno para cada pixel. No entanto, deve-se notar que uma textura interpolada linearmente pode revelar a estrutura poligonal da aproximação da superfície [CRO90]. Quando a superfície é definida por patches (superfícies definidas através de funções paramétricas) ou outras primitivas, o espaço de coordenadas da textura pode ser definido similarmente. Quando os pixels da imagem são determinados pela subdivisão de um patch, o espaço de textura também deve ser subdividido.

\subsubsection{Mapeamento do Espaço de Textura}

Normalmente, para envolver a superfície com uma textura, o espaço de textura deve ser obtido a partir de uma transformação inversa durante o cálculo das funções de iluminação. Entretanto, outros efeitos podem ser obtidos se a transformação inversa for feita em outro momento do processo de iluminação. Se o espaço de coordenadas de textura é obtido a partir de uma transformação do espaço de coordenadas do objeto para o espaço de coordenadas do mundo, o objeto parecerá mover-se através da textura como ele se move no mundo (cena). Isto pode ser de muita valia para criar imagens de movimento contínuo com um padrão complicado de iluminação e sombreamento, ou variações como uma cena embaixo da água [CRO90].

O efeito causado por sombras complexas de uma árvore pode ser facilmente reproduzido extraindo-se informações da imagem da árvore e da fonte de luz através de transformações do espaço do mundo para definir uma função de textura 3D. Os objetos intersectados por essa

\footnotetext{
${ }^{1}$ do inglês viewing pipeline
} 
função têm seu sombreamento modificado para produzir o efeito de sombra e luz. Entretanto, é preciso cuidado para evitar funções que produzam auto-sombreamento de partes do objeto.

Funções simples para preenchimento do espaço de textura não são difíceis de se obter. $\mathrm{O}$ exemplo $f(x, y, z)=\sin (c y)$ produz um espaço com faixas parametrizadas pelo eixo $y$. A partir dessa, funções mais interessantes podem ser imaginadas. O padrão vermelho e verde apresentado no ovo da figura 2.2 foi produzido utilizando um procedimento semelhante ao pseudocódigo do quadro 2.1. Este código cria um espaço de textura 3D semelhante a um tabuleiro tridimensional.

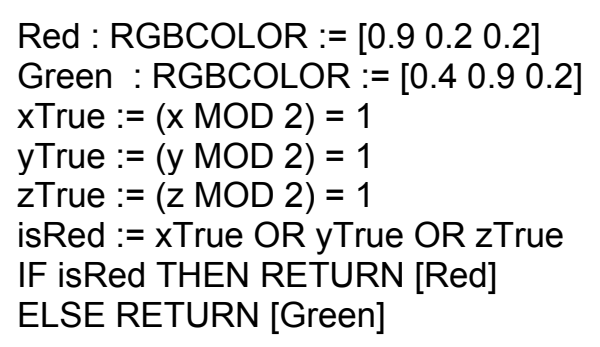

Quadro 2.1 - Código usado para texturizar o ovo da figura 2.2.

O ovo colorido da figura 2.9 usa o pseudocódigo do quadro 2.2 para prover uma superposição simples de três senos, modulando o vermelho ao longo do eixo $x$, o verde ao longo do eixo $y$, e o azul ao longo do eixo $z$.

Red, Green, Blue: REAL;

Red: $=\left(\operatorname{Sin}\left[10.0^{*} \mathrm{x}\right]+1.0\right) / 2.0$;

Green: $=\left(\operatorname{Sin}\left[10.0^{*} \mathrm{y}\right]+1.0\right) / 2.0$;

Blue:= $\left(\operatorname{Sin}\left[10.0^{*} z\right]+1.0\right) / 2.0$;

RETURN [ [Red, Green, Blue] ];

Quadro 2.2 - Código usado para texturizar o ovo da figura 2.9.

Os senos podem ser usados de outras formas. O pseudocódigo do quadro 2.3 é usado para produzir a transparência do copo da figura 2.1. 


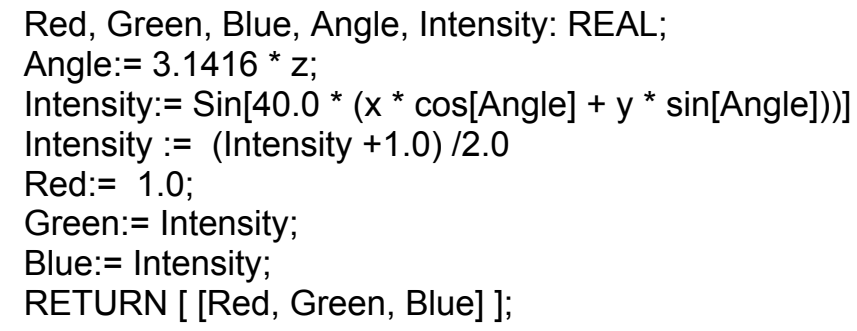

Quadro 2.3 - Código usado para gerar a transparência no copo da figura 2.1.

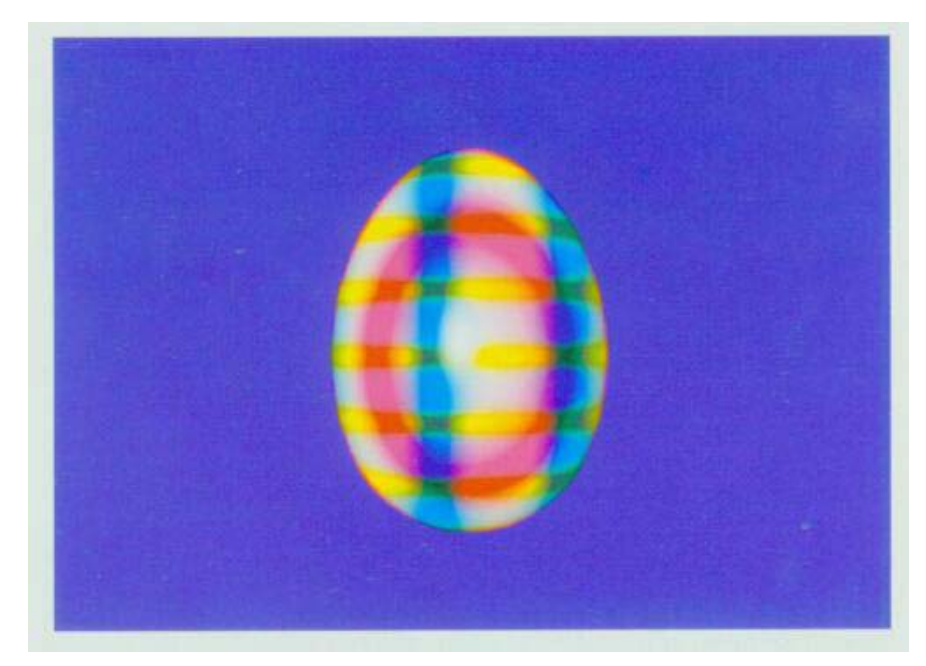

Figura 2.9 - Aplicação de uma função simples para preenchimento do espaço de textura [CRO90].

Mais interessante, porém, são as texturas “orgânicas", que podem ser geradas através de uma função de preenchimento de textura baseada em funções de ruídos aleatórios [PER85]. Estas funções podem gerar texturas elaboradas, como a da chaleira da figura 2.10. Esta textura é baseada na função de ruído de Perlin, da seguinte maneira: uma tabela de valores pseudoaleatórios é colocada sobre uma grade $3 \mathrm{D}$ de inteiros. $\mathrm{O}$ valor de textura é determinado por interpolação dos valores nos oito vértices do voxel no espaço da textura. Uma função cúbica é usada para suavizar a interpolação e evitar ruídos de alta freqüência espacial na textura. O resultado é uma textura baseada em ruídos concentrados numa determinada faixa. A função de ruído pode ser modificada para se autorepetir num padrão de $1 / f$, produzindo um padrão fractal [CRO90]. A cada interação as coordenadas do espaço de textura são dobradas, melhorando assim a resolução da textura. 
Para produzir a textura da chaleira da figura 2.10, a função de Perlin é calculada para coordenadas no espaço da textura, resultando no valor de cada pixel na superfície da chaleira. Para prover melhor realismo, uma função para simular padrões naturais é adicionada ao resultado da função de Perlin, preenchendo o espaço da textura com padrões irregulares naturais. O nível de detalhes da textura é limitado pelo tamanho da iteração $1 / f$ na função. A função de ruído é muito cara para ser calculada, limitando na prática o tamanho da iteração.

Ambos os métodos, texturas sólidas e texturas de superfície requerem a amostragem de funções de textura em pontos discretos. Isto pode causar aliasing sempre que os pontos estiverem muito espaçados no domínio da função de textura. Soluções para este problema vão desde o supersampling para melhorar a distribuição dos pontos calculados, até técnicas elaboradas e caras para aproximar a integral na área ao redor do pixel representado. Este tópico será discutido na seção 2.4 .

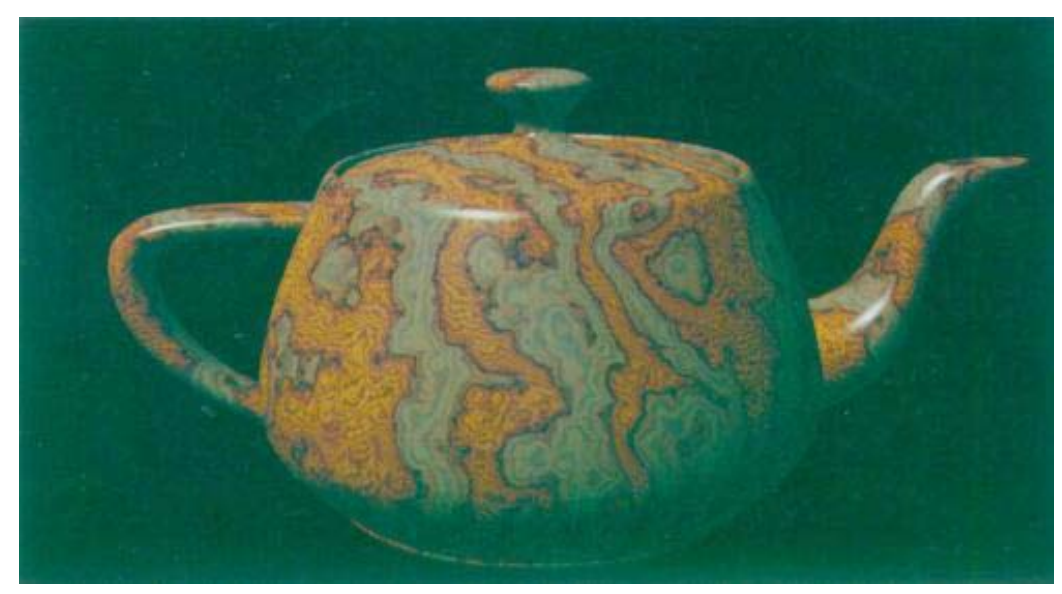

Figura 2.10 - Chaleira usando um textura sólida pseudonatural [CRO90].

\subsection{Textura Procedimental}

A definição de textura procedimental é enganosa. O adjetivo procedimental é usado em ciência da computação para denotar entidades descritas por código de programa, ao invés de por estruturas de dados [EBE98]. Por exemplo, em inteligência artificial há uma distinção entre representações procedimentais de conhecimento e representações declarativas. Mas muito do que se faz em computação tem um aspecto procedimental em algum nível, e todos 
procedimentos têm parâmetros ou entradas que podem ser vistos como declarativos. Em mapeamento de texturas sobre uma superfície, o componente procedimental é o módulo mapeador da textura, e o componente declarativo é a imagem da textura. Porém, a característica mais forte da textura procedimental é que ela é sintética, gerada a partir de um programa ou modelo, ao invés de por uma imagem digitalizada ou pintada.

A textura procedimental tem uma representação mais compacta do que a imagem de textura, pois o tamanho de um procedimento é, geralmente, da ordem de kilobytes, enquanto a imagem de textura é da ordem de megabytes, particularmente no caso de texturas sólidas, onde a textura 3D é extremamente grande. No entanto, pesquisadores têm usado imagens de tomografia para obter volumes de imagens gerados utilizando textura sólida [EBE98]. Além disso, a representação procedimental não tem uma resolução fixa. Em muitos casos a função gera um nível de detalhes que, geralmente, não é exibido. E, se for necessário maior resolução, basta executar o procedimento recursivamente até a resolução desejada. Com isso, a textura procedimental não cobre uma área fixa, ou seja, não tem um tamanho fixo, podendo assim ser escalada na proporção desejada.

A parametrização da textura procedimental pode gerar classes de textura, ao invés de uma única textura fixa. Isso permite gerar várias texturas com o mesmo procedimento, podendo diminuir o custo computacional de gerar várias texturas diferentes, calculando a função apenas uma vez. Porém, muitas destas vantagens são apenas potenciais, ou seja, a textura procedimental provê as ferramentas para se obter estas vantagens, mas muito esforço é necessário para tirar proveito de todas as vantagens. Uma textura procedimental mal escrita pode por a perder todas as vantagens desta abordagem.

Programar e depurar uma textura deste tipo é uma tarefa árdua. A programação é, geralmente, complexa, principalmente em casos não triviais. Em muitos casos, o resultado é inesperado e difícil de ser controlado. Também pode acontecer do cálculo da textura ser mais lento do que o acesso à textura armazenada na memória. Existem várias técnicas para criar texturas complexas que, basicamente, pertencem a duas classes: combinação de procedimentos simples e modelagem matemática do fenômeno, discutidas nas seções 2.4.2 e 2.4.3, respectivamente. 


\subsubsection{Funções e Valores de Textura}

Uma função de textura deve retornar um valor ou um conjunto de valores dentro de um intervalo para valores de entrada definidos sobre um domínio 2D ou 3D. Para um simples exemplo, tome a função $\sin (c y)$, que pode ser aplicada para gerar uma textura sólida [CRO90; EBE98] gerando um objeto com faixas regulares. Por outro lado, pode ser aplicada para gerar uma textura de superficie, colocando faixas em cada polígono independentemente. Por essa razão, cada patch contém uma réplica da imagem de textura.

O estudo de funções de textura, ou texturas procedimentais como também são chamadas, é fascinante por si só. Funções analíticas simples podem gerar bons resultados [CRO90]. Mas, em diversas situações, funções algorítmicas e funções baseadas em imagens têm se mostrado mais eficazes. Muitas vezes, texturas são usadas para prover realismo, e nesses casos, imagens fotográficas do tipo da textura desejada são muito mais fáceis de obter do que funções analíticas ou aproximações algorítmicas que produzem o resultado esperado.

Para gerar uma textura sólida a partir de uma função, a superfície representada em uma cena deve ser intersectada com a função e calculada para cada ponto representado por um pixel na imagem. Isto requer que se mantenham as coordenadas de superfície sem nenhuma alteração durante todo o pipeline de visualização, incluindo transformação, recorte, e conversão matricial por varredura. Alternativamente, uma matriz de transformação inversa pode ser aplicada para recuperar as coordenadas originais. Para gerar uma textura de superfície a partir de uma função, algum mapeamento deve estar disponível para associar elementos na superfície de um objeto a elementos no domínio da função de textura. Há inúmeras maneiras de estabelecer o mapeamento entre o domínio de funções de textura e o domínio de definição da superfície.

\subsubsection{Combinação de Procedimentos Simples}

Uma boa maneira de se construir procedimentos de textura complexos é a partir da combinação de procedimentos simples. Isso pode ser feito de muitas maneiras. Dentre elas podemos citar o layering, a composição funcional, e a síntese espectral, discutidas a seguir. 


\section{Layering}

A técnica de layering consiste em sobrepor padrões simples para gerar um padrão mais complexo. Por exemplo, as cores de duas camadas de textura podem ser combinadas. Geralmente, esta combinação é controlada por uma função mix, que tem a seguinte forma:

$C=\operatorname{mix}(C 0, C 1, f)$;

em que $f$ controla qual cor deve ser usada. Se $f$ é 0 , a cor $C 0$ é escolhida, se é $1 C l$ é escolhida, e em valores intermediários as cores são interpoladas. $C 0$ e $\mathrm{C} 1$ podem ser cores ou subtexturas, que serão combinadas de acordo com o parâmetro $f$. Pode-se, também, usar esta mesma função mix para filtrar uma cor ou transparência em relação à outra.

\section{Composição Funcional}

Uma outra maneira de combinar funções simples para formar funções complexas é a composição funcional, usando as saídas de uma ou mais funções simples como entrada de outras funções. Por exemplo, uma função gera um número que varia de 0 a 1 de uma determinada maneira, e este número é usado por outras funções que podem gerar diferentes cores para diferentes valores da entrada numérica. Uma função deve ter pontos de um espaço de textura como entrada e produzir pontos de saída no espaço de entrada de uma segunda função. A técnica de composição funcional é muito poderosa para a geração de textura procedimental, sendo muito utilizada. Na literatura de ciência da computação a programação funcional é uma boa fonte de técnicas para combinar funções. Linguagens funcionais como LISP e Prolog são, basicamente, linguagens de composição de funções.

\section{Síntese Espectral}

É possível gerar padrões complexos e texturas semelhantes à textura natural combinando componentes senoidais de diferentes freqüências, amplitudes e fases. A teoria de análise de Fourier diz que funções podem ser representadas por uma soma de termos senoidais. A 
transformada de Fourier toma uma função definida em um domínio espacial ou temporal e a descreve no domínio da freqüência, que é representado por amplitude e fase de uma série de ondas senoidais. Quando esta série de ondas senoidais é somada, elas reproduzem a função original, e esta transformação é chamada de transformada inversa de Fourier [EBE98].

A síntese espectral é uma implementação da transformada inversa discreta de Fourier de um domínio de freqüência para um domínio espacial. Dadas a amplitude e a fase de cada componente senoidal basta somá-las para obter a função desejada. Este tipo de combinação pode ser usado para gerar nuvens. Porém, nesse caso deve-se evitar a repetição de padrões na textura. Existem alguns truques para evitar a repetição periódica de padrões, como algumas freqüências básicas que produzem um padrão aleatório na textura.

\subsubsection{Modelagem Matemática}

Nem todas as texturas podem ser geradas a partir da combinação de procedimentos simples, muitas vezes é necessário modelar o fenômeno que gera o padrão desejado. Para isso, existem diversos modelos matemáticos, sendo que alguns dos mais utilizados em computação gráfica são apresentados a seguir.

\section{Ruídos}

Para gerar padrões irregulares em uma textura, precisamos de primitivas irregulares, chamadas de ruído. Esta é uma função de característica estocástica que quebra a monotonia dos padrões regulares. O uso do termo "aleatório" ou "estocástico" em computação deve ser entendido como "aparentemente aleatório" ou "pseudoaleatório", porque uma textura totalmente aleatória não é desejável.

Uma função de ruído ideal possui repetição para determinadas entradas pseudoaleatórias. Também possui uma faixa de valores, geralmente de -1 a 1 , e banda limitada com freqüência máxima próxima de 1 . Além disso, não exibe periodicidade óbvia ou padrões regulares. Também é uma função estacionária, ou seja, é invariante com relação à translação, e 
isotrópica, invariante com relação à rotação. Existem várias funções para a geração de ruído. Por exemplo, uma função de ruído de valor pode ser computada interpolando valores aleatórios dentro de uma faixa especificada. A chave deste método está no processo de interpolação. Podem ser usadas desde interpolação linear até interpolação cúbica. A interpolação linear não produz uma suavização adequada, além de não possuir uma derivada contínua. Uma boa escolha é a interpolação cúbica, ou por uma função spline.

Outra função que pode ser usada é a função de ruído de gradiente. Esta abordagem usa um gradiente pseudoaleatório para cada coordenada inteira da textura e, com esses gradientes, gera-se uma função estocástica para criar a textura. Os valores da textura nos pontos de coordenadas inteiras são zero. Para maior eficiência do procedimento os gradientes são gerados numa esfera de raio 1. Porém, esta técnica pode gerar padrões regulares horizontais e verticais na textura.

Uma abordagem que reúne o melhor das abordagens acima é chamada de ruído valorgradiente, em que a função estocástica usa uma média ponderada entre o valor do ponto e o gradiente, de modo a eliminar os padrões regulares da textura e ainda preservar o poder espectral da função gradiente.

\section{$2.5 \quad$ Amostragem e Antialiasing}

Em métodos baseados na utilização de imagens como texturas, um grande esforço é despendido para evitar o problema do aliasing. Isso ocorre devido a natureza discreta da imagem digital, pois um pixel da imagem possui uma área definida. E quando ocorre a interpolação entre o espaço da superfície e o espaço da textura, alguns valores acabam sendo fracionários, provocando assim uma aparência serrilhada da imagem. Uma das primeiras técnicas de tratamento do aliasing consistia em fazer uma média ponderada de todos os pontos da textura que são mapeados em um ponto da superfície. Este método produz bons resultados, porém tem um custo computacional muito alto se muitos pontos da textura contribuírem para cada ponto da superfície. Outras abordagens mostraram-se mais eficientes por terem menor custo computacional. A seguir são apresentados dois métodos que tratam o problema de aliasing a um custo computacional aceitável. 


\subsubsection{Imagens de Textura Multirresolução}

Willians [WIL83] notou que, calculando pequenas imagens de textura nas quais o valor de cada pixel é uma média ponderada de um conjunto de pontos da imagem original, muitos dos cálculos para obter o valor de uma média poderiam ser reutilizados para muitos pontos. Esta técnica requer que a área da textura mapeada para cada pixel seja quadrada. Enquanto uma varredura da superfície do objeto é executada, o deslocamento nas coordenadas de textura indica qual subimagem da textura será utilizada, reduzindo os cálculos envolvidos.

Esta técnica pode ser estendida para imagens RGB da seguinte maneira. Utilizando-se um buffer de 512 x 512 pixels, por exemplo, geram-se três texturas de 256x256 pixels, uma para cada componente de cor, e preenche-se o buffer utilizando os três primeiros quadrantes. No quadrante restante, de dimensão 256x256, criam-se três texturas de $128 \times 128$ pixels, e preenche-se o quadrante livre de forma similar a anterior. Recursivamente todo o buffer de textura é preenchido, sempre dividindo pela metade a resolução. Com isso, cada pixel em uma imagem de textura pequena corresponde a quatro pixels na imagem de resolução imediatamente superior.

As coordenadas de textura são escaladas apropriadamente e quatro pixels da textura são lidos de cada mapa de textura. As coordenadas de textura são usadas para interpolar os quatros pixels que melhor aproximam o valor exato da coordenada de textura. Tendo recuperados dois valores para o pixel (ou cores), a parte fracional do deslocamento da textura é usada para interpolar estes valores. O primeiro conjunto de interpolações serve para suavizar as variações entre pixels adjacentes, no caso de mais de um pixel da imagem ser mapeado no mesmo pixel da textura. O conjunto final de interpolações suaviza as transições entre as texturas de diferentes resoluções. Um exemplo desta textura é mostrado na figura 2.11. A importância desta abordagem é que os valores de textura são computados em tempo constante. Algoritmos de tempo constante geralmente podem ser implementados em hardware para serem executados em tempo real. 


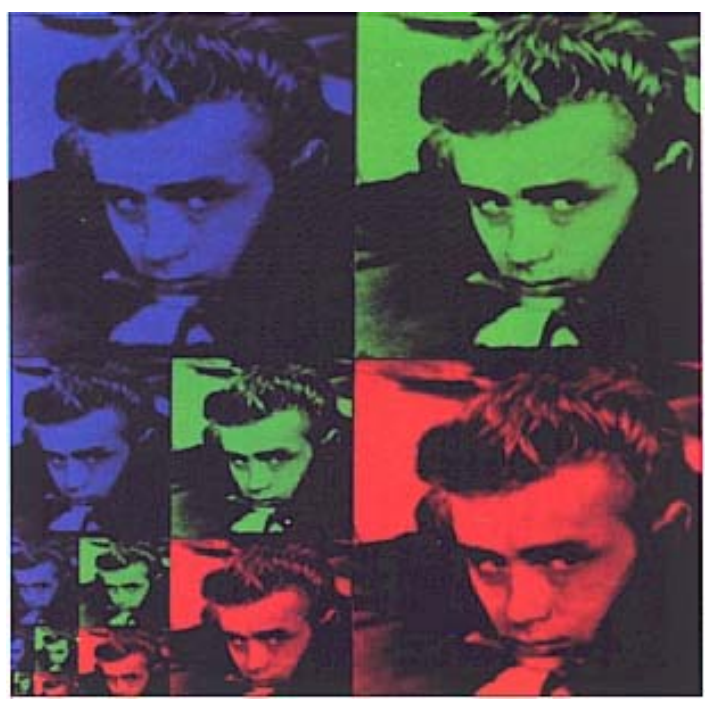

Figura 2.11 - Exemplo de uma textura multirressolução [WAT92].

\subsubsection{Imagens de Textura Integrada}

Outro método consiste em generalizar uma área da textura para uma área retangular alinhada aos eixos do espaço de textura. Este método funciona particularmente bem quando a imagem de textura tem padrões retilíneos, como o tabuleiro da figura 2.12. Uma imagem pode ser integrada por soma dos seus pixels. O valor de textura que representa o valor médio do pixel sobre uma subimagem de uma textura pode ser calculado pela integral dessa subimagem. Assim, uma tabela pode ser construída de maneira que os valores representem a integral de retângulos alinhados aos eixos do sistema de coordenadas da textura.

Construindo esta tabela como uma matriz, o valor do elemento $(i, j)$ é o valor da área que vai do ponto $(0,0)$ até $(i, j)$. Desse modo, a área de um retângulo $\mathrm{S}$ com ponto superior direito $(\mathrm{x} 1$, y1) e ponto inferior esquerdo $(\mathrm{x} 2, \mathrm{y} 2)$ é dada por:

$$
S=T(x 1, y 1)-T(x 2, y 1)-T(x 1, y 2)+T(x 2, y 2)
$$

onde $T(i, j)$ é o valor do elemento $(i, j)$ na tabela de áreas $T$. Para ter o valor do pixel, é necessário que $S$ seja dividido por $(\mathrm{x} 1-\mathrm{x} 2)(\mathrm{y} 1-\mathrm{y} 2)$. 


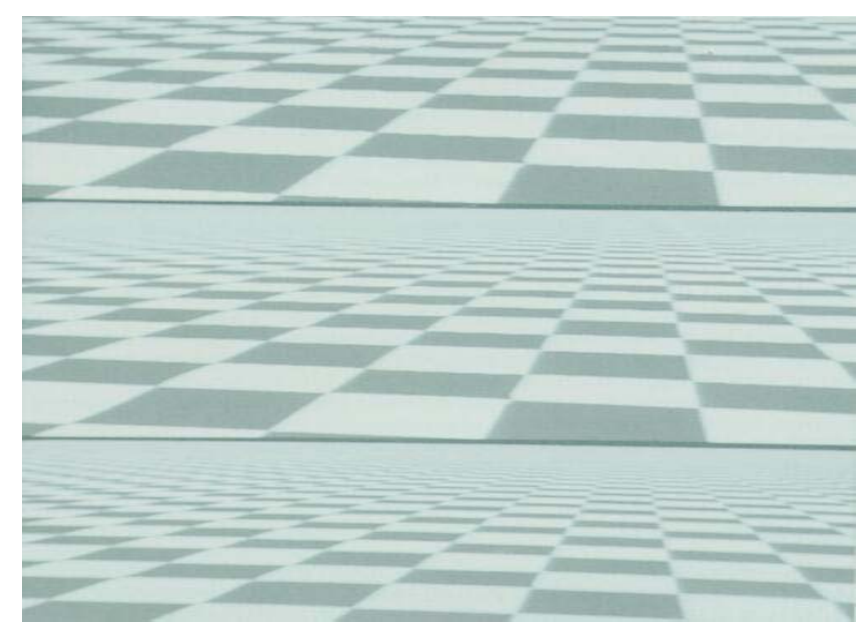

(a)

(b)

(c)

Figura 2.12 - Textura de tabuleiro. Com aliasing (a), multirresolução (b) e integrada (c) [CRO90].

Como na textura multirresolução, a interpolação entre as tabelas é usada para suavizar variações entre valores de textura quando um pixel da textura corresponde a vários pixels da imagem. 


\section{Técnicas de Visualização baseadas em Texturas}

\subsection{Considerações Iniciais}

Com o avanço da tecnologia o hardware gráfico passou a implementar muitas funções que antes só eram executadas por software. Dentre estas, estão as funções para tratamento e mapeamento de texturas $2 \mathrm{D}$ e 3D. Com isso, muitos algoritmos utilizados em computação gráfica e visualização passaram a utilizar texturas de modo a aproveitar as funções disponíveis por hardware. Neste capítulo serão apresentadas algumas técnicas que fazem uso da textura para acelerar ou facilitar a visualização de dados. Na seção 3.2 são apresentadas técnicas baseadas em mapeamento de textura para mapeamento de cores, geração de isolinhas, recorte de superfícies e filtragem de informações. Na seção 3.3 discute-se o uso de textura para rendering volumétrico direto. Já a seção 3.4 aborda a aplicação de técnicas de textura procedimental para visualização de dados escalares e vetoriais.

\subsection{Textura como Alternativa para Mapeamento por Cores, Isolinhas, Recorte e Filtragem.}

A textura pode ser usada de várias formas em visualização. Uma alternativa é usá-la para mapeamento por cores, geração de isolinhas, recorte de superfície e filtragem de informações. Nesta seção serão apresentadas técnicas baseadas em mapeamento de textura para as estratégias de visualização citadas acima.

\subsubsection{Mapeamento por Cores}

A codificação por cores é uma das maneiras mais usuais de exibir informação escalar sobre uma superfície. Por exemplo, pode ser usada para codificar temperaturas, níveis de estresse em partes mecânicas ou interações potenciais nas superfícies das moléculas. Um problema com a implementação de codificação por cores utilizando tonalização por Gouraud [FOL90; HEA94] ocorre quando há alto contraste na variação do código de cor definido sobre uma geometria tecelada esparsamente. Uma vez que a codificação por cor está concluída, e todos os vértices da geometria 3D têm uma tripla RGB associada, as cores dos pixels na vizinhança 
de um vértice são geradas por interpolação linear no espaço de cor RGB, diminuindo assim o contraste entre as informações. Como conseqüência, todas as entradas fora da faixa entre duas triplas RGB não serão representadas e a informação será perdida. Na figura 3.1, uma escala de cinza simétrica é usada para definir uma escala de cor mostrada no lado direito da figura.3.1. No lado esquerdo, a interpolação no espaço RGB não reflete a escala de cor. Há uma perda substancial de informação durante o processo de rendering.

Este problema pode ser resolvido armazenando a escala de cores como uma textura 1D [TES98]. A informação escalar é usada como coordenada de textura para os vértices da superfície. A interpolação é feita no espaço da textura e a coloração é feita para cada pixel. Assim, o alto contraste na variação do código de cor é possível mesmo para superfícies tonalizadas por Gouraud.

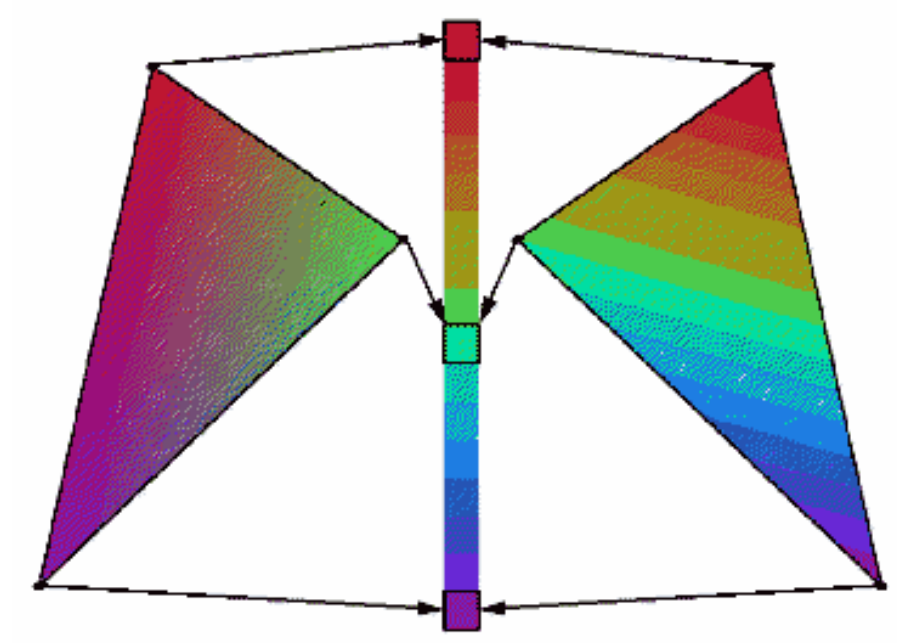

Figura 3.1 - Interpolação RGB (esquerda) e mapeamento de textura (direita) [TES98].

A figura 3.2 mostra a diferença entre os dois métodos com um exemplo concreto: a superfície da molécula de etanol está colorida de acordo com o potencial eletrostático da superfície, utilizando interpolação RGB tradicional (esquerda) e mapeamento de textura (direita). 


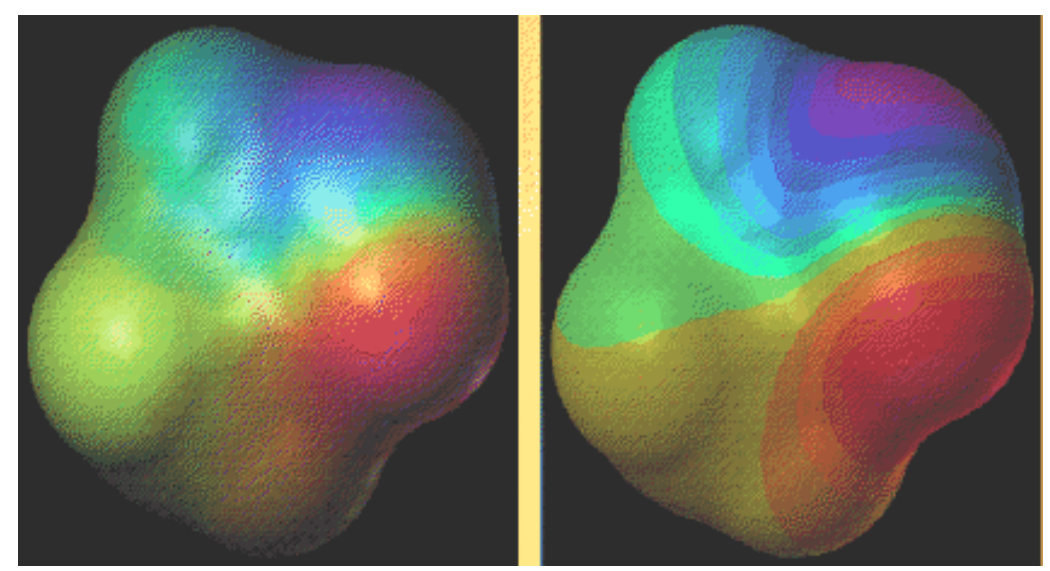

Figura 3.2 - Molécula de etanol, usando interpolação RGB (esquerda) e mapeamento de textura (direita) [TES98].

A independência entre o espaço de coordenadas da textura e do objeto traz vantagens para acomodar mudanças na escala de cores em tempo real [TES98]. Por exemplo, aplicando uma transformação simples como translação, a linha zero do código de cores pode ser deslocada. Aplicando uma transformação de escala pode-se ajustar a faixa de valores da textura.

\subsubsection{Isolinhas sobre Superfícies}

Similar às bandas de cores em codificação por cores, isolinhas de contorno sobre a superfície de um objeto provêm informação valiosa sobre a geometria do objeto e de suas propriedades, sendo muito usadas em aplicações de análise visual. Por exemplo, em um mapa topográfico elas podem representar a altura acima de algum plano fixado nas coordenadas do mundo. As curvas também podem representar propriedades intrínsecas da superfície, como potencial de interação ou distribuição de estresse.

Com mapeamento de textura, isolinhas podem ser aplicadas utilizando-se a mesma configuração da codificação de cores. Novamente a textura é 1D, preenchida com a cor da superfície do objeto. E para cada valor da isolinha uma outra cor é associada. A figura 3.3 mostra uma aplicação da textura para exibir o potencial hidrofóbico da Gramicidina A [TES98]. O canal de formação da molécula é mostrado como isolinhas sobre a superfície molecular. 
O escalamento do espaço da textura pode ser usado para controlar o espaçamento entre os contornos. De maneira semelhante, a translação do espaço da textura produz o deslocamento de todos valores de contorno. Note que não foi alterado nada na geometria do objeto durante o procedimento. $\mathrm{O}$ ajuste do espaçamento dos contornos pode ser feito em tempo real e ser totalmente interativo.

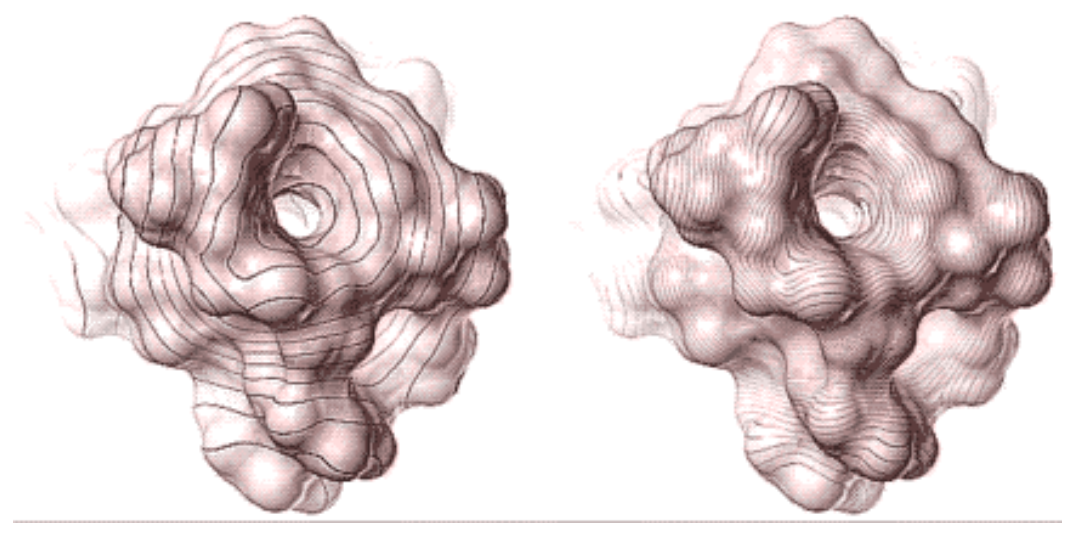

Figura 3.3 - Isolinhas na superfície, mostrando a escala no espaço de textura. Textura original à esquerda e textura escalada à direita. [TES98].

Uma extensão do conceito apresentado acima pode ser usada para mostrar métricas baseadas em um conjunto de planos de referência sobre superfícies arbitrárias. A figura 3.4 demonstra a aplicação de uma textura 2D para inserir marcas na superfície do zeolítio [TES98]. Neste caso, a textura precisa ser $2 \mathrm{D}$ para que a associação entre as coordenadas de textura e a superfície do objeto seja criada automaticamente: a distância do vértice do objeto aos planos de referência é calculada por hardware e transformada para as coordenadas de textura. Neste caso particular dois planos ortogonais são fixados para orientação da geometria do objeto. Este tipo de representação associa a medida exata de tamanho e unidade de distância à superfície do objeto. 


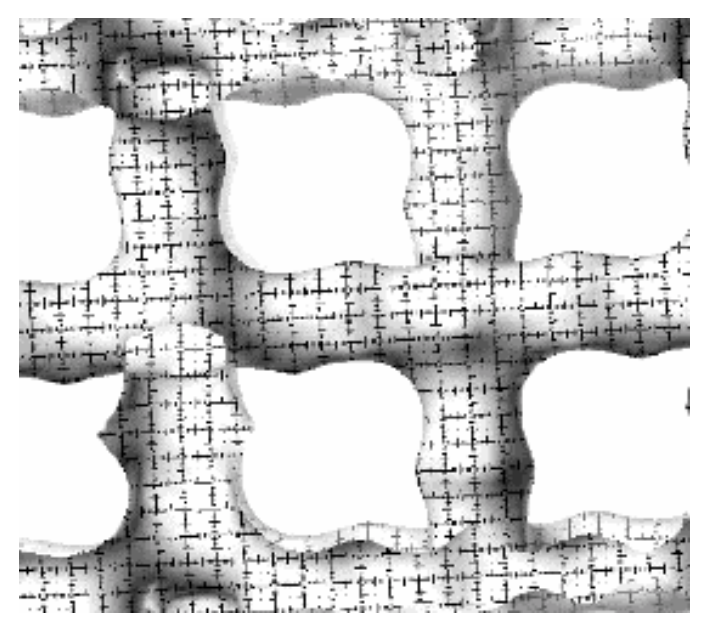

Figura 3.4 - Mostra a métrica na superfície molecular do zeolítio com uma textura 2D [TES98].

\subsubsection{Filtragem de Informação}

O conceito de usar textura 1D para codificar por cores as propriedades de uma superfície pode ser estendido para 2D e até 3D. Com isso, um máximo de três propriedades independentes podem ser visualizadas simultaneamente [TES98]. No entanto, uma tabela de cores multidimensional apropriada deve ser definida. Uma possibilidade é combinar a escala de cor 1D da figura 3.1 com o padrão de threshold 1D da figura 3.3. Ou seja, as cores são usadas para mapear uma propriedade, e as isolinhas para mapear uma segunda propriedade. Assim, é possível visualizar duas propriedades simultaneamente sobre a mesma superfície, mantendo a capacidade de distinguir claramente as informações.

Uma outra abordagem usa uma propriedade para filtrar outra e exibir o resultado sobre a superfície do objeto. Isso pode ser feito de duas maneiras: (1) o filtro permite ao cientista distinguir entre informações importantes e irrelevantes, por exemplo, mostrar os pontos de aquecimentos em uma superfície. Ou (2), o filtro pode inserir uma propriedade qualitativa em um contexto quantitativo, por exemplo, usar o desvio padrão de um valor para indicar quão precisa é a representação de uma propriedade de um ponto da superfície [TES98].

Um bom exemplo consiste em combinar o potencial eletrostático (ESP - Electrostatic Potential) e o potencial lipofílico molecular (MLP - Molecular Lipophilic Potential) da superfície da Gramicidina A. O potencial eletrostático dá alguma informação sobre como 
partes específicas da molécula podem interagir com outras moléculas, e o potencial lipofílico molecular dá uma boa estimativa de onde a molécula tem contato com a água ou com uma membrana. A molécula é uma proteína que está localizada na membrana dos bioorganismos, regulando o transporte de moléculas de água e íons. A figura 3.5 mostra a superfície da Gramicidina A codificada por cores, exibindo ESP filtrado com o MLP. A superfície é pintada com cores ou tons de cinzas nas regiões onde a superfície têm determinados valores de lipofobicidade. A parte da superfície que tem ação lipofílica está pintada de branco. Neste exemplo a informação é filtrada suprimindo todas as informações abaixo de um certo limite. Em outros casos, um filtro contínuo pode ser mais apropriado para permitir uma granularidade de informação menor.

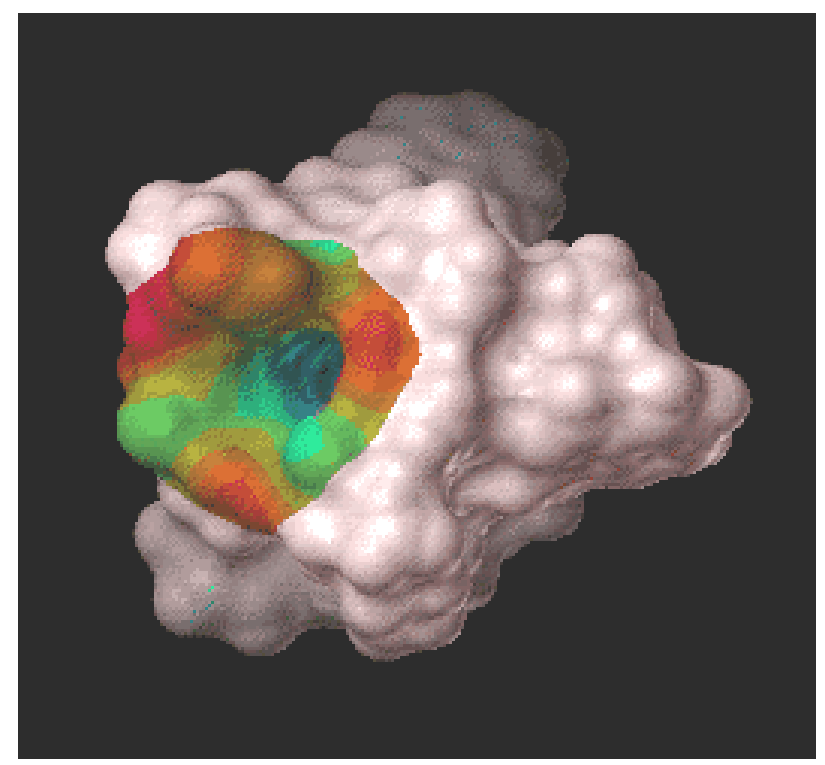

Figura 3.5 - Superfície da Gramicidina A mostrando ESP filtrado com MLP [TES98].

Outra combinação útil é a filtragem do potencial eletrostático com o campo elétrico. Tomando o valor absoluto do campo elétrico, o filtro pode facilmente identificar o maior gradiente local do campo numa área, o que ajuda a identificar os lugares de ligação. Com uma translação do espaço de textura, pode-se interativamente mudar o filtro de threshold ou mudar a aparência do mapa de cores.

\subsubsection{Recorte de Superfícies Arbitrárias}

A filtragem de informação citada acima afeta puramente a informação de cor do mapa de cores. Em muitos casos, a transparência pode ajudar a entender geometricamente uma 
propriedade particular. Por exemplo, a flexibilidade local de uma estrutura molecular pode ser representada visualmente associando-se maior opacidade às partes mais rígidas. $\mathrm{O}$ aumento da transparência indica regiões mais flexíveis. O mapa de transparência pode ser combinado com outras propriedades codificadas por cor, representando propriedades dinâmicas da molécula em diferentes contextos.

Uma extensão da variação contínua da transparência na superfície, como o exemplo da flexibilidade molecular mencionado acima, usa a transparência para remover partes da superfície, dependendo da propriedade codificada na textura [TES98]. Isto pode ser feito atribuindo-se valores alfa apropriados aos vértices. Aplicado ao exemplo de filtragem de informação na Gramicidina A, o recorte de superfície usando-se textura pode ser implementado definindo-se valores de opacidade zero onde anteriormente era branco. Esta técnica é mostrada na figura 3.6.

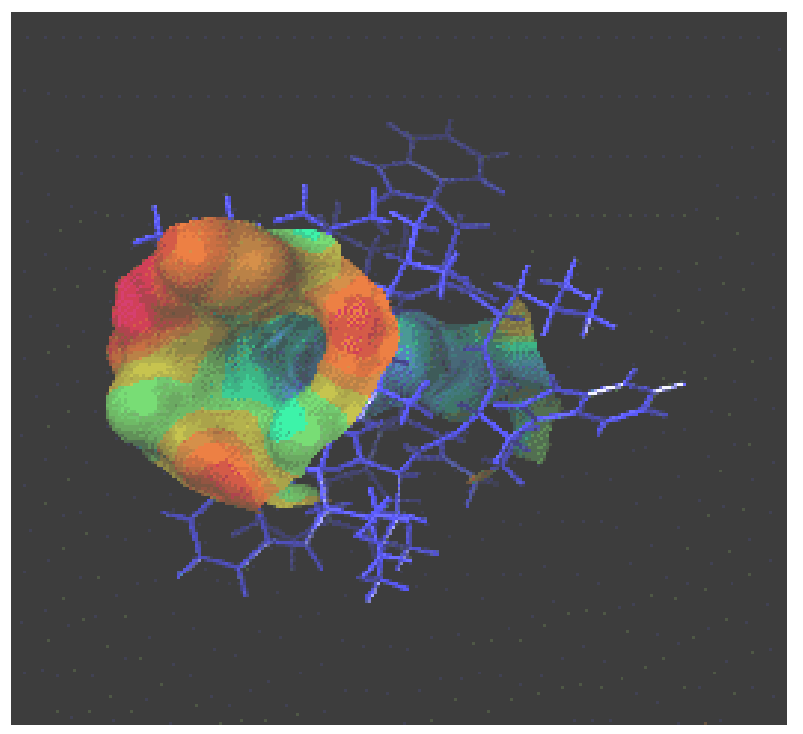

Figura 3.6 - Recorte da superfície da Gramicidina A de acordo com MLP [TES98].

Há uma vantagem muito grande em usar uma textura alfa como componente da filtragem de informação: informação irrelevante pode ser eliminada, enquanto informação geométrica escondida pela superfície é revelada diretamente no contexto da superfície. Além disso, a faixa de recorte pode ser alterada interativamente apenas transladando-se o espaço da textura. 


\subsection{Textura como Alternativa Eficiente para Rendering Volumétrico Direto}

Rendering volumétrico direto é uma técnica de visualização usada para mostrar dados 3D sem o passo intermediário de derivar uma representação geométrica como uma superfície. A primitiva gráfica característica é o voxel, termo derivado de volume element e análogo a pixel. No entanto, um voxel é descrito por outras propriedades além da cor, como opacidade ou parâmetros de tonalização.

Na maioria dos casos a informação volumétrica é armazenada usando apenas um canal de cor. Isto permite usar as tabelas de cores para uma interpretação alternativa de cor. Antes de uma entrada particular da tabela de cores ser renderizada no frame buffer, o valor da cor é interpretado como um índice para uma tabela de cores. Mudando-se rapidamente a cor e/ou opacidade ou usando-se diferentes funções de transferência, várias estruturas do volume são interativamente reveladas.

$\mathrm{O}$ uso de mapeamento de textura para renderizar as imagens volumétricas permite um desempenho melhor que outras técnicas de rendering volumétrico. Um grau maior de flexibilidade é atingido, pois para aplicar transformações ao volume, basta aplicar transformações no espaço da textura [GEL96]. Uma interatividade maior pode ser alcançada usando-se hardware gráfico no mapeamento desta textura.

\subsubsection{Rendering Volumétrico com Texturas 2D}

Nesta abordagem, a textura 2D pode substituir diretamente as imagens na pilha que compõe um volume. Um conjunto de polígonos quadriláteros é renderizado do fundo para frente, com cada polígono associado a sua própria textura (se a profundidade do polígono corresponder à localização de uma imagem). Polígonos entre as fatias que compõem a pilha podem ser texturizados em dois passos, isto é, o polígono é renderizado duas vezes. A cada vez ele associa uma das duas imagens como uma textura e um filtro com o fator de peso linear apropriado. Desta maneira, fatias intermediárias podem ser obtidas mesmo que o hardware gráfico não suporte interpolação de textura em três dimensões. 
O volume resultante parece corresponder aos polígonos da pilha de imagens alinhados paralelamente a tela. Entretanto, se o conjunto de imagens estiver orientado perpendicularmente à tela, não será possível obter uma visualização correta. Este problema pode ser facilmente resolvido pré-processando-se o volume de dados em três pilhas de imagens independentes e orientadas perpendicularmente entre si. A pilha mais apropriada pode ser escolhida baseada na orientação do volume. Assim, uma pilha de polígonos texturizados é rotacionada até um ângulo de visão crítico, então a função de rendering escolhe um dos dois conjuntos adicionais de polígonos texturizados, dependendo da orientação do objeto. Assim, o volume pode ser reorientado em tempo real com o auxílio de hardware gráfico.

\subsubsection{Rendering Volumétrico com Texturas 3D}

O método descrito na seção anterior não é a única possibilidade, mas é a mais trivial para implementar rendering volumétrico em tempo real usando mapeamento de textura. Assim, o hardware gráfico tem o máximo de desempenho, por ser otimizado para fazer mapeamento de textura 2D. No entanto, há certas limitações para essa abordagem: (1) a memória necessária deve ser três vezes maior do que o conjunto de dados original, sendo crítica no caso de volumes de dados grandes, como em imagens médicas ou microscópicas; (2) a geometria da amostragem do volume deve ser alinhada com as texturas 2D de acordo com a profundidade, isto é, superfícies arbitrárias construídas a partir de uma malha de triângulos não são facilmente coloridas dependendo das propriedades da vizinhança do volume. Por esta razão, arquiteturas avançadas de rendering suportam texturas 3D por hardware.

Uma implementação de um processo de mapeamento de texturas 3D simples consiste em um volume composto de fatias paralelas com orientação arbitrária, que será representado diretamente pela textura. O polígono planar, que será usado como geometria, deve ser grande o suficiente para conter um corte do objeto, como ilustrado na figura 3.7. A propriedade visualizada nesta figura é a probabilidade da água estar distribuída em volta da molécula de açúcar. A orientação do volume, que é uma transformação no espaço da textura, é a mesma da estrutura molecular. Tanto a molécula com a textura volumétrica, como o polígono de corte, 
podem ser reorientados em tempo real. Esta estratégia foi estudada e implementada no Grupo de Computação Gráfica e Processamento de Imagens do ICMC dentro do projeto Visualização Volumétrica em Odontologia [SOA00], financiado pela FAPESP.

Uma extensão da abordagem de planos de corte conduz a uma visualização do volume inteiro. Uma pilha de fatias planares, orientadas paralelamente à tela do computador, compõe a textura 3D. Os planos são processados de trás para frente e em intervalos suficientemente pequenos. Transformações sobre o volume são executadas para manipular a orientação da textura, mantendo os planos paralelos à tela computador, como pode ser visto na figura 3.8, que mostra um exemplo de uma aplicação médica que usa esta abordagem.

Este tipo de visualização é grandemente melhorado pela atualização interativa da tabela de cores usada para definir a textura. Na verdade, o propósito geral do editor da escala de cores é poder variar as cores, ou a transparência, com base na informação escalar associada a um ponto do volume $3 \mathrm{D}$.

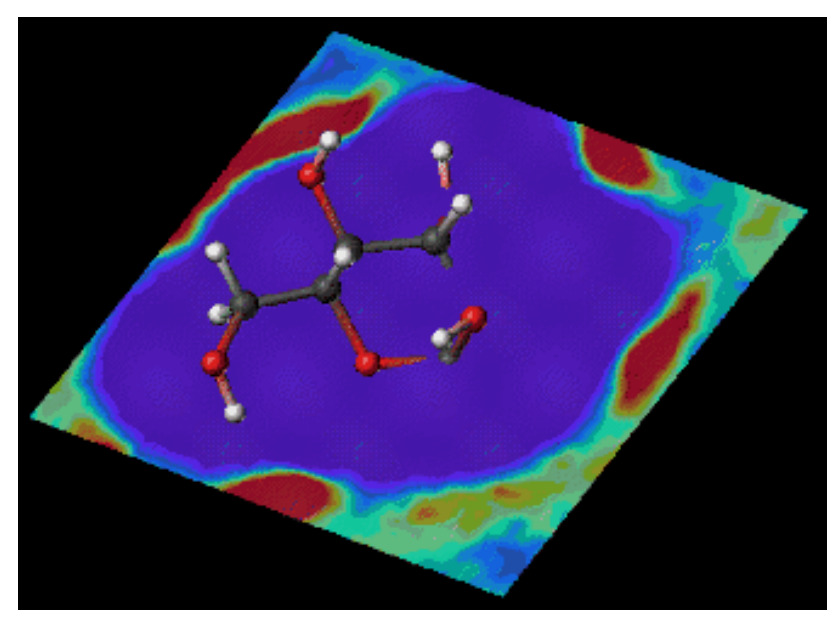

Figura 3.7 - Plano de corte dentro da densidade da água que cerca a molécula de açúcar [TES98].

O conceito de plano de corte pode ser estendido para um objeto de forma arbitrária [TES98]. A idéia é analisar uma propriedade volumétrica e mostrá-la através de primitivas geométricas do objeto analisado do volume. A independência da transformação do objeto para a textura 3D oferece completa liberdade de orientação da superfície com relação ao volume. O exemplo da superfície molecular é uma oportunidade para ter a informação sobre a vizinhança volumétrica atualizada em tempo real, baseado na orientação da superfície. 


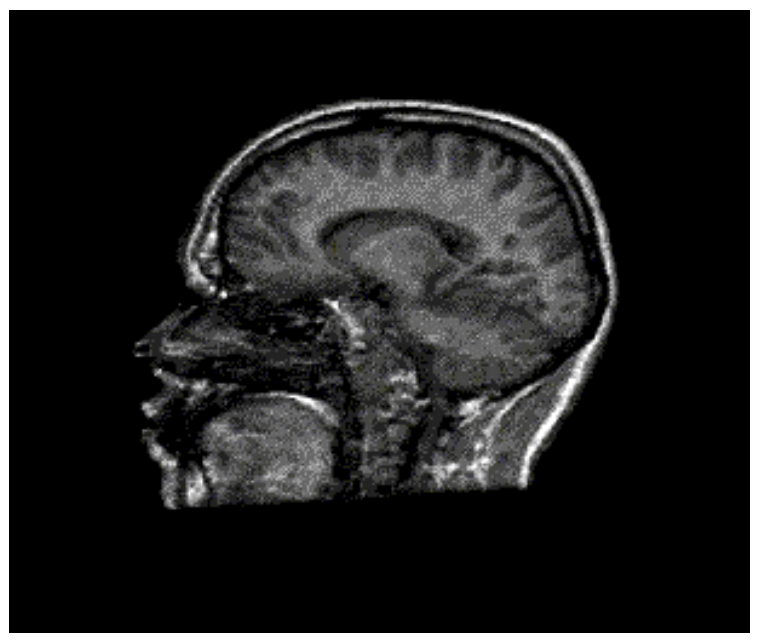

Figura 3.8 - Rendering Volumétrico de dados de Ressonância Magnética usando pilha de fatias paralelas à tela [TES98].

\subsection{Textura Procedimental como Estratégia de Visualização}

Com o aumento do poder computacional, os conjuntos de dados a serem visualizados também aumentaram consideravelmente. Esses dados são, na sua maioria, obtidos de simulações que usam um modelo simplificado do fenômeno em estudo. Com um poder computacional alto, os modelos podem ser mais precisos, gerando assim uma quantidade bem maior de dados, geralmente 3D. E em muitos casos, esses dados não são puramente escalares, tendo características vetoriais, ou seja, não possuem somente magnitude, mas também direção e sentido. Assim, a utilização de uma textura 3D implementada em hardware, e baseada diretamente no volume torna-se inaceitável, pois o hardware não suporta essa variedade e quantidade de dados. Uma possível solução para esse problema é o uso de técnicas de textura procedimental. Ela é definida como um procedimento, ou função, que produz um espaço de textura sem, no entanto, armazenar explicitamente a textura. No contexto de visualização, a textura procedimental é mais do que isso, e pode oferecer uma alternativa para o mapeamento de atributos dos dados em atributos visuais. Dentre essas técnicas utilizadas em visualização, destacam-se o LIC (line integral convolution) e o Spot Noise. A seção seguinte apresenta uma breve descrição da técnica de Spot Noise. A técnica de LIC será abordada no Capítulo 4 em maior profundidade. 


\subsubsection{Visualização de Escalares e Vetores com "Spot Noise"}

No spot noise os dados são representados pela variação de intensidade, e o valor de um pixel isolado é, essencialmente, randômico. A textura é produzida de forma que a intensidade varie lentamente na direção do fluxo e rapidamente na direção perpendicular ao fluxo. A função de ruído da textura é a soma de um grande número de pequenas funções de intensidades chamadas spots [POS99].

O spot noise [WIJ91] é uma analogia espacial do shot noise, um tipo especial de função randômica usada em muitas aplicações de engenharia. Ela é produzida por repetições sucessivas de pulsos independentes em intervalos randômicos. Cada pulso tem valor $a_{i} h(t-$ $\left.t_{i}\right)$, assim a função $f$ resultante é dada por:

$$
f(t)=\sum_{i} a_{i} h\left(t-t_{i}\right)
$$

onde $t_{i}$ são valores da variável independente (por exemplo, tempo). O poder espectral de $f(t)$ está diretamente relacionado com a energia espectral de $h(t)$, como segue:

$$
S_{h}(\omega)=|H(\omega)|^{2}
$$

onde $H(\omega)$ é a transformada de Fourier de $h(t)$. Se $a_{i}$ for zero e se há $v$ repetições por unidade de tempo, então:

$$
P_{f}(\omega)=v<a_{i}^{2}>S_{h}(\omega)
$$

O análogo espacial também tem muitas aplicações, por exemplo, na teoria da difração. Considerando o pulso como um ponto sobre um plano, temos o método de spot noise. $\mathrm{O}$ tamanho do ponto (spot) é limitado e, geralmente, pequeno comparado ao tamanho do segmento a ser sintetizado. Em analogia com o shot noise, o spot noise pode ser definido como:

$$
f(x)=\sum_{i} a_{i} h\left(x-x_{i}\right)
$$

onde $x_{i}$ são posições randômicas no plano. Se há $v$ repetições por unidade de área, então:

$$
P_{f}(k)=v<a_{i}^{2}>S_{h}(k)
$$

onde $k$ é um vetor de freqüência bidimensional. 


\section{Síntese da textura}

O poder espectral da textura e a energia espectral do ponto (spot) são os mesmos, exceto pelo fator de escala [WIJ91]. Spot noise pode ser construído no domínio da freqüência via multiplicação da transformada de Fourier $H(k)$ por um fator de escala e a adição de um deslocamento randômico de fase de $a_{k}$ para $H(k)$. A adição do deslocamento de fase randômico $a_{k}$ é equivalente à multiplicação por $W(k)=e_{k}^{i a}$. Se o poder espectral de $w(k)$ for distribuído sobre todas as freqüências, $w(k)$ é chamado de ruído branco. De acordo com o teorema da convolução [WIJ91], a multiplicação no domínio da freqüência é equivalente a convolução no domínio espacial, e o spot noise pode ser sintetizado via convolução de $h(x)$ com o ruído branco.

Um exemplo de ruído branco é um conjunto de valores randômicos disposto sobre uma malha. O spot noise pode ser sintetizado por um filtro de convolução de uma grade randomicamente preenchida com um ponto (spot), sendo comparado a uma filtragem de uma imagem muito ruidosa com um ponto como filtro de kernel, uma técnica padrão em processamento de imagens. Técnica similar é usada na síntese de texturas naturais [EBE98].

O uso dessa técnica para a visualização dos dados pode ser realizado variando-se o tamanho e a forma do ponto. Isto requer um ponto variável $h(p, x)$, cujas propriedades sejam controladas por um conjunto de parâmetros determinados via mapeamento do dado $m$ para um dado $d(x)$ que corresponde à coordenada de textura $x$. Spot Noise para visualização de dados pode ser sintetizado usando-se a seguinte função para variação dos pontos:

$$
f(x)=\sum_{i} a_{i} h\left(m\left(d\left(x_{i}\right)\right), x-x_{i}\right)
$$

A essência deste método é que os dados a serem visualizados são deformados. Para cada ponto, muitos pontos da textura (spots) são associados aos valores de dados correspondentes. Isto não é problema se a variação de dados diferentes é pequena em relação ao tamanho do ponto. Outra solução é usar uma definição alternativa de ponto variável, na qual a textura no ponto $x$ é considerada como se a parte da textura estacionária construída com os pontos 
idênticos que contém as propriedades correspondem ao dado no ponto $x$, de acordo com a função abaixo.

$$
f(x)=\sum_{i} a_{i} h\left(m(d(x)), x-x_{i}\right)
$$

Outra interpretação é usar o ponto como um filtro de kernel para o processo pontual de Poisson. Uma possível implementação, não muito eficiente, para pontos grandes, é via abordagem de Perlin [WIJ91]. Esta abordagem pode ser implementada, não via escalamento, mas via convolução de ruído:

$$
f(x, y)=\sum_{i} \sum_{j} h(m(d(x)), x+i, y+j) \text { Noise }(x+i, y+j)
$$

E a variação do ponto é dada por:

$$
\sigma^{2}=v<a_{i}^{2}>\iint h^{2}(x) d x
$$

Note que, em geral, a variação de $a_{i}$ pode ser adaptada por uma função de $x_{i}$, se for necessária uma variação uniforme da textura de acordo com pontos variados.

\section{Parâmetros da Textura.}

Um disco é a maneira mais simples de representar o ponto (spot). A figura 3.9 mostra três discos com raios diferentes e suas texturas correspondentes. As diferenças entre texturas podem ser explicadas por seus poderes espectrais. Para o caso $2 \mathrm{D}$, quando pontos pequenos são usados, as amostras de diferentes localizações não possuem relação umas com as outras, e o resultado é o ruído branco. Porém, se pontos grandes são usados os fatores randômicos degeneram e o resultado acaba sendo fractal, tendo o aspecto de nuvens. Para um tamanho intermediário do ponto acontecem os dois efeitos simultaneamente. Numa visão geral, o resultado é ruído branco, enquanto que os detalhes têm características fractais. 


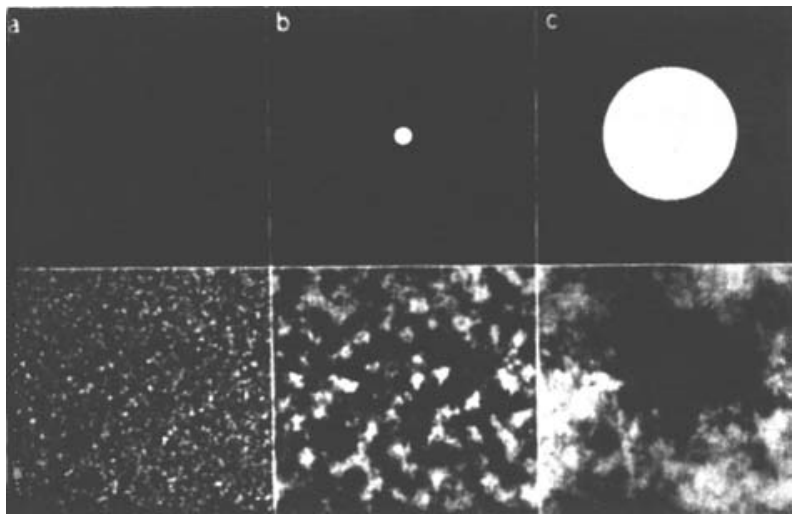

Figura 3.9 - Pontos de tamanhos diferentes [WIJ91].

A textura apresentada na seção anterior é invariante sob uma rotação, isto é, isotrópica. A textura será isotrópica se o ponto for rotacionado simetricamente, ou se o ponto, randomicamente posicionado, também for randomicamente rotacionado. O poder espectral $P_{f}(k)$ da função de ruído $f(x)$ resulta do uso de pontos randomicamente rotacionados $h(x, y)$ com energia espectral $S_{h}\left(k_{1}, k_{2}\right)$, sendo dado por:

$$
P_{f}(k) v<a_{i}^{2}>\frac{1}{2 \pi|k|} \int_{0}^{2 \pi} S_{h}(|k| \cos \alpha,|k| \sin \alpha) d \alpha
$$

Se é usada uma rotação não randômica, o comprimento das linhas nos pontos poderia gerar uma textura anisotrópica.

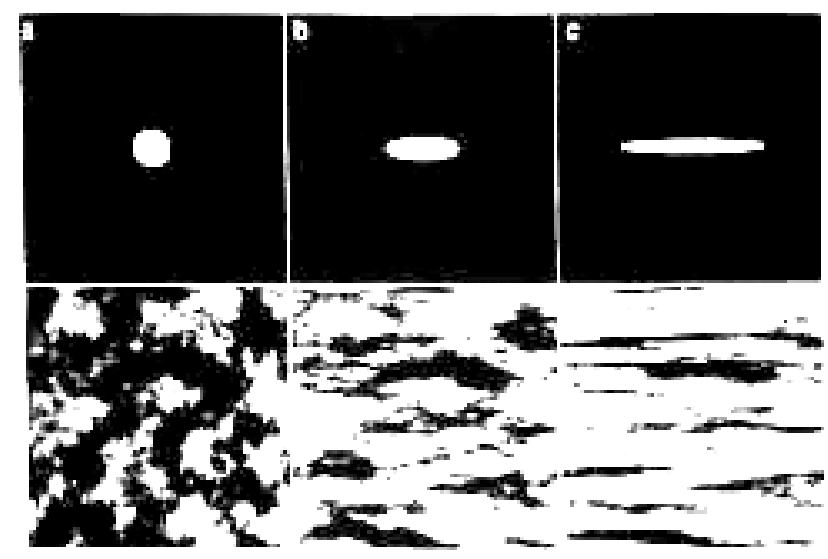

Figura 3.10 - Escalamento não-proporcional [WIJ91].

Uma maneira simples de gerar uma textura anisotrópica é escalar não uniformemente o ponto, a figura 3.10 mostra o efeito do uso de elipses no lugar de discos. Para elipse alongadas, a 
textura tem característica fractal na direção do eixo alongado e característica de ruído branco no eixo mais curto. O efeito de escalamento do ponto não é simplesmente o escalamento da textura. A textura é deformada localmente, e grandes detalhes na textura permanecem no mesmo lugar.

Muitas texturas exibem padrões, isto é, estruturas repetitivas ao longo de uma área. Muitos padrões apresentam-se na função de correlação como oscilações com magnitude decrescente. A figura 3.11 mostra que, se o ponto tiver algum padrão regular, a textura também o terá. Um ponto composto por círculos concêntricos gera uma textura isotrópica.

Estes tipos de pontos têm três níveis de detalhe: cada nível corresponde a uma característica da textura. O tamanho global do ponto determina a escala da componente de ruído branco, a largura e o espaçamento da linhas determinam a largura e o espaçamento dos padrões.

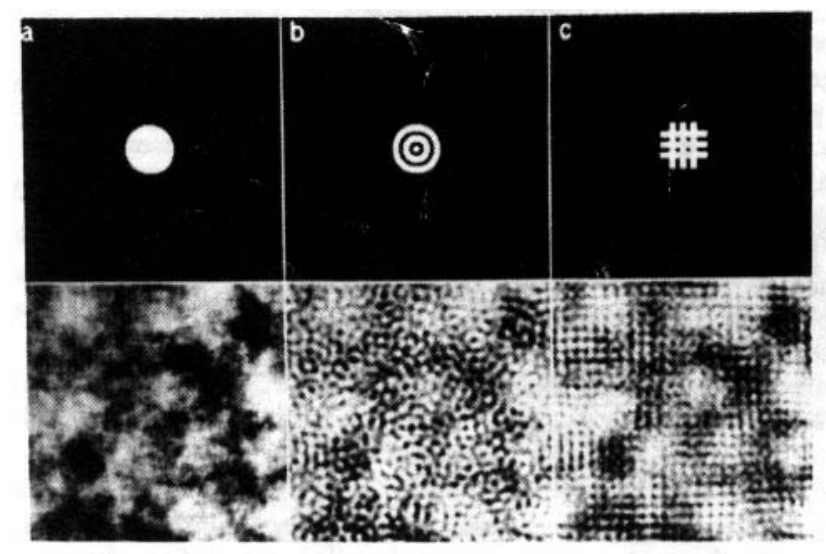

Figura 3.11 - Padrões Regulares na Textura [WIJ91].

Nos exemplos anteriores foi visto que a forma do ponto (spot) influencia fortemente a textura. Mais alguns exemplos são mostrados na figura 3.12. O uso de quadrados como pontos produzem padrões horizontais e verticais (fig. 3.12a). Se o quadrado for distorcido em um diamante, o resultado é facilmente previsível (fig. 3.12b). A figura 3.12c mostra um ponto com a forma de um quarto de círculo. A textura resultante parece com a visão da superfície de um planeta ou com uma paisagem lunar sem crateras. 


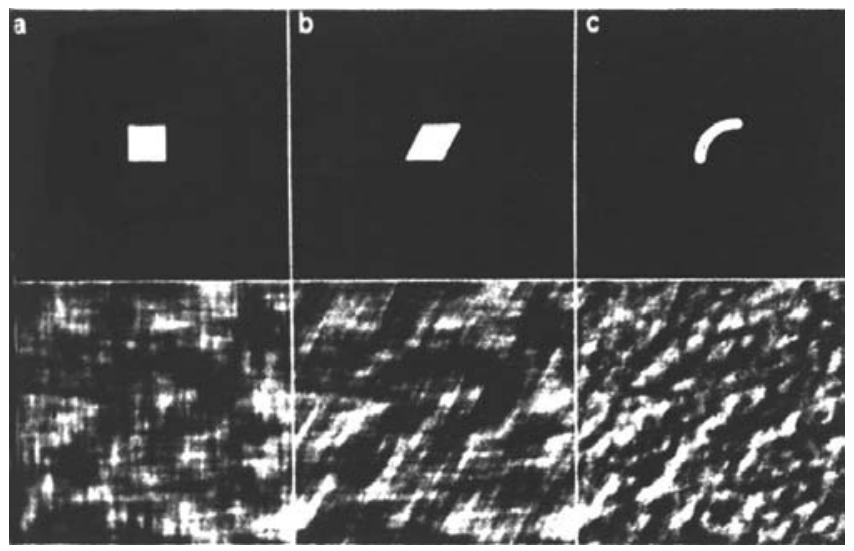

Figura 3.12 - Diferentes Formas para o Ponto (Spot) [WIJ91].

\section{Combinação com Outras Técnicas}

As streamsurfaces são criadas pelo movimento de partículas ao longo de uma linha de fluxo. Uma visualização com streamsurfaces dá apenas informações parciais do fluxo na superfície, sendo que a magnitude e direção com o plano são perdidos. O spot noise gerado para uma streamsurface pode ser usado para visualizar esta informação [WIJ95]. O resultado do mapeamento do spot noise sobre uma streamsurface pode ser visto na figura 3.13.

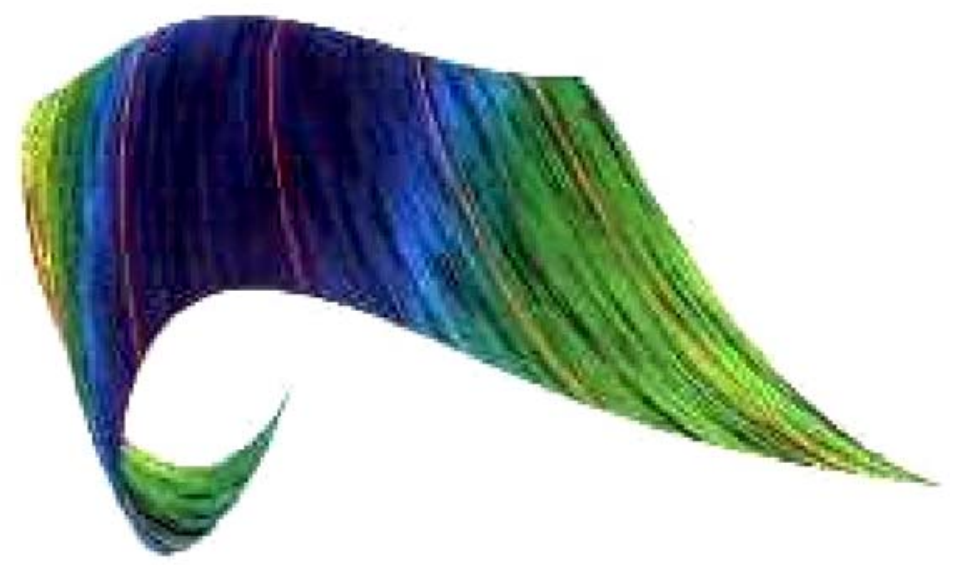

Figura 3.13 - Spot Noise sobre uma streamsurface [WIJ95].

Simulações de fluidos, muitas vezes, produzem dados como velocidade, pressão e temperatura. A textura de spot noise pode ter associada uma cor para mostrar grandezas quantitativas. Na figura 3.14, a pressão está mapeada para cor. A superfície é uma fatia de um 
conjunto de dados. O uso de spot noise é essencial para mostrar o fluxo principal em que a velocidade é grande, junto com a recirculação do fluxo.

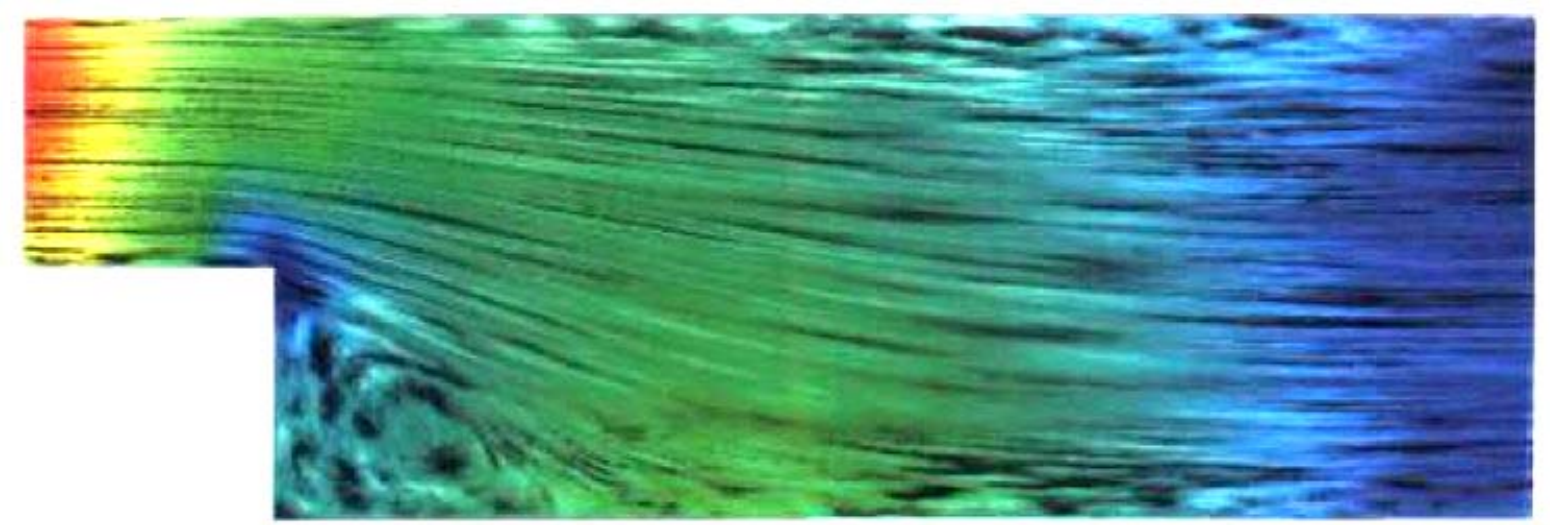

Figura 3.14 - Cor mostrando pressão, utilizando spot noise [WIJ95].

Em experimentos de túnel de vento a velocidade do fluido pode ser visualizada utilizando óleo pigmentado. Em imagens de simulação isto pode ser feito utilizando o spot noise, que com pequenas modificações, pode produzir imagens similares as dos túneis de vento. Ao contrário do spot noise padrão, este só usa os pontos positivos para emular um pigmento branco sobre a superfície preta. A figura 3.15 mostra uma imagem gerada com esta técnica.

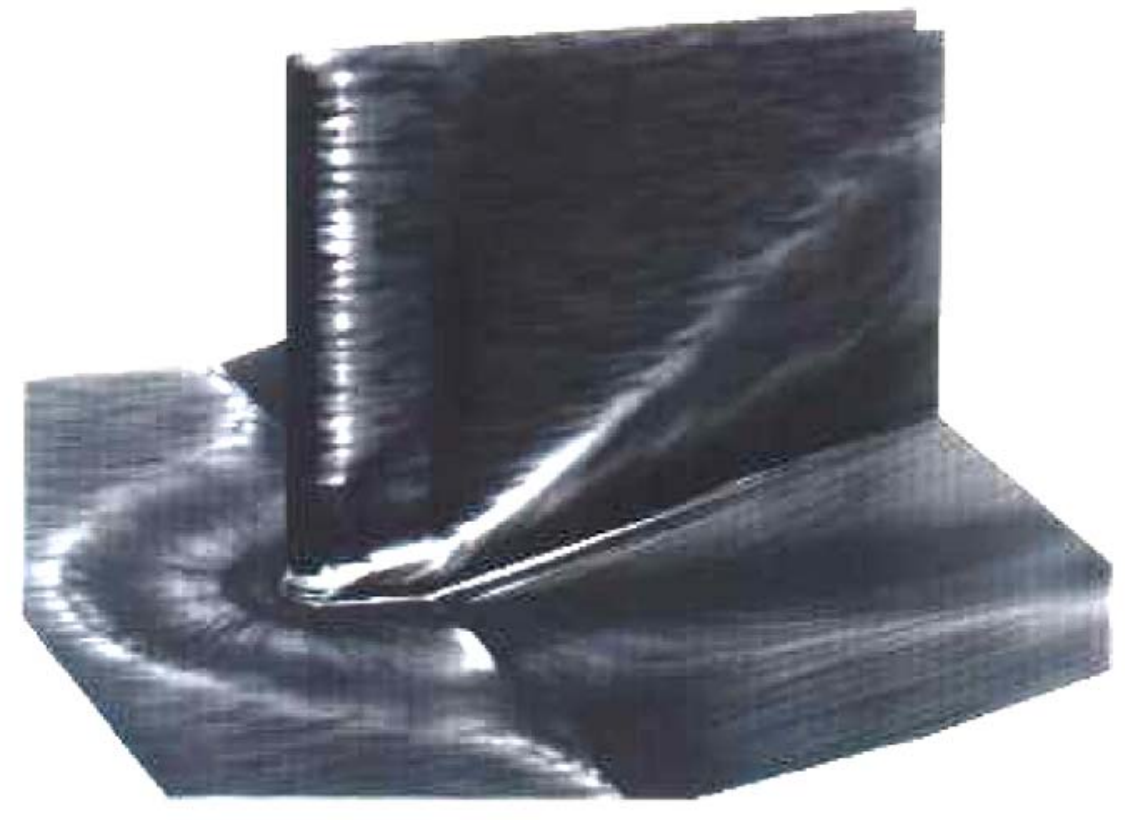

Figura 3.15 - Visualização da fricção do vento sobre uma superfície em simulador de túnel de vento [WIJ95]. 


\section{Visualização de Dados Vetoriais usando “Line Integral Convolution" (LIC)}

\subsection{Considerações Iniciais}

Atualmente existe um considerável número de técnicas para visualização de dados vetoriais. Dentre elas podemos citar Spot Noise [POS99; GRÖ99; WIJ91], Streamlines [GRÖ99; SCH98], StreamSurface [GRÖ99], Particles Traces[SCH98], Deformable Surfaces [POS99; SCH98], e Line Integral Convolution (LIC). Dentre elas destacam-se o LIC e o Spot Noise, que são técnicas globais [POS99] que fazem uso do conceito de textura procedimentais para a geração da visualização. O Spot Noise foi brevemente descrito no capítulo 3. Neste capítulo será apresentada a técnica LIC, seus princípios e conceitos básicos. A seção 4.2 introduz os fundamentos da técnica. A seção 4.3 aborda o método de interpolação com o algoritmo de traçado de linha conhecido como DDA. A seção 4.4 descreve o método de interpolação com streamlines. Finalmente, a seção 4.5 apresenta a técnica de interpolação conhecida como Método de Runge-Kutta de Segunda Ordem, além de suas vantagens e desvantagens.

\subsection{Line Integral Convolution (LIC)}

Técnicas de visualização de vetores baseadas em texturas foram estudadas intensivamente nos últimos anos. Tipicamente, uma textura de alta freqüência (figura 4.1(a)) é filtrada de acordo com um campo vetorial (figura 4.1(b)) produzindo uma visão global do fluxo inteiro (figura 4.1(c)).

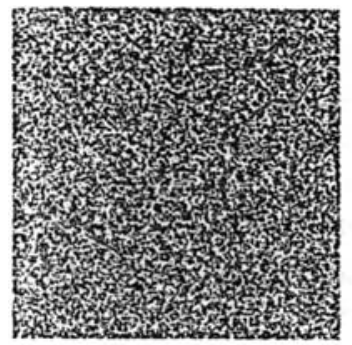

(a)

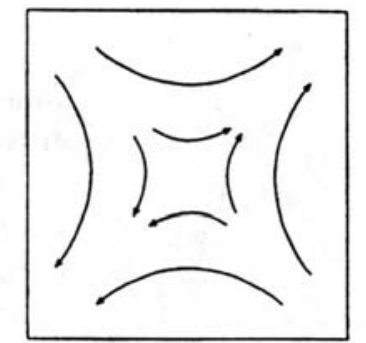

(b)

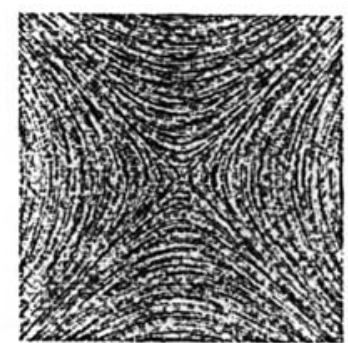

(c)

Figura 4.1 - (a) Ruído branco, (b) campo vetorial 2D, (c) textura de ruído branco filtrada com o campo vetorial [GRÖ99]. 
A aplicação do filtro de convolução integral de linha (LIC) suaviza uma textura de entrada de ruído branco ao longo do campo vetorial, como ilustrado na figura 4.1 [GRÖ99]. Durante a geração da imagem LIC ocorre a interpolação do campo vetorial com o espaço de textura definido. Essa interpolação é a parte mais importante de todo o algoritmo de LIC. Nas seções 4.3, 4.4 e 4.5 são apresentadas técnicas que podem ser usadas para essa interpolação, assim como suas vantagens e desvantagens.

\subsection{Interpolação Usando Algoritmo DDA (Digital Differential Analyser)}

A interpolação é umas das partes mais importantes desta técnica e pode ser implementada de várias maneiras, influenciando assim a visualização. Uma abordagem consiste na generalização do algoritmo geral de traçado de retas (DDA) [FOL90; HEA94] e do algoritmo de convolução descrito na seção 3.4.1. Para isso cada vetor do campo define uma reta, que é gerada pelo filtro de kernel tangencial em duas direções opostas (positiva e negativa em relação ao vetor) e com um comprimento $L$ em cada sentido. A textura então é mapeada de um-para-um com o campo vetorial. Os pixels da textura mapeados sobre a reta são somados e normalizados pelo tamanho do filtro de kernel $2 L$, e então atribuído à posição do vetor na imagem de saída.

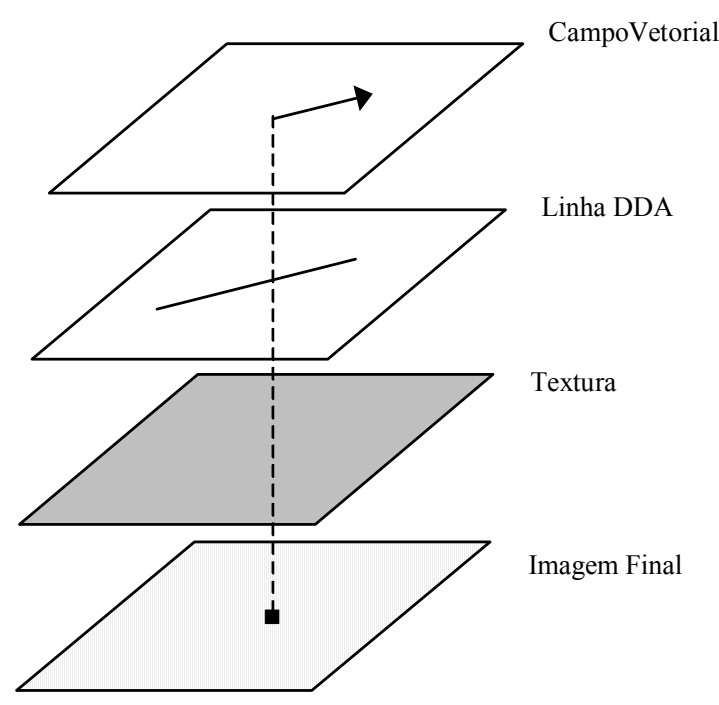

Figura 4.2 - Mapeamento do vetor por convolução DDA gerando a imagem de saída.

Essa abordagem apesar de eficiente pode ser imprecisa. O algoritmo de DDA assume que o campo vetorial local pode ser aproximado por uma reta. Para os pontos do campo vetorial, 
onde o raio local da curvatura é grande, essa suposição é verdadeira. Porém, onde existir estruturas complexas menores que o tamanho da reta DDA (e o raio da curvatura for menor) a aproximação dada por essa reta não será precisa.

O algoritmo de interpolação usado pela técnica de Spot Noise também sofre desse problema caso o ponto (spot) seja alongado elipticamente na direção do campo vetorial local. Se esse eixo maior da elipse exceder o "tamanho" do campo vetorial local, a imagem gerada pelo Spot Noise será imprecisa ao representar esse campo vetorial. Uma medida precisa da vizinhança do campo vetorial local requer uma análise global desse campo. Atualmente não existem técnicas para análise global automática desses campos, e técnicas não automáticas são computacionalmente caras e ainda são áreas ativas de pesquisas [CAB93].

\subsection{Interpolação por Streamlines}

A vizinhança do campo vetorial pode ser aproximada com precisão, calculando-se uma streamline com centro em um pixel $(x, y)$ e que se move na direção do campo vetorial, porém em ambos os sentidos. Para isso a técnica de LIC usa um filtro unidimensional determinado pela integração do vetor a ser visualizado. A intensidade $I\left(x_{0}\right)$ para uma posição $x_{0}$ da imagem de saída é calculada por:

$$
I\left(x_{0}\right)=\int_{s 0-s 1}^{s 0+s 1} k\left(s-s_{0}\right) T(\sigma(s)) d s
$$

onde $T$ é a textura de entrada, $\sigma(\mathrm{s})$ é a streamline parametrizada ao longo de $x_{0}\left(x_{0}=\sigma\left(s_{0}\right)\right)$ e $K()$ descreve o kernel de convolução. $s_{l}$ especifica o tamanho da streamline na operação do filtro. Os valores da textura ao longo do segmento da streamline $\sigma(s),\left(s_{0}-s_{1} \leq s \leq s_{0}+s_{1}\right)$, são ponderados segundo seus valores de kernel $K()$ correspondentes. Eles são acumulados para dar a intensidade $I\left(x_{0}\right)$ na posição $x_{0}$. Várias funções de kernel $k()$ podem ser usadas na operação de filtragem.

Apenas a componente direcional do campo vetorial é usada no cálculo da streamline. A magnitude pode ser usada em etapas de pós-processamento ou usadas para combinar várias técnicas, como por exemplo, mapeamento de cores. O cálculo da streamline é sensível a erros 
de arredondamento. Para minimizar esse erro a um custo computacional aceitável usa-se o método de interpolação conhecido como Runge-Kutta de Segunda ordem

\subsection{Método de Runge-Kutta de Segunda Ordem}

O método de Runge-Kutta de Segunda Ordem é o aperfeiçoamento do método de Euler para resolução de equações diferenciais ordinárias [PRE92]. Este consiste em:

$$
y_{n+1}=y_{n}+h f\left(x_{n}, y_{n}\right)
$$

onde a solução dessa equação é dada variando $x_{n}$ para $x_{n+1} \equiv x_{n}+h$. Esta fórmula é assimétrica, avançando para a solução de acordo com o intervalo $h$. Isto significa que o erro do passo é uma potência de $h$ menor que a correção, isto é $O\left(h^{2}\right)$. Há muitas razões para o método de Euler não ser usado em aplicações práticas, entre elas, o método não é preciso como outros que usam o mesmo tamanho de passo, e ainda não é considerado estável suficiente para uso prático.

Uma melhoria pode ser introduzida usando o passo acima como uma "tentativa" para um passo intermediário. Partindo desse passo intermediário, calcula-se o valor real para o intervalo. Para isso usa-se:

$$
\begin{aligned}
& k_{1}=h f\left(x_{n}, y_{n}\right) \\
& k_{2}=h f\left(x_{n}+\frac{1}{2} h, y_{n}+\frac{1}{2} k_{1}\right) \\
& y_{n+1}=y_{n}+k_{2}+O\left(h^{3}\right)
\end{aligned}
$$

Assim a simetrização cancela o termo de erro de primeira ordem, tornando esse, um método de segunda ordem. De fato esse método é chamado de Método de Runge-Kutta de Segunda Ordem, ou método do ponto intermediário (midpoint). 


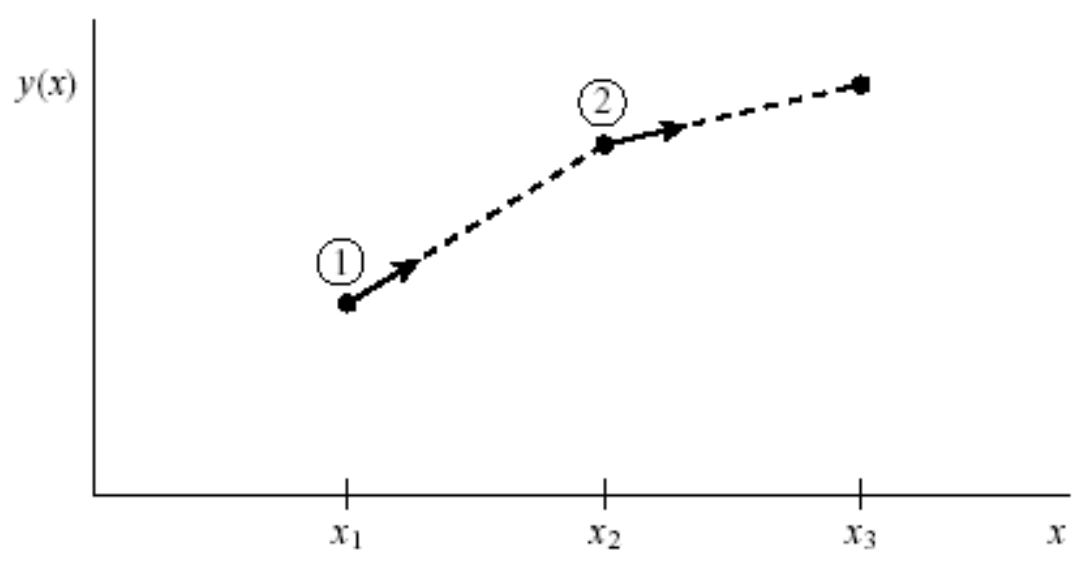

Figura 4.3 - Ponto calculados através do método de Euler. A imprecisão é claramente notada.

Claramente nota-se a diferença entre o Método de Euler (figura 4.3) e o Método de RungeKutta de Segunda Ordem (figura 4.4). Aplicando essa técnica para o cálculo da streamline citada na seção 4.4 consegue-se duas grandes vantagens: a precisão necessária para um uso prático dessa técnica, e um custo computacional aceitável, uma vez que técnicas de interpolação precisas possuem um custo computacional relativamente alto.

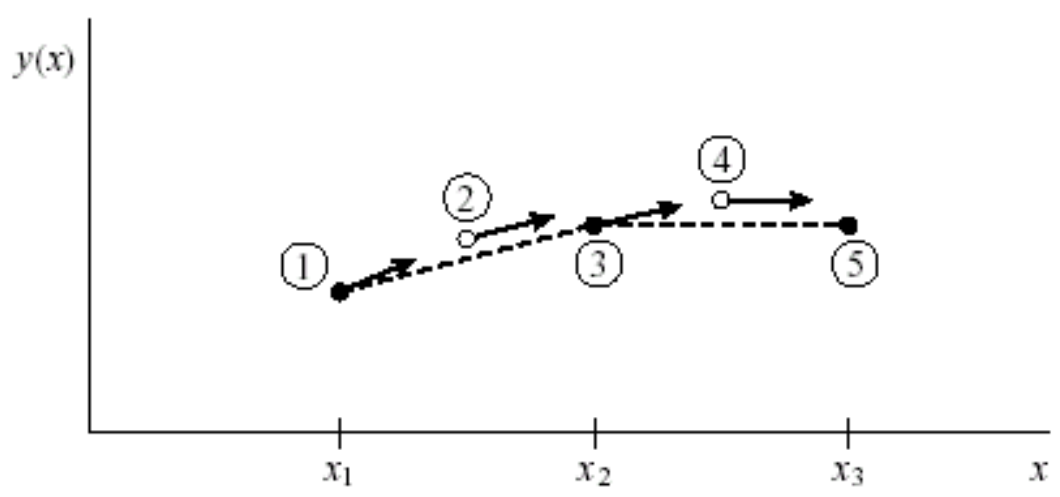

Figura 4.4 - Método de Runge-Kutta de Segunda Ordem. Pontos intermediários $(2,4)$ melhoram a precisão em relação ao método de Euler.

\subsection{Uso e Limitações}

Para uma imagem, um filtro de kernel constante, como os citados acima, dá uma boa impressão da direção do fluxo. A utilização de um filtro periódico passa-baixa e o deslocamento de fases destes kernels em sucessivas imagens permitem animar o campo do fluxo, mostrando o fluxo, seu movimento e sua orientação. Imagens LIC codificam a direção 
do fluxo e a magnitude da velocidade, mas elas não mostram a orientação do fluxo, que pode ser ilustrado pela animação. Entretanto há casos em que apenas as imagens estão disponíveis ou são necessárias, como em livros ou artigos. Além disso, imagens LIC são caracterizadas por uma alta freqüência espacial do fluxo. Isto dá uma boa impressão do campo vetorial, mas é suscetível aos efeitos do aliasing no caso da imagem ser manipulada, aumentada ou impressa. O filtro de convolução integral de linha orientado (OLIC) foi desenvolvido para mostrar a orientação de um fluxo, mesmo em imagens, e não é tão suscetível ao efeito de aliasing [GRÖ99].

Há duas diferenças básicas entre LIC e o OLIC. As imagens LIC, tipicamente, usam texturas de ruído densas, já as imagens OLIC utilizam apenas texturas esparsas. Uma textura esparsa pode ser vista como um conjunto "pingos de tinta" distribuídos sobre uma folha de papel. O campo de vetores borra estes "pingos", mas eles estão tão afastados que o borrão provocado pelos vetores não se sobrepõe sobre outro pingo. A segunda diferença entre LIC e OLIC é que este último usa kernels de convolução assimétricos. Um kernel tipo "rampa" como ilustrado na figura 4.5 e que produz traços nos pingos com intensidade variável ao longo das streamlines. Como a textura esparsa não permite que ocorram sobreposições de traços, a orientação do fluxo é visível mesmo em imagens paradas.

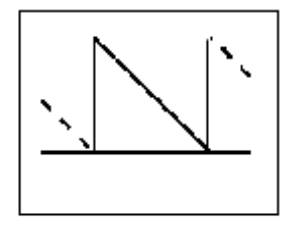

Kernel de convolução

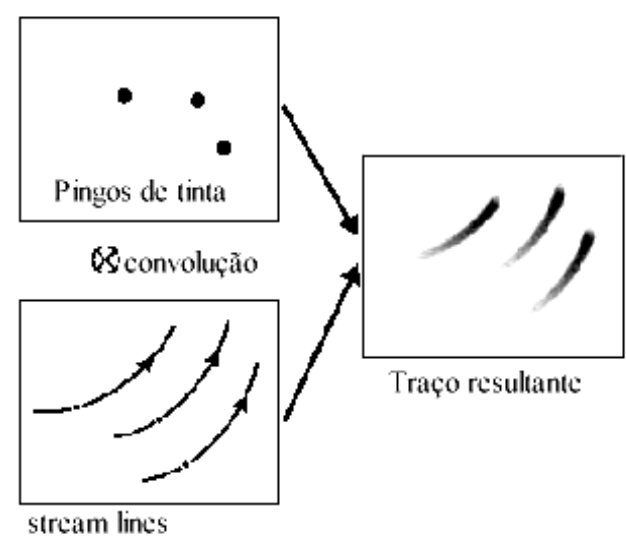

Figura 4.5 - OLIC: LIC com textura esparsa e função kernel tipo rampa.

$\mathrm{Na}$ figura 4.6 a diferença entre LIC e OLIC é claramente visível. A figura 4.6(a) mostra uma imagem LIC de um fluxo circular. Nesta imagem não é possível distinguir o sentido do fluxo. A figura 4.6(b) mostra uma imagem OLIC com fluxo no sentido horário e na figura 4.6(c) mostra o fluxo no sentido anti-horário. 
As posições iniciais dos pingos na textura esparsa devem ser selecionadas cuidadosamente para evitar a formação de padrões macroscópicos indesejáveis na imagem OLIC. No entanto esta técnica possui um custo computacional muito alto, devido à interpolação necessária para se aplicar o kernel "rampa".

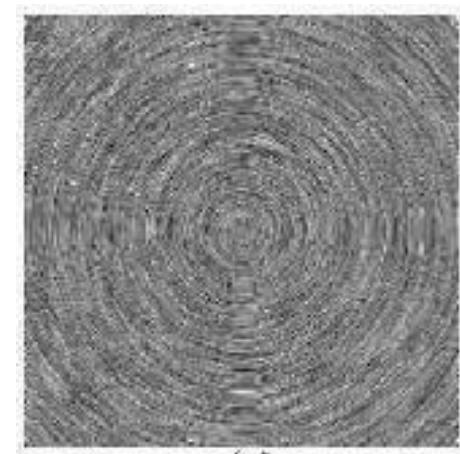

(a)

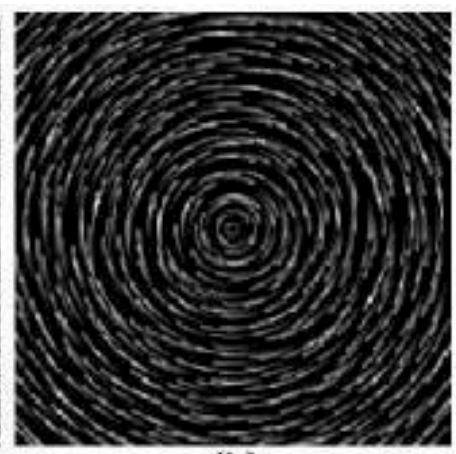

(b)

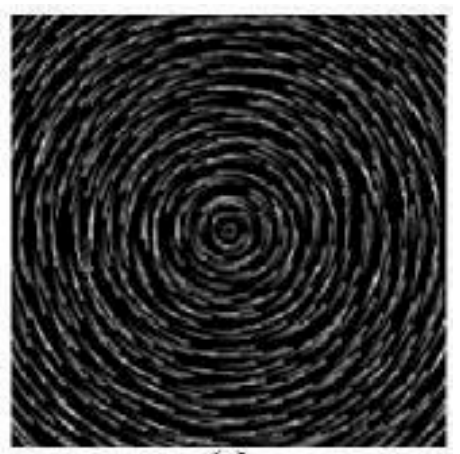

(c)

Figura 4.6- (a) Imagem LIC de um fluxo circular, (b) Imagem OLIC com fluxo horário, (c) Imagem OLIC com fluxo anti-horário [GRÖ99].

Outro problema da técnica OLIC ocorre quando se tenta fazer um mapeamento de cores sobre a imagem gerada. A natureza esparsa da textura impede que o cálculo da cor do pixel seja exato, por não possuir uma área bem definida. Já o LIC tradicional permite que o cálculo seja feito com grande precisão, pois o tamanho do pixel é relativo ao volume e pode ser alterado de acordo com a necessidade. Essa técnica é descrita com mais detalhes no capítulo 5. 


\section{Implementação}

\subsection{Considerações Iniciais}

O Grupo de Computação Gráfica e Processamento de Imagens (CG \& PI) do ICMC vem trabalhando no estudo, implementação e melhoria de técnicas de Visualização no contexto do projeto PowerVis [MIN97; OLI98; OLI98a]. O projeto visa a criação e implementação de técnicas de visualização para possibilitar a aplicação das técnicas de mapeamento gráfico existentes por potenciais usuários de sistemas de visualização. Este trabalho, em nível de mestrado, se insere no contexto do projeto PowerVis, e implementa estratégias procedimentais de geração de texturas, incorporadas à biblioteca VTK. Com isso, disponibiliza-se, de forma integrada ao VTK (Visualization Toolkit), uma classe para geração de imagens LIC a partir de texturas bidimensionais em visualizações de dados vetoriais. A seção 5.2 apresenta uma breve descrição sobre o VTK. As interfaces de entrada e saída da classe vtkImageLIC, implementada nesse trabalho, são abordadas na seção 5.3. Os métodos de parametrização dessa classe são apresentados na seção 5.4 e o método responsável pela geração do resultado é detalhado na seção 5.5.

\subsection{O Visualization ToolKit}

O VTK (Visualization ToolKit) é um software multi-plataforma de baixo custo [SCH98] que oferece uma biblioteca de algoritmos e estruturas de dados para visualização compatível com plataformas UNIX e Windows NT. O software foi desenvolvido em $\mathrm{C}++$ segundo o paradigma de orientação a objetos e é extensível, com o código fonte disponível, permitindo o desenvolvimento de novas aplicações com uma interface gráfica própria, a alteração das técnicas já implementadas e a inclusão de novas técnicas de visualização. A geração de visualizações é feita com a criação de programas que descrevem pipelines de visualização que são seqüências de transformações sobre os dados de entrada até a renderização da imagem final na tela, como mostra a figura 5.1. 


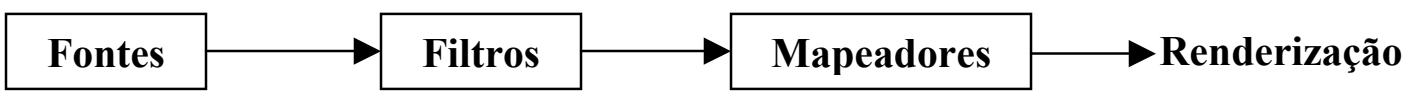

Figura 5.1 - Pipeline de visualização segundo o VTK.

O VTK possui um conjunto de classes com funcionalidades específicas, que podem ser dos tipos Fonte, Filtro, Mapeador e Gráfico. Objetos da classe fonte iniciam o pipeline de visualização, fazendo a leitura de arquivos de dados externos ou criando dados a partir de instâncias de objetos, e gerando um ou mais conjuntos de dados de saída. Objetos da classe filtro recebem pelo menos um conjunto de dados de entrada e geram um ou mais conjuntos (em geral, transformados) de dados de saída. Os mapeadores finalizam o pipeline de visualização, recebendo um ou mais objetos de entrada, e fazendo o mapeamento desses dados para um determinado dispositivo ou para uma biblioteca gráfica. Os Escritores (writers) são mapeadores que escrevem dados em um arquivo. Os objetos do tipo Gráfícos implementam a funcionalidade do núcleo de renderização. Esses objetos permitem a manipulação de fontes de luz, câmeras e atores, das propriedades dos atores e dos atributos de renderização (como a cor de fundo do renderizador). O VTK é capaz de estabelecer a comunicação entre o processo de renderização e o dispositivo de apresentação, gerenciando as janelas no dispositivo de apresentação nos PCs (no ambiente Windows NT) e no UNIX (no ambiente X Window).

Entre as classes do VTK, a classe vtkTexture estabelece a interface entre um arquivo de entrada (que fornece a imagem de textura) e as funções de mapeamento de textura da biblioteca gráfica. Uma instância dessa classe pode ser associada a um único ou a múltiplos atores, permitindo que vários objetos gráficos compartilhem uma mesma textura. Instâncias da classe vtkTexture podem receber como entrada (através do método SetInput) um conjunto de dados do tipo vtkStructuredPoints (um volume de dados regular, ou estruturado). Isso permite que um pipeline de visualização seja construído para ler, processar, e/ou gerar um mapa de textura. Por exemplo, o objeto vtkRendererSource pode ser usado para converter uma imagem renderizada em um conjunto de pontos estruturados. Outra classe importante é a vtkImplicitTextureCoords é um filtro para a geração de coordenadas de textura 1D, 2D e 3D, ou 3 funções implícitas respectivamente. Usada em combinação com vtkBooleanTexture ou 
outro mapa de textura criado pelo usuário, pode realçar ou recortar uma geometria sem a necessidade de processamento geométrico complexo.

A técnica implementada neste trabalho pode ser facilmente incorporada ao VTK como uma classe chamada vtkImageLIC, sendo um filtro que recebe os dados vetoriais como entrada, e retorna uma imagem bidimensional como saída. Esta classe e sua implementação são apresentadas nas seções seguintes.

\subsection{Classe vtkImageLIC}

A classe vtkImageLIC, implementada neste trabalho de mestrado, recebe como entrada dados vetoriais definidos sobre uma geometria regular e processa essa informação utilizando outras classes do VTK. A saída deste filtro é uma imagem bidimensional que pode ser enviada a um mapeador para ser apresentado na tela, ou também enviado ao "escritores" para ser gravado em um arquivo. A entrada, os métodos implementados e a saída dessa classe são apresentados nas seções seguintes.

\subsubsection{Dados de Entrada}

A classe vtkImageLIC recebe como entrada dados vetoriais sobre uma geometria regular definida. Esses dados são representados no VTK pela classe vtkStructuredPoints considerada a representação mais simples e compacta dessa biblioteca. Para se definir uma classe desse tipo, necessita-se apenas de informações sobre as dimensões, o espaçamento e a origem dessa representação [SCH98]. As dimensões definem a topologia deste conjunto de dados, enquanto o espaçamento e a origem definem sua geometria. Por este motivo diz-se que este conjunto de dados está definido implicitamente. O número total de pontos contidos neste conjunto de dados é $n_{x} \times n_{y} \times n_{z}$ onde $n_{x}, \quad n_{y}, \quad n_{z}$ são as dimensões que definem a classe vtkStructuredPoints.

A cada ponto $(x, y, z)$, definido para a classe vtkStructuredPoints, pode-se associar dados de vários tipos definidos por outras classes do VTK. A mais importante no contexto desde projeto chama-se vtkVectors. Essa classe permite associar um vetor tridimensional a uma 
geometria definida pela classe vtkStructuredPoints. Nela cada ponto $(x, y, z)$ terá associado a si um vetor $(t, u, v)$. O número de vetores da classe vtkVectors deve ser o mesmo que o número de pontos definidos na classe vtkStructuredPoints.

Tanto a geometria definida pela classe vtkStructuredPoints como os vetores definidos pela classe vtkVectors devem ser preenchidos utilizando as classes e os métodos de leitura próprios do VTK, como vtkStructuredPointsReader e vtkVectorsReader. Essas classes garantem que os dados lidos e inseridos nas classes de entrada estão de acordo com as especificações das mesmas.

A classe vtkImageLIC não lê diretamente os arquivos que contenham um conjunto de dados vetoriais, pois as classes citadas acima fazem isso da melhor maneira necessária para esse projeto. Esta classe apenas recebe os dados definidos pela classe vtkStructuredPoints.

\subsubsection{Dados de Saída}

A classe vtkImageLIC tem como saída uma imagem bidimensional com dimensões relativas ao volume de dados de entrada. A saída é representada pela classe vtkImageData. Esta classe pode ser representada por suas dimensões $n_{x}, n_{y}, n_{z}$. Para esse projeto foi usado o valor 1 (um) na dimensão $n_{z}$ com o intuito de prover uma imagem bidimensional, uma vez que uma imagem tridimensional necessita de técnicas complexas para ser visualizada.

Essa classe vtkImageData possui associado a cada ponto $(x, y, z)$ uma tripla HSV (Hue, Saturation, Value) que define a matiz, a saturação e o valor para esse ponto da imagem. Esse sistema de cores foi adotado por ser o mais adequado na coloração da imagem. A matiz é calculada a partir do valor obtido pela interpolação do campo vetorial. A saturação da cor é constante e vale 1 (um), o valor máximo para esse parâmetro. O parâmetro valor é obtido através da magnitude do vetor no ponto correspondente. Esse processo será explicado em detalhes na seção 5.5 .

A saída da classe vtkImageLIC pode ser usada por qualquer mapeador ou escritor que aceite dados do tipo vtkImageData. Através dos mapeadores essa imagem pode ser exibida na tela. 
Os "escritores" gravam essa imagem em arquivos de saída. Caso seja necessário, também se pode usar a imagem de saída como entrada em um filtro apropriado para uma etapa de pósprocessamento.

\subsection{Métodos da Classe vtklmageLIC}

Todas as funcionalidades da classe vtkImageLIC são e devem ser acessadas utilizando os métodos implementados dentro dessa classe. Assim pretende-se evitar o acesso a estruturas e parâmetros internos mantendo-se, assim, o encapsulamento da classe e a facilidade de uso que o paradigma de orientação a objetos proporciona. Os métodos implementados nesta classe são descritos nas seções subseqüente.

\subsubsection{Método New()}

Este método implementado dentro da classe vtkImageLIC cria uma instância (objeto) do mesmo tipo da classe. Este método deve, obrigatoriamente, ser o primeiro a ser chamado, uma vez que os outros métodos somente estão acessíveis após a criação do objeto, retornando um ponteiro para o objeto criado. O método está definido como:

vtkImageLIC *vtkImageLIC::New()

\subsubsection{Método SetInputData()}

Este método é um dos mais importantes dessa classe, pois através dele o conjunto de dados é inserido dentro do objeto. O parâmetro para esse método deve ser obrigatoriamente do tipo vtkStructuredPoints que deve conter a topologia, geometria e campo vetorial definidos. $\mathrm{O}$ método está definido como :

void vtkImageLIC::SetInputData(vtkStructuredPoints *) 


\subsubsection{Método SetViewPlane()}

O método SetViewPlane define o plano de visão utilizado para gerar a visualização. Somente os planos paralelos aos eixos $x, y, z$ podem ser escolhidos. A escolha entre os planos XY, XZ e YZ é feita, respectivamente, pelas rotinas SetViewPlane(PLANE_XY), SetViewPlane(PLANE_XZ) e SetViewPlane(PLANE_YZ). O plano de visão padrão é o plano XY. Este método está definido como:

void vtkImageLIC::SetViewPlane(int)

\subsubsection{Métodos ToPlaneXY(),ToPlaneXZ(), ToPlaneYZ()}

Estes três métodos também estão associados ao plano de visão. Eles são usados para rotacionar todo o conjunto de dados de acordo com o plano de visão desejado. Isso é necessário, pois devido a uma limitação do VTK, não há a possibilidade de se calcular o valor do pixel de acordo com streamlines de planos diferentes, uma vez que a imagem é bidimensional e uma projeção da streamline no plano de imagem causa perda significativa de dados. O dado de entrada deve ser o conjunto de dados definido pela classe vtkStructuredPoints. A saída desse método é o mesmo conjunto de dados rotacionado de acordo com o plano de visão definido pelo método SetViewPlane() descrito na seção 5.4.3. A definição dos métodos é:

vtkStructuredPoints *vtkImageLIC::ToPlaneXY(vtkStructuredPoints *)
vtkStructuredPoints *vtkImageLIC::ToPlaneXZ(vtkStructuredPoints *)
vtkStructuredPoints *vtkImageLIC::ToPlaneYZ(vtkStructuredPoints *)

\subsubsection{Método SetSlice()}

Este método define qual fatia do volume de dados será usado no processo de interpolação da streamline com a textura de ruído, criando um plano paralelo ao plano definido pelo método SetViewPlane(). O parâmetro de entrada desse método é do tipo float e o valor padrão é 1.0 
(um), de modo que uma fatia de coordenada real pode ser selecionada. O método é definido como:

void vtkImageLIC::SetSlice (float)

\subsubsection{Método SetPropagationFactor()}

O método SetPropagationFactor() define o fator de propagação da streamline. Esse fator é usado para o cálculo do comprimento da streamline, influenciando assim a visualização final. O valor de entrada para esse método é do tipo de float e o valor padrão é 1.0 (um). Quanto maior for este valor, maior será o comprimento da streamline. A definição do método é:

void vtkImageLIC::SetPropagationFactor(float)

\subsubsection{Método SetNumberOfPointsPerCell()}

Este método define o número de pontos para o cálculo da streamline. Quanto maior esse valor, maior será a precisão da streamline, porém mais tempo será necessário para efetuar-se o cálculo da mesma. O parâmetro de entrada deve ser inteiro, e o valor padrão para esse parâmetro é 10 (dez). Esse parâmetro define a precisão da streamline em relação ao campo vetorial.Quanto mais pontos a streamline possuir, maior será a aproximação do campo vetorial. Porém quanto maior o número de pontos definidos, mais tempo será necessário para o cálculo dessa streamline. O valor definido como padrão alia a maior precisão possível com o menor custo computacional. O método é definido como:

void vtkImageLIC::SetNumberOfPointsPerCell(int)

\subsubsection{Método SetZoomFactor()}

O método SetZoomFactor() define o fator de ampliação (zoom) que a imagem gerada vai possuir. Esse fator é um múltiplo das dimensões do conjunto de dados. Este método aceita 
como dados de entrada valores reais maiores que 0 (zero). Valores entre 0.1 e 0.9 reduzem o tamanho da imagem resultante em relação ao conjunto de dados, aumentando assim a velocidade do cálculo. Valores maiores que 1.0 produzem imagens maiores que o conjunto de dados original, porém demandam um maior tempo para a geração dessa imagem. No entanto, a resolução da imagem não é alterada, ampliando também detalhes pequenos na imagem. $\mathrm{O}$ valor padrão para esse parâmetro é 1.0 (um), que indica que a imagem resultante terá o mesmo tamanho do plano definido no conjunto de dados. Este método é definido como:

void vtkImageLIC::SetZoomFactor(float)

\subsubsection{Método GetVectorRange()}

Este método retorna o intervalo de magnitudes do campo vetorial. Esse intervalo é utilizado no cálculo das cores da imagem que é baseado na magnitude do vetor. Note que esse método só pode ser usado depois que o conjunto dados for carregado através do método SetInputData() descrito na seção 5.4.2. O método é definido como:

float $*$ vtkImageLIC::GetVectorRange()

\subsubsection{Método CalculateHue()}

O método CalculateHue() retorna o valor da matiz da cor de acordo com o valor de entrada e com o intervalo de magnitude do campo vetorial. $\mathrm{O}$ valor de entrada para esse método é o valor da magnitude do vetor, que será normalizado e convertido para a matiz. O valor retornado por esse método varia de 60 a 360 . O método é definido como:

float vtkImageLIC::CalculateHue(float)

\subsubsection{Métodos SetColorMapOn() e SetColorMapOff()}


Os métodos SetColorMapOn() e SetColorMapOff() estão relacionados com o mapeamento de cores da magnitude do campo vetorial. O método SetColorMapOn() habilita a classe vtkImageLIC a exibir a magnitude do campo vetorial através do mapeamento por cores. Para desabilitar esse mapeamento basta utilizar o método SetColorMapOff(). Estes métodos são definidos como:

void vtkImageLIC::SetColorMapOn(void)

void vtkImageLIC:SetColorMapOff(void)

\subsection{O Método Execute()}

O método Execute() é o mais importante método da classe vtkImageLIC, pois através dele ocorre a geração da imagem de saída a partir do conjunto de dados de entrada. Os métodos apresentados anteriormente são usados apenas para se definir parâmetros ou executar pequenos cálculos. Já o método Execute() trata de todos os cálculos envolvidos na geração de imagem LIC, levando em consideração todos os parâmetros definidos anteriormente, como ZoomFactor, PropagationFactor, Slice entre outros. Por toda sua complexidade, as diversas partes que compõem esse método serão divididas em várias subseções para um melhor entendimento.

\subsubsection{A Textura de Ruído}

A primeira parte implementada dentro do método Execute() diz respeito à criação da textura de ruído. Esta textura deve ter as dimensões igual ou maiores que a imagem a ser produzida por esse processo. Assim sendo o tamanho da imagem é afetado pela dimensão do plano de visão escolhido do conjunto de dados e pelo fator de ampliação (ZoomFactor). Dessa maneira a textura deve ter dimensão igual ou superior a $\left(n_{x}\right.$ x ZoomFactor, $n_{y}$ x ZoomFactor $)$ onde $n_{x}$ e $n_{y}$ são as dimensões do conjunto de dados. Para a geração da textura de ruído com as dimensões definidas acima, usa-se a classe vtkImageNoiseSource [SCH98] que produz uma textura de ruído aleatório dadas as dimensões dessa textura. A textura gerada por essa classe pode ser 2D ou 3D, porém como a imagem resultante da classe vtkImageLIC é bidimensional, a textura é gerada com a dimensão no eixo $z$ igual 1 (um). O trecho de código do quadro 5.1 mostra como criar a textura de ruído citada acima: 


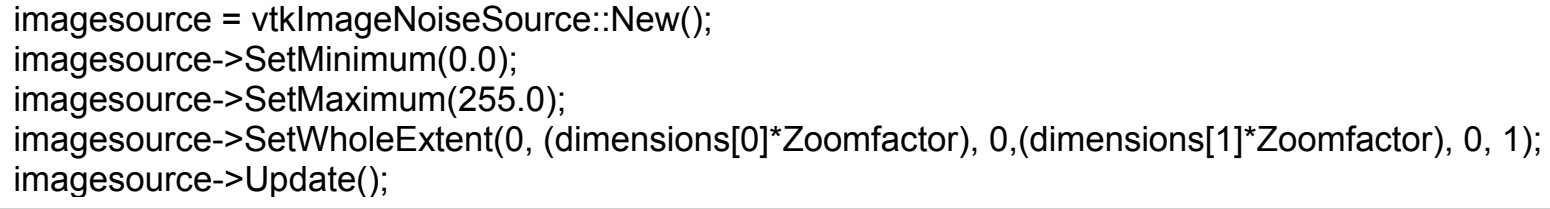

Quadro 5.1 - Trecho de código usado para gerar a textura de ruído através da classe vtkImageNoiseSource.

Após a geração desta textura, necessita-se transformar o espaço da textura para que possa ser utilizada com outras classes do VTK. Para isso usa-se a classe vtkImageToStructuredPoints [SCH98] que recebe como dados de entradas objetos do tipo vtkImage e retorna objetos do tipo vtkStructuredPoints. Com isso, cria-se um espaço de coordenadas para a textura.

\subsubsection{Geração das Streamlines}

Durante a criação da textura, o conjunto de dados de entrada permanece intacto. Não é necessário utilizá-lo, uma vez que a textura deve ser gerada aleatoriamente. Tendo a textura sido criada, parte-se para o cálculo das streamlines de acordo como campo vetorial do conjunto de dados de entrada.

O cálculo das streamlines é feito para cada ponto da fatia definida através dos métodos SetSlice() e SetViewPlane() (seções 5.4 .5 e 5.4.3, respectivamente). Isso é necessário, pois o campo vetorial pode influenciar diferentemente pontos adjacentes. E cada ponto definido pela streamline está associado um ponto da textura gerada anteriormente. Desse modo, a streamline é utilizada para interpolar os valores da textura de modo a obter o valor da intensidade a ser atribuído a esse ponto da fatia na imagem resultante. $\mathrm{O}$ cálculo da streamline deve ser feito para todos os pontos da fatia, de maneira a preencher todos os pontos da imagem resultante.

Para o cálculo das streamlines usa-se a classe vtkStreamLine definida pelo VTK [SCH98], que recebe como dados de entrada, através do método SetInput(), um campo vetorial definido dentro de uma classe vtkStructuredPoints. Utilizando o método de Runge-Kutta para a interpolação do campo vetorial, a classe vtkStreamLine gera uma streamline a partir de um ponto $(x, y, z)$ definido pelo método SetStartPosition() e em ambos sentidos do campo vetorial 
se o método SetIntegrationDirectionToIntegrateBothDirections() for utilizado. Os tamanhos do passo de integração e do passo dentro do campo vetorial podem ser definidos pelos métodos SetIntegrationStepLength() e SetStepLength(), respectivamente. O trecho de código utilizado para se calcular uma streamline para o ponto $(x, y, z)$ é mostrado no quadro 5.2.

O resultado da geração destas streamlines é uma estrutura poligonal representada dentro do VTK pela classe vtkPolyData [SCH98]. Esta classe define uma geometria irregular por meio da definição de pontos, retas, polígonos, e superfícies. Cada streamline gerada é representada dentro da classe vtkPolyData por uma célula (cell). Cada uma destas células é composta de pontos que são usados para a interpolação com a textura.

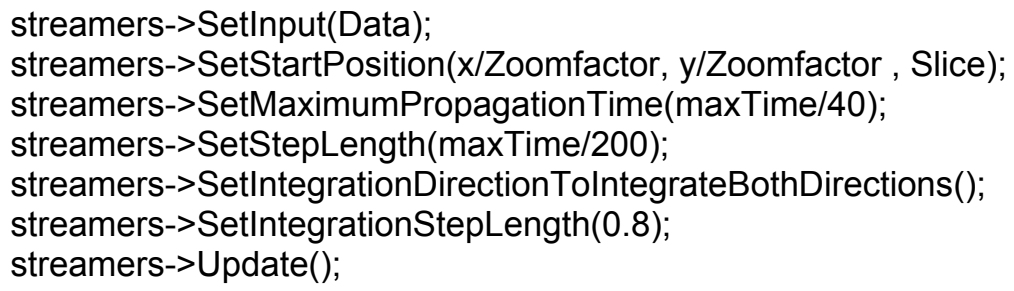

Quadro 5.2 - Trecho de código usado para gerar uma streamline a partir do ponto $(x, y, z)$.

\subsubsection{A Interpolação entre a Textura e as Streamlines}

Uma vez obtida a textura e as streamlines necessita-se, então, interpolar as classes que representam estas estruturas para obter, assim, a imagem LIC. A interpolação neste ponto torna-se simples. Para cada ponto da imagem final (ou da fatia definida) tem-se associada uma streamline. Essa streamline, por sua vez, tem definidos vários pontos que a compõe. Assim sendo toma-se cada ponto $(x, y, z)$ da streamline como sendo um ponto pertencente a textura de ruído. Desse modo, somam-se os valores de textura para todos os pontos da streamline, dividindo-os pelo número de pontos que compõe esta streamline. Esse valor obtido torna-se, então, o valor da intensidade do pixel para a imagem resultante. Uma vez que a imagem resultante usa o espaço HSV para definir suas cores, essa intensidade é atribuída ao campo "valor" (V) dessa tripla. Calculando-se essa interpolação para todos os pontos da imagem resultante, temos a imagem LIC que representa a fatia do conjunto de dados definida no início 
do processo. O resultado desse processo é armazenado na classe vtkImageData de forma a ser utilizado por outras classes do VTK para exibição na tela ou armazenamento em arquivos.

\subsubsection{Mapeamento por Cores da Magnitude Vetorial}

Uma melhoria introduzida neste trabalho é o mapeamento por cores para representar a magnitude do campo vetorial, uma vez que o LIC puro representa apenas a direção desse fluxo. Para isso, durante a interpolação entre a streamline e a textura (seção 5.5.3) calcula-se a magnitude normalizada do vetor no ponto $(x, y, z)$. Partindo deste valor, o método CalculateHue() da classe vtkImageLIC computa o valor da matiz para esse ponto. Desse modo, tem-se um pixel definido pela matiz (obtida a partir da magnitude do vetor), pelo valor (obtido a partir da direção e sentido do vetor), e por uma saturação constante, no caso deste trabalho com o valor máximo 1 (um).

Esse mapeamento por cores facilita a visualização do fluxo, uma vez que são exibidas simultaneamente duas informações: a magnitude e a direção do campo vetorial. Para campos vetoriais muito densos essa abordagem torna mais fácil a visualização global do campo, facilitando assim, o trabalho de investigação destes dados. A escala de cores vai do amarelo ao vermelho passando pelo verde e depois azul. Esta seqüência equivale à seqüência de cores do modelo HSV. Desse modo, a cor amarela representa a menor magnitude do conjunto de dados, assim como, a vermelha representa o vetor de maior magnitude do conjunto. 


\section{Resultados Obtidos}

\subsection{Considerações Iniciais}

Este trabalho teve por objetivo o estudo e implementação da técnica de visualização de dados vetoriais conhecida como Line Integral Convolution (LIC). Utilizando-se da biblioteca de classe VTK (Visualization Toolkit), implementou-se esta técnica segundo o paradigma de orientação a objetos. A classe implementada, chamada de vtkImageLIC, segue os mesmos padrões empregados pelo VTK. Desse modo garante-se completa integração dessa classe implementada com outras classes do VTK.

Este capítulo aborda os principais resultados obtidos com a implementação da classe vtkImageLIC. A seção 6.2 apresenta a visualização de um conjunto de dados de testes, gerados a partir de uma função simples. A seção 6.3 aborda a visualização de dados do campo magnético ao redor de um neurônio virtual. Finalmente a seção 6.4 detalha a visualização do fluxo de um fluido gerado a partir de simulação numérica.

\subsection{Visualização de um Conjunto de Dados de Teste}

O conjunto de dados ilustrado nessa seção não possui nenhum valor científico. Apenas foram usados para a calibragem dos parâmetros padrões da classe vtkImageLIC durante a fase de desenvolvimento e implementação. Esses dados foram gerados a partir de funções vetoriais simples.

Nesta seção, o conjunto de dados possui um campo vetorial circular em torno de um eixo $x$. A função usada para gerar este dados vetoriais é dada por:

$$
f(x, y, z)=(x,-z, y)
$$

O conjunto de dados possui dimensão de 60 vetores em cada eixo, e com origem no ponto $(0,0,0)$. Estes dados foram armazenados no formato VTK ASCII [SCH98] utilizando a classe 
escritora vtkStructuredPointsWriter. Um exemplo do cabeçalho deste arquivo é mostrado no quadro 6.1.

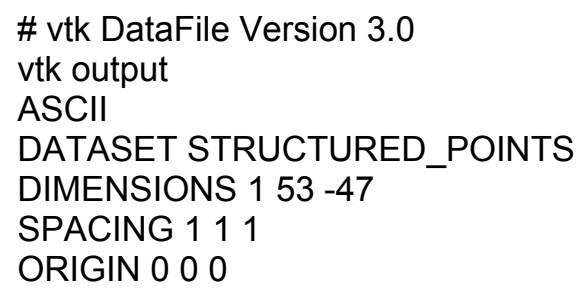

Quadro 6.1 - Cabeçalho de um arquivo de dados do VTK.

A figura 6.1 mostra uma visualização de seis fatias desse conjunto de dados. O fator de ampliação (ZoomFactor) é o valor padrão (um) e as fatias selecionadas são as de número: 5, $15,25,35,45,55$. Estas fatias possuem intervalos regulares ao longo de todo volume, uma vez que a função usada para gerar esse conjunto de dados produz dados simétricos ao redor da origem $(0,0,0)$.
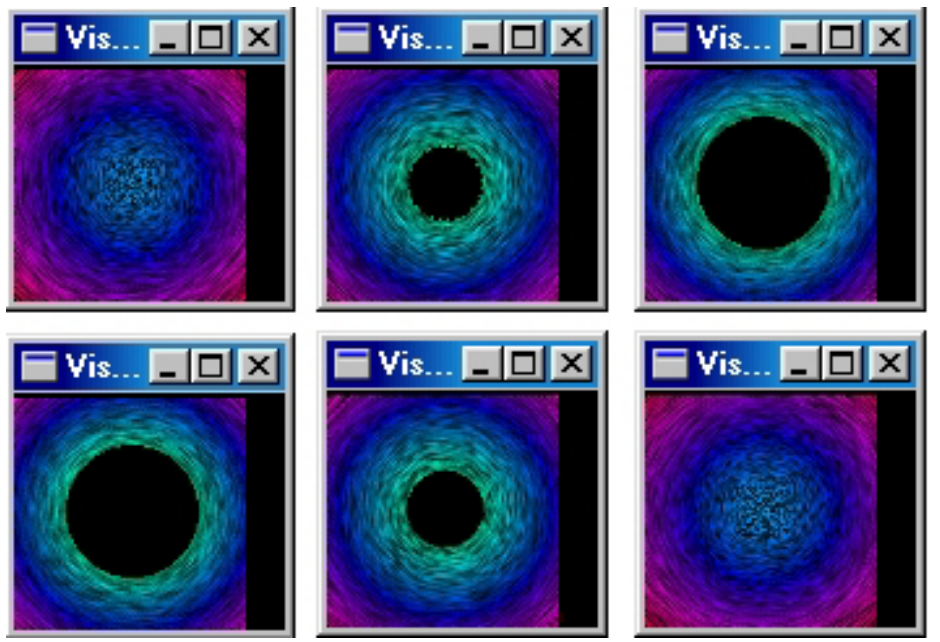

Figura 6.1 - Imagens LIC relativas às fatias 5, 15, 25, 35, 45 e 55 do conjunto de dados.

Os dados representados na figura 6.1 exibem claramente o campo vetorial. Porém muitas vezes necessita-se ampliar a imagem para analisar detalhes menores com maior precisão. Para isso basta alterar o parâmetro ZoomFactor. Na figura 6.2 são mostradas várias imagens com ZoomFactor 2.0, 3.0 e 4.0, respectivamente. Este parâmetro representa o fator de multiplicação em relação ao conjunto de dados original. 

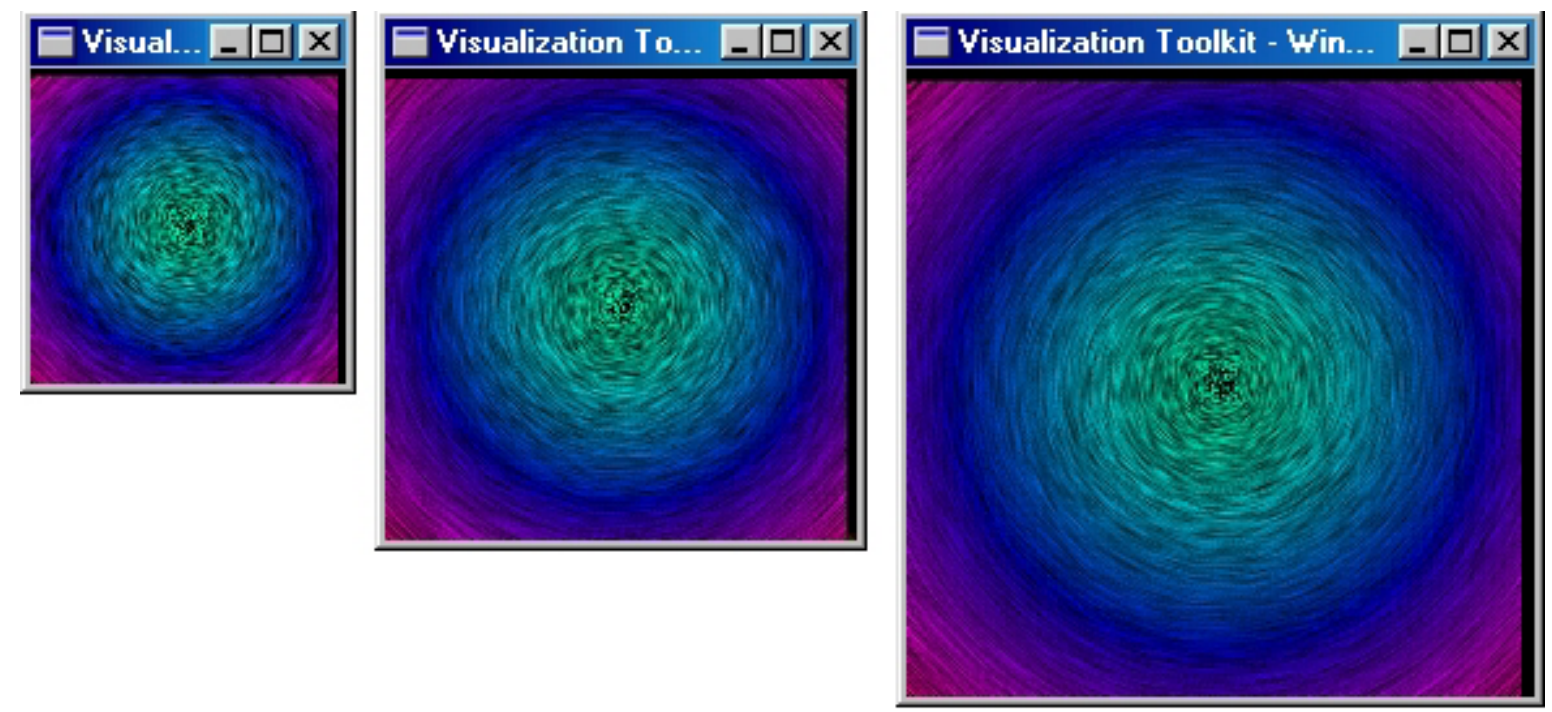

Figura 6.2 - Imagens LIC com fator de ampliação (ZoomFactor) igual a 2.0, 3.0 e 4.0 respectivamente.

Outro recurso importante da classe vtkImageLIC é o que permite a escolha de um plano de visão para o conjunto de dados através do método SetViewPlane(). A figura 6.3 mostra esse conjunto de dados utilizando os planos XY, XZ, YZ, respectivamente.
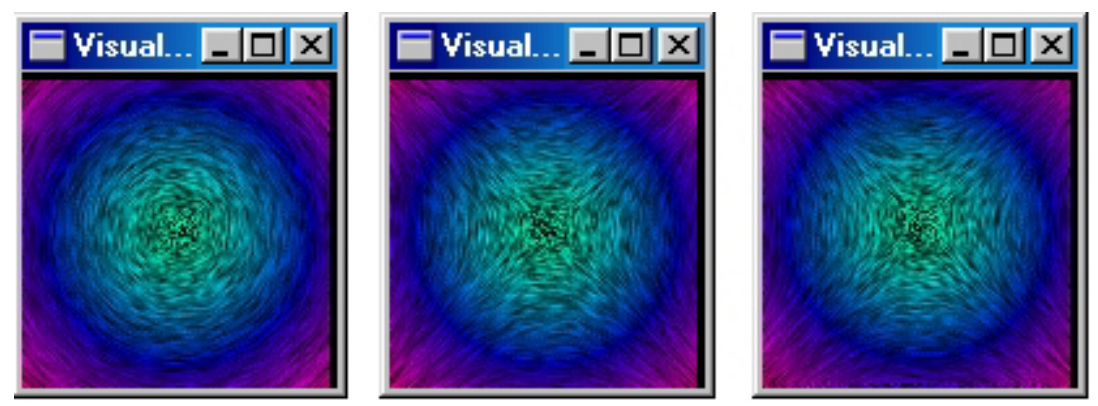

Figura 6.3 - Imagens LIC representando os planos XY, XZ, YZ respectivamente.

Todas as imagens mostradas anteriormente usam o mapeamento por cores implementado dentro da classe vtkImageLIC. A figura 6.4 mostra uma comparação entre uma imagem mapeada por cores, e outra, em tons de cinza. Para habilitar ou desabilitar esse mapeamento, usam-se os métodos SetColorMapOn() ou SetColorMapOff(). 

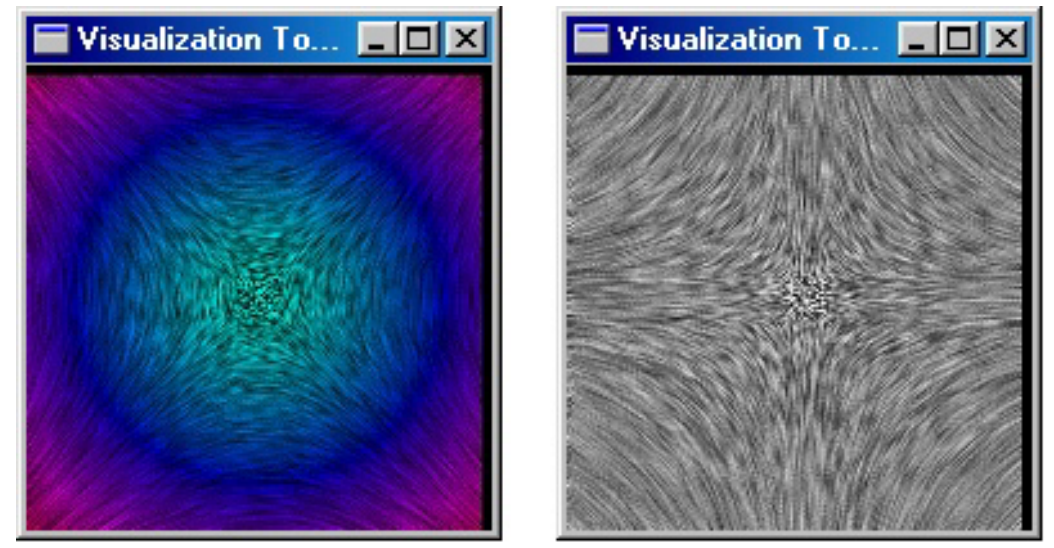

Figura 6.4 - Comparativo entre uma imagem LIC mapeada por cores e em tons de cinzas.

Este conjunto de dados possui 3600 vetores por fatia. Assim, todo o volume de dados possui 216000 vetores relevantes. Desse modo, torna-se inviável utilizar técnicas como streamlines, streamsurfaces [GRÖ99]. A técnica LIC gera uma imagem levando em consideração todo o conjunto vetorial, ao contrário de outras técnicas. Uma comparação entre uma imagem LIC e uma visualização por streamline é apresentada na figura 6.5. Essa imagem LIC leva em consideração todos os 3600 vetores da fatia selecionada. Já a visualização por streamlines usa apenas 144 vetores por fatia. Assim, a técnica implementada possibilita a visualização de mais informações que outras técnicas comumente usadas.
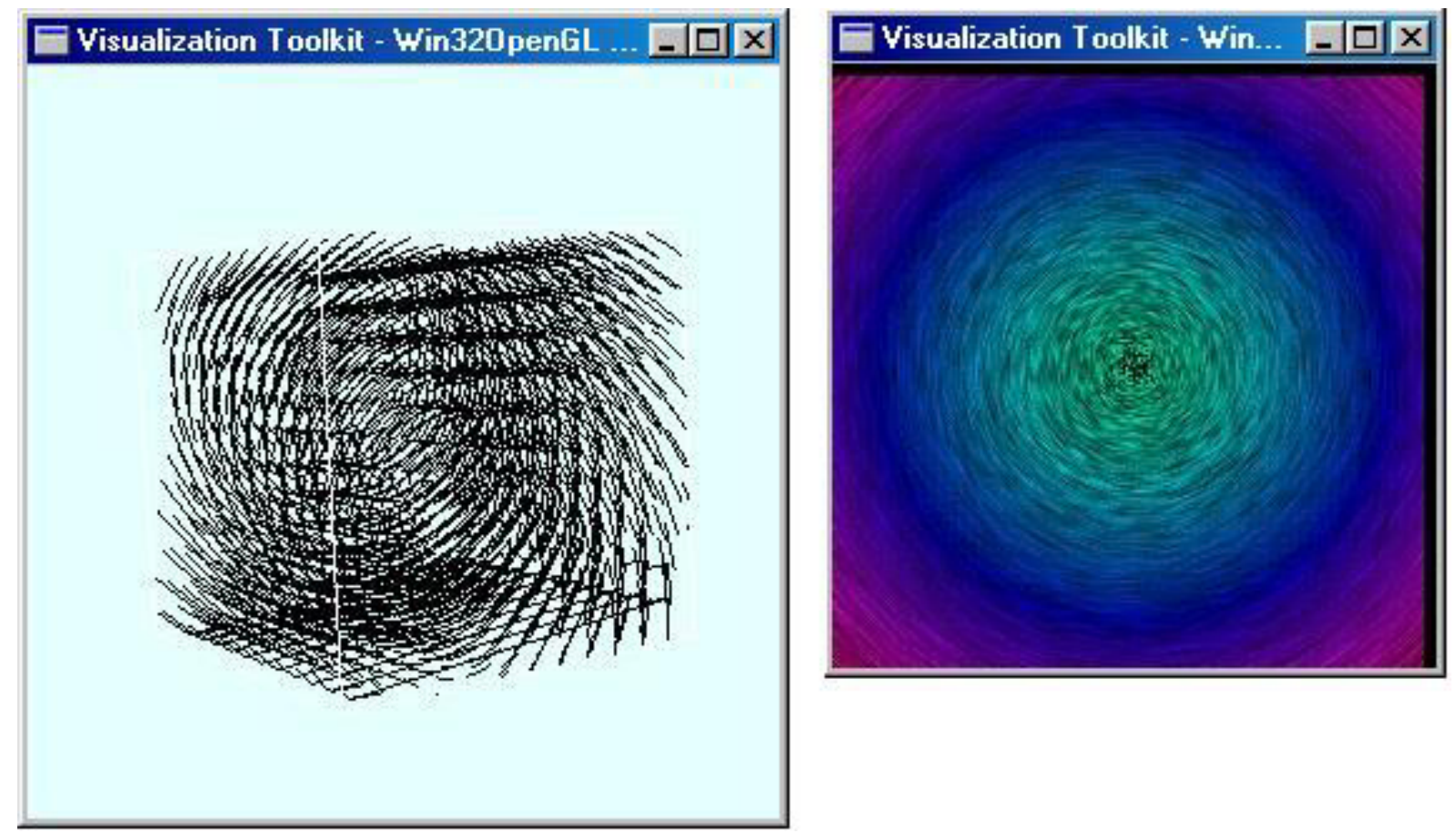

Figura 6.5 - Comparativo entre visualização por streamline (a esquerda) e uma imagem LIC (a direita). 


\subsection{Visualização de um Conjunto de Dados Vetoriais de um Neurônio Virtual}

O conjunto de dados apresentado nesta seção, representa um neurônio virtual gerado pelo Instituto de Física (IFSC) da Universidade de São Paulo, situado na cidade de São Carlos. Estes dados foram cedidos por esse instituto em função da cooperação com o Grupo de Computação Gráfica e Processamento de Imagens do Instituto de Ciências Matemáticas e Computação da Universidade de São Paulo.

Esse conjunto de dados possui dimensões de 60 x 60 x 60 vetores, nos eixos x, y, z, respectivamente. A densidade de dados desse conjunto é muito alta, sendo um conjunto que se adequa perfeitamente nos requisitos e propostas da classe vtkImageLIC. Assim, é possível gerar boas visualizações em todos os eixos, ao contrário do que seria esperado, caso os dados fossem esparsos.A figura 6.6 mostra imagens LIC desse conjunto de dados. As fatias apresentadas são as de número 24, 26, 28, 30, 32, 34, 36 e 38. Esse intervalo concentra os dados mais relevantes desse conjunto.
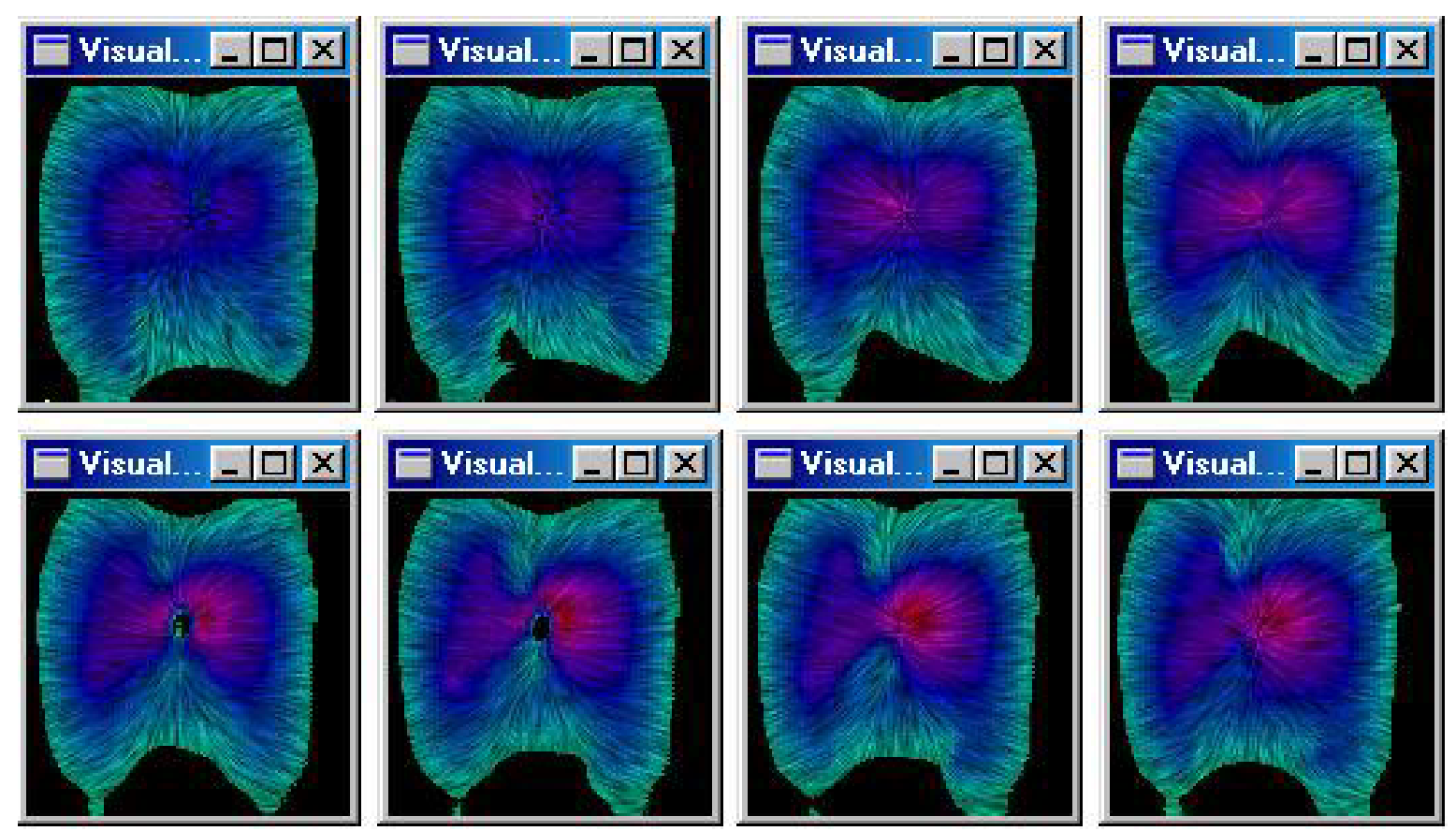

Figura 6.6 - Fatias de número 24, 26, 28, 30, 32, 34, 36 e 38 do conjunto de dados vetoriais de um neurônio virtual. 
A figura 6.7 mostra imagens LIC desse conjunto de dados pelos planos de visão XY, XZ, YZ. Por ser densamente definido, este conjunto de dados permite gerar imagens nos vários planos de visão. Isso facilita a compreensão do volume de dados, uma vez que a classe vtkImageLIC apenas produz imagens bidimensionais.
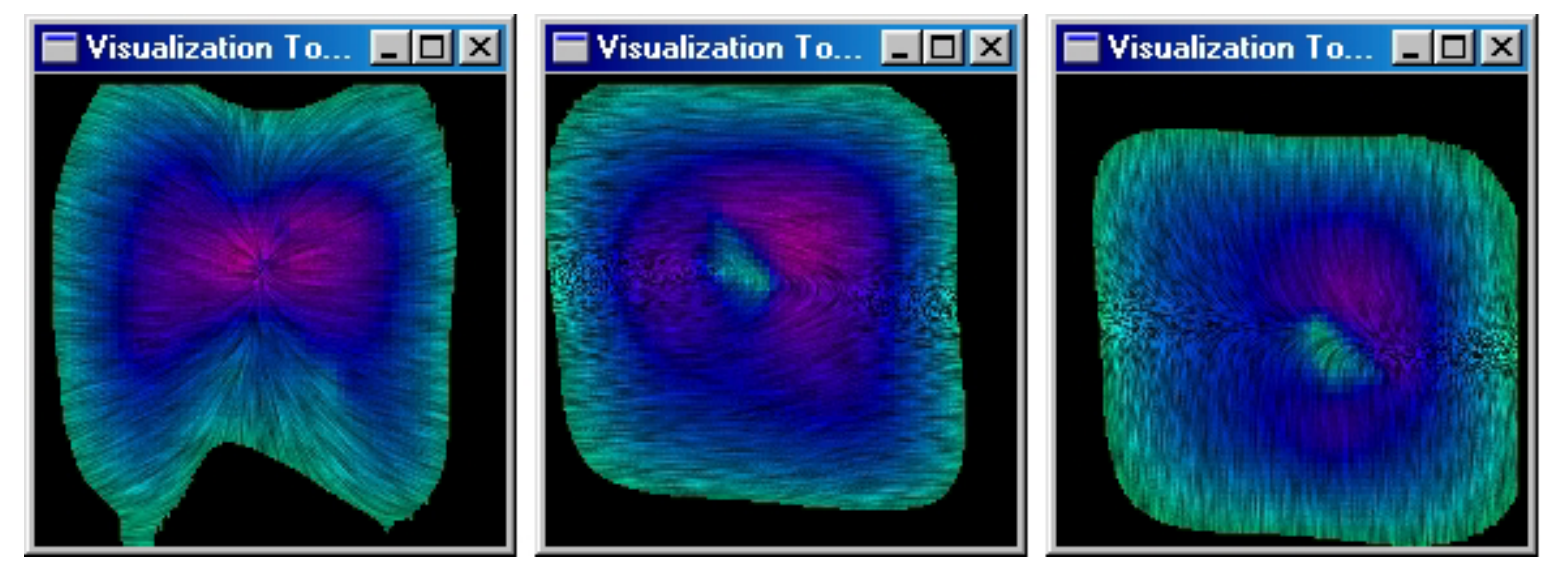

Figura 6.7 - Imagens LIC dos dados vetoriais de um neurônio virtual pelo planos XY, XZ, YZ, respectivamente.

Mais uma vez o mapeamento de cores torna-se fundamental na compreensão do conjunto de dados. Uma comparação entre uma imagem mapeada por cores e outra apenas com intensidades de cinza é apresentada na figura 6.8.
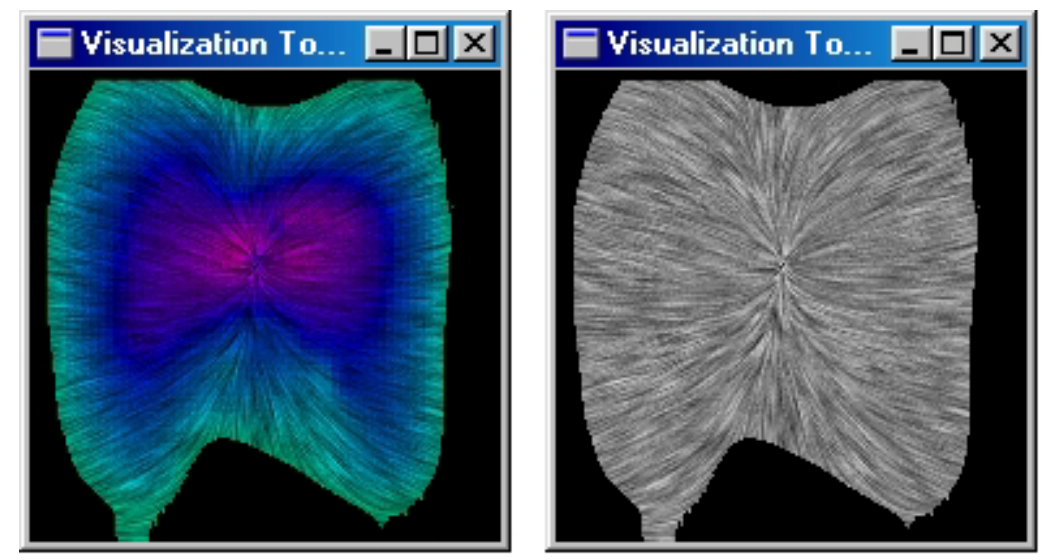

Figura 6.8 - Comparativo entre imagens LIC colorida e em tons de cinzas do campo vetorial de um neurônio virtual .

Na figura 6.9 é mostrada uma imagem LIC em comparação com uma visualização por streamline. Novamente a imagem LIC, por considerar mais dados para a geração da imagem, 
permite uma visualização mais rica do que aquela gerada pela técnica de streamline. Nesse caso a imagem LIC considerou aproximadamente 30000 vetores por fatia, enquanto a visualização por streamlines considerou apenas 124 vetores.
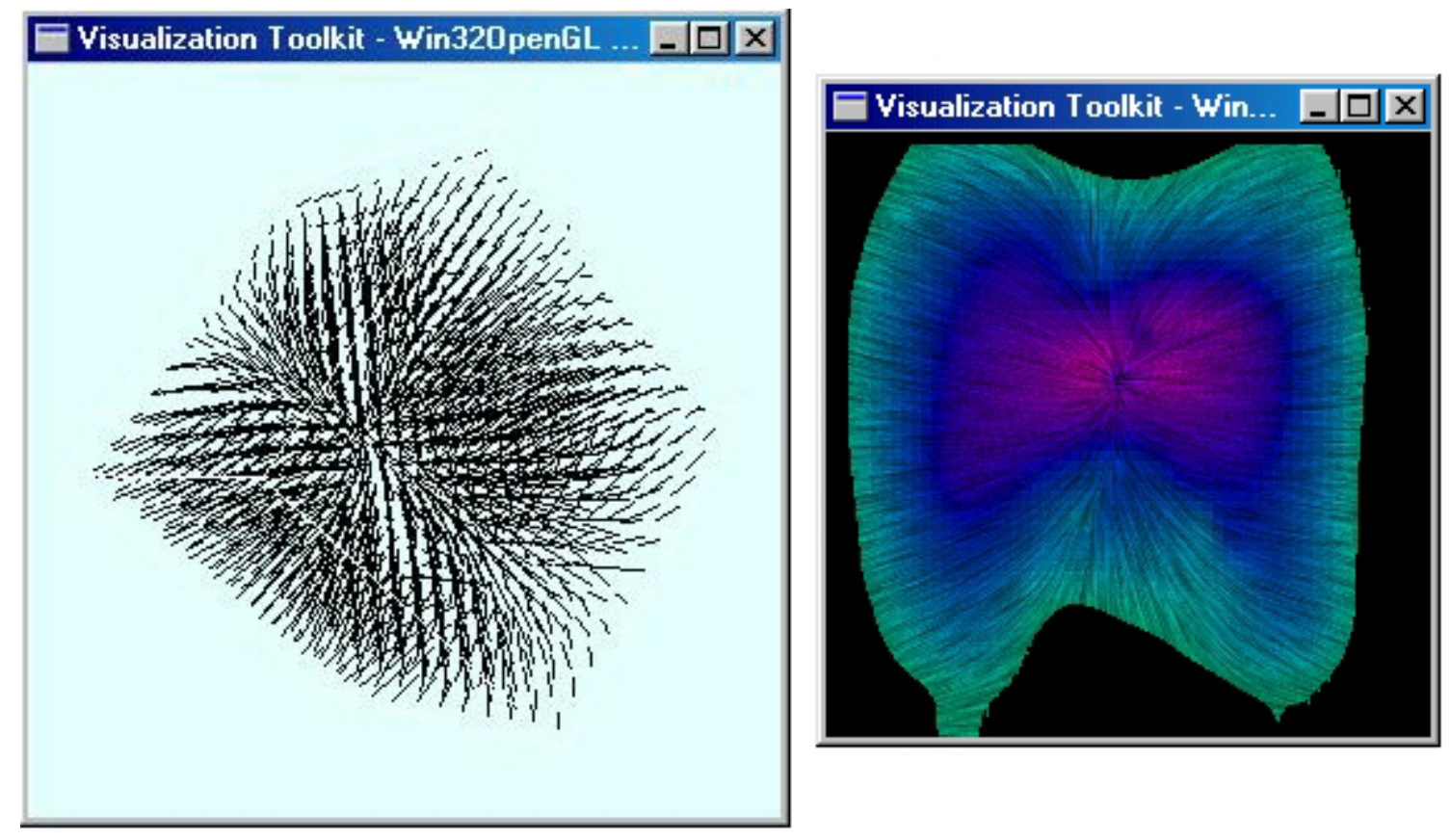

Figura 6.9 - Comparativo entre uma visualização por streamline e uma imagem LIC.

\subsection{Visualização de um Conjunto de Dados Esparsos}

A classe vtkImageLIC apresenta bons resultados para um conjunto de dados densos como o caso do campo vetorial do neurônio vetorial apresentado na seção 6.3. O conjunto de dados apresentado nesta seção possui um campo vetorial esparso. A classe vtkImageLIC não foi implementada visando este tipo dados. Porém este é um caso onde, mesmo sendo esparsos, a técnica LIC facilita a visualização do fenômeno representado. A figura 6.10 mostra os dados relativos às fatias de número 8.0, 8.2, 8.4, 8.5, 8.7 e 8.9 pelo plano de visão $\mathrm{XY}$, do volume de um fluido com dados vetoriais esparsos. Esses dados foram gerados por simulações numéricas do Grupo de Dinâmicos dos Fluidos do Instituto de Ciências Matemáticas e Computação da Universidade de São Paulo.

Apesar deste conjunto de dados produzir imagens interessantes no plano XY, não produz imagem alguma nos planos XZ e YZ, pois nestes planos os dados são totalmente esparsos. 
Isso pode ser verificado na imagem por streamlines da figura 6.11. Uma imagem LIC também é apresentada nesta figura, para efeito comparativo entre as técnicas.
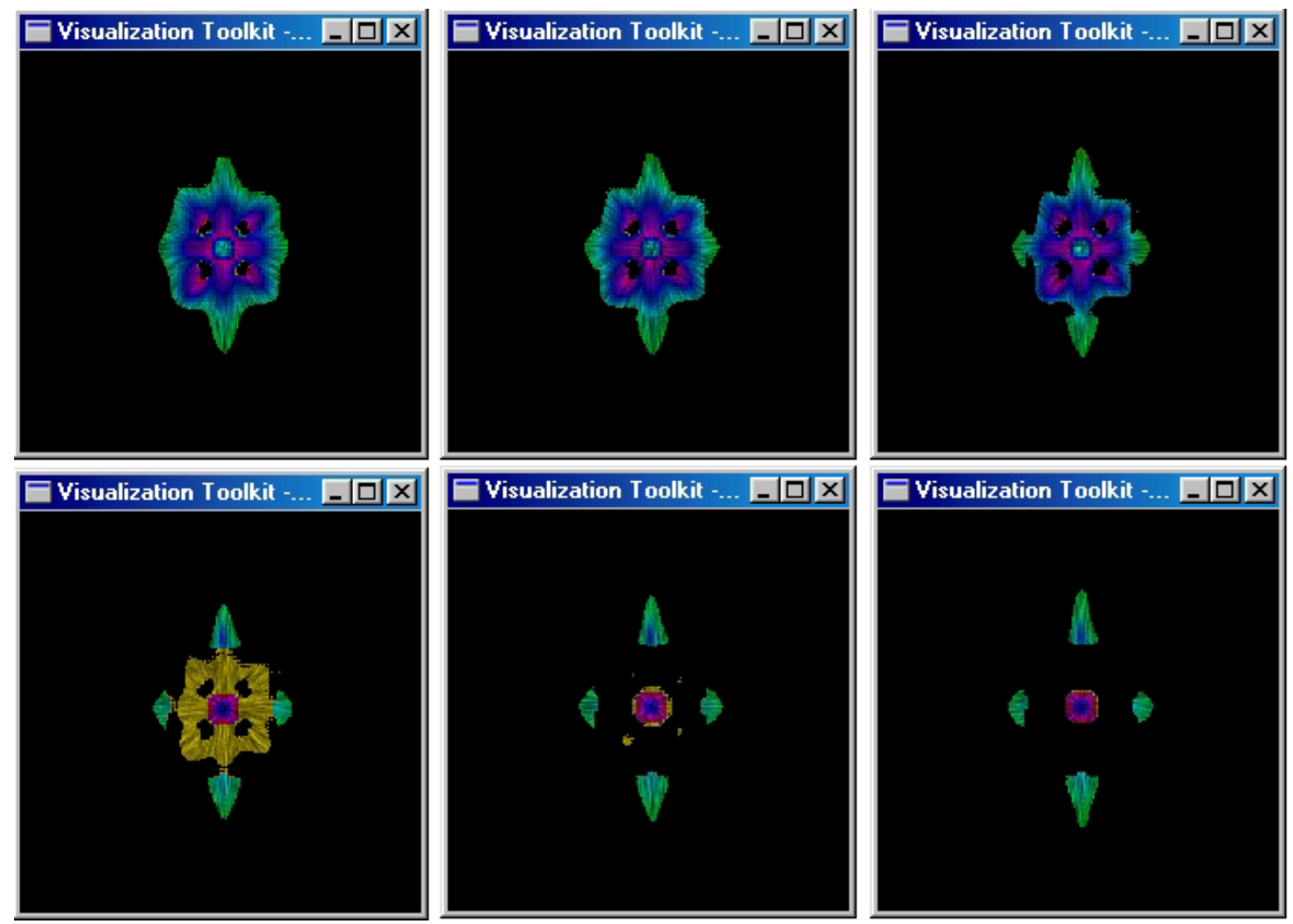

Figura 6.10 - Fatias de número 8.0, 8.2, 8.4, 8.5, 8.7, 8.9 do conjunto de dados esparsos de um fluido gerado por simulações numéricas.

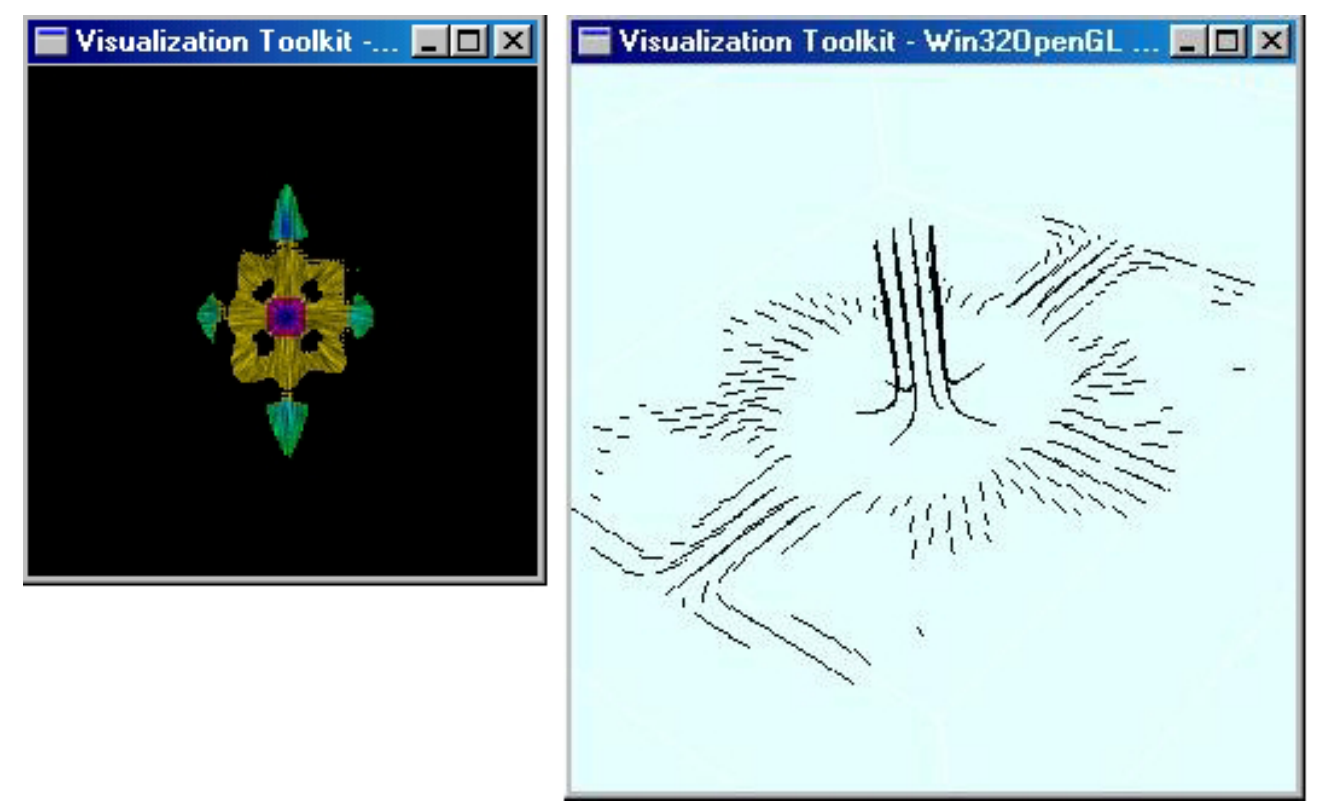

Figura 6.11 - Comparativo entre visualização por streamlines e imagem LIC. 
O mapeamento por cores usado neste conjunto de dados torna mais fácil a visualização do comportamento do fluido. Neste conjunto de dados as cores representam a velocidade do fluido. A figura 6.12 mostra esse conjunto de dados visualizado com cores e em tons de cinzas.
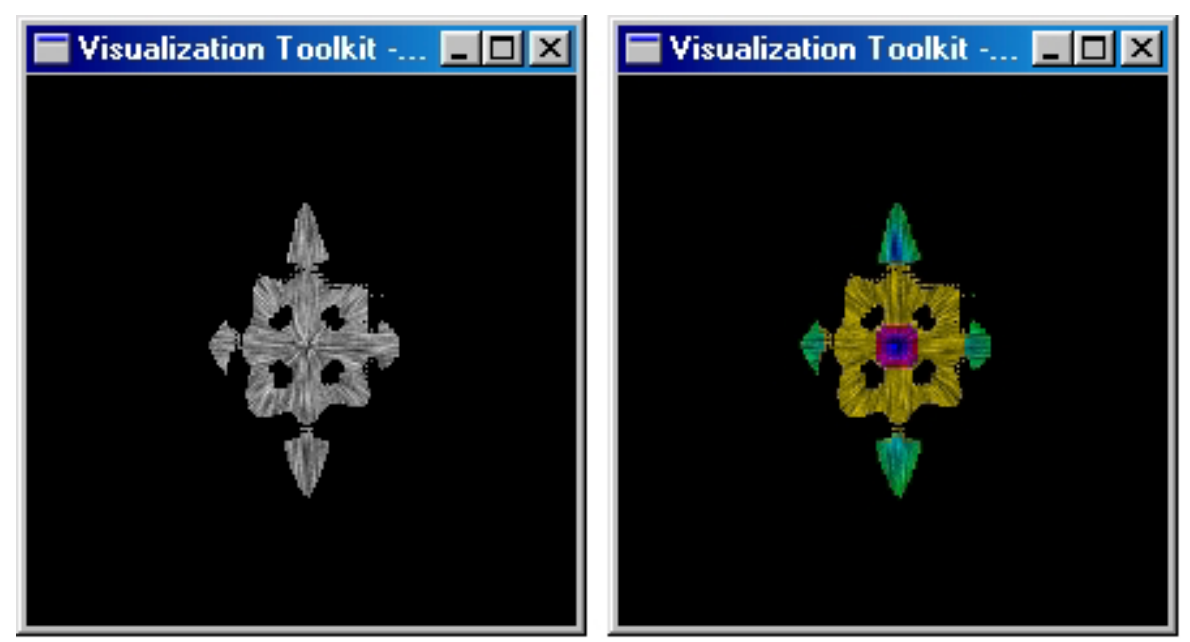

Figura 6.12 - Comparativo entre imagens com mapeamento por cores e em tons de cinzas. 


\section{Conclusões}

A classe vtkImageLIC implementada neste trabalho tem por objetivo gerar visualizações bidimensionais de um conjunto de dados vetoriais densos. Apesar disso, o conjunto de dados deve estar definido num domínio tridimensional, uma vez que os cálculos executados por esta classe necessitam de um volume de dados tridimensionais e de um plano de visão.

Como apresentado no capítulo 6, a classe vtkImageLIC produz bons resultados na visualização de dados vetoriais densos. Estes dados são considerados densos por conterem uma grande quantidade de dados relevantes ao fenômeno por eles representados. Os conjuntos de dados apresentados na seção 6.2 e 6.3 possuem essas características. Já o conjunto de dados apresentado na seção 6.4 possui dados relevantes apenas em algumas regiões, o que faz com que a visualização do fenômeno seja restrita àquela região.

A implementação da classe vtkImageLIC obedeceu o estilo ANSI $\mathrm{C} / \mathrm{C}++$ de programação, o que garante grande portabilidade entre diferentes compiladores $\mathrm{C} / \mathrm{C}++$ e sistemas operacionais (Linux, Windows e UNIX).

A adoção do paradigma de orientação a objetos também possibilitou que a classe vtkImageLIC fosse incluída e se tornasse, assim, parte integrante da biblioteca VTK podendo interagir diretamente com as classes pertencentes ao VTK. Isso contribuiu para a portabilidade, uma vez que a biblioteca VTK é flexível e facilmente extensível (como citado no capítulo 5).

Por pertencer ao VTK a classe vtkImageLIC se tornou facilmente extensível. Isso possibilita que outras funcionalidades e até melhorias nas funcionalidades já existentes possam ser facilmente implementadas. Algumas propostas para isso são apresentadas na seção subseqüente. 


\subsection{Trabalhos Futuros}

A classe vtkImageLIC implementada neste trabalho possui funcionalidades que suprem a proposta apresentada no projeto original de mestrado. Porém, estas funcionalidades não esgotam as possibilidades desta técnica. Pelo contrário, permite muitas extensões e melhorias.

O mapeamento de cores implementado nesta classe, possui uma paleta de cores fixa. Isso garante uma visualização adequada da magnitude do campo vetorial. Porém, um pesquisador poderia definir sua própria paleta de cores de maneira a realçar algumas características particulares do seu conjunto de dados.

Uma vez que a classe utiliza imagens RGB e funções de conversão entre o espaço RGB e o espaço HSV usado para os cálculos, sua extensão para a utilização de outro espaço de cor, ou até mesmo a definição do intervalos de magnitudes para esse mapeamento torna-se fácil, enriquecendo, assim, as funcionalidades desta classe.

A visualização gerada pela classe vtkImageLIC não permite a distinção de sentido do campo vetorial, uma vez que a imagem gerada é estática. Porém, ao variar-se a textura de ruído para uma mesma fatia do conjunto de dados, será permitido que esta seqüência de imagens gerada, seja animada de forma a mostrar o sentido do campo vetorial.

A implementação da classe permite que várias imagens sejam geradas com texturas de ruídos diferentes, uma vez que para cada imagem gerada, uma textura nova é criada aleatoriamente. Assim sendo, a implementação de um método ou classe que gere uma animação a partir das imagens LIC gerada por esta classe é uma tarefa desejável e interessante.

O plano de visão definido na classe vtkImageLIC é restrito aos planos principais XY, XZ, YZ. A implementação de um método para a definição de um plano de visão arbitrário torna essa classe muito poderosa, uma vez que, a partir disso, uma imagem LIC poderia ser gerada de qualquer fatia pertencente ao volume. Porém, isto não é um trabalho trivial, pois a geração das streamlines durante o cálculo da imagem LIC deveria considerar essa mudança de orientação. 
Outro problema a ser enfrentado no caso de um plano visão arbitrário é que as imagens não tem as mesmas dimensões ao longo de um plano de visão. Por exemplo, no caso do plano de visão ser perpendicular à diagonal do volume de dados. As dimensões das imagens variam ao longo da diagonal, variando de 1 nas extremidades da diagonal e chegando a um valor máximo no meio dessa diagonal. Isso causa problemas tanto no cálculo da imagem, como no cálculo das streamlines.

\subsection{Considerações Finais}

A classe vtkImageLIC implementada neste trabalho auxilia o pesquisador a visualizar conjuntos de dados vetoriais de maneira mais simples, e por fatias, permitindo a seleção de regiões especificas do volume. Além disso, é de fácil utilização, uma vez que os valores padrões das propriedades desta classe, geram uma visualização adequada para a maioria dos conjunto de dados.

Para conjuntos de dados com características particulares, os métodos implementados permitem alterar as propriedades desta classe, tornando-a mais flexível. A adição ou melhoria dos métodos implementados também pode produzir uma robustez maior desta classe, de maneira a tratar outros conjuntos de dados ou prover outras funcionalidades não previstas neste trabalho. 


\section{Referências Bibliográficas}

[BRO92] Brodlie, K.W., et al., Scientific Visualization Techniques and Applications, Springer-Verlag, 1992.

[CAB93] Cabral, L., Leedom, L.C., "Imaging Vector Fields Using Line Integral Convolution”, Computer Graphics Procedings, pp. 263-270, ACM Press, 1993.

[CRO90] Crow, F. C, “Texture” in Rogers, D. F, Earnshaw, R. A (eds), Computer Graphics Techniques - Theory and Pratice, pp. 159-187, Springer-Verlag, 1990.

[EBE98] Ebert. D. S., et al., Texturing \& Modeling - A Procedural Approach, 2a Edição, Academic Press Professional, 1998.

[FOL90] Foley, J. D., et al., Computer Graphics - Principles and Pratice, 2a edição, AddisonWesley, 1990.

[GEL96] Gelder, A., Kim, K, "Direct Volume Rendering with Shading via ThreeDimensional Textures", University of California, CA, tech report, July, 1996.

[GER94] Gershon, N. - "From Perception to Visualization", in Rosemblum, L. et al. (eds), Scientific Visualization, Advances and Challenges, Academic Press, 1994.

[GRÖ99] Gröller, E., et al, "Visualization of Dynamical Systems", Future Generation Computer Systems, vol. 15, pp. 75-86, Elsevier Science, 1999.

[HEA94] Hearn, D., Baker, P. - Computer Graphics in C, Prentice-Hall, 1994

[KIU96] Kiu, M., Banks, D. C., "Multi-Frequency Noise for LIC", Proceedings of Visualization'95, IEEE Press, pp. 121-126, 1996.

[MIN97] R. Minghim e M.C.F. de Oliveira, "PowerVis: Empowering the User with a MultiModal Visualization System", Proceedings II Workshop on Cybernetic Vision, dezembro de 1996, IEEE CS Press, 1997, pp. 106-111.

[MIN97a] R. Minghim e M.C.F. de Oliveira, "Uma Introdução à Visualização Computacional", XVI JAI - Jornadas de Atualização em Informática, XVII Congresso da Sociedade Brasileira de Computação, cap. 3, pp. 85-132.

[OLI98] M.C.F. de Oliveira; R. Minghim; S.M. Tutida e V.C. Salvador, "Towards Perception Driven Visualization", Proceedings 1998 International Symposium on Computer Graphics, Image Processing and Vision (SIBGRAPI'98), Rio de Janeiro, RJ, 20 a 23 de outubro de 1998, pp. 127-134. 
[OLI98a] M.C.F. de Oliveira e R. Minghim. Visualization Experiences in the Light of Visualization Effectiveness. Proceedings Int. Symposium on Advances on Signal, Image Processing, Computer Vision and Graphics of the World Multiconference on Systemics, Cybernetics and Informatics (SCI-98), Orlando, USA, 12 a 16 de julho de 1998, pp. 529536.

[PER85] Perlin, K., “An image synthesizer”, Computer Graphics, Vol. 19, pp. 287-296, 1985.

[PRE92] Press, William H. et.al., "Numerical Recipes in C - The Art of Science Computing", Second Edition, Cambridge University Press, 1992.

[POS99] Post, F. H., et al, "Global, geometric, and feature-based techniques for vector field visualization", Future Generation Computer Systems, vol. 15, pp. 87-98, Elsevier Science, 1999.

[SOA00] Soares, I. P., Visualização Volumétrica em Odontologia, Dissertação de Mestrado, ICMC-USP, maio de 2000.

[SCH98] W. Schroeder; K. Martin e B. Lorensen. The Visualization Toolkit: An ObjectOriented Approach to 3D Graphics. $2^{\text {a }}$ edição, Prentice-Hall, 1998.

[SHI98] M.H. Shimabukuro; R. Minghim e P.R.D.B. Licciardi. Visualization and Reconstruction in Dentistry. Proceedings Information Visualization'98 (IV'98), Londres, Reino Unido, julho de 1998, IEEE CS Press, pp. 25-31.

[TES98] Teschner, M., Henn C., “Texture Mapping in Technical, Scientific, and Engineering Visualization”, SIGGRAPH'98 Course Notes 17, 1998, 17 p.

[TUT98] S.M. Tutida. Mapeamento por Cores Baseado em Aspectos de Percepção Visual. Dissertação de Mestrado, ICMC-USP, maio de 1998.

[WAT92] Watt, A., Watt, M., Advanced Animation and Rendering Techniques - Theory and Pratice, Addison-Wesley, 1992.

[WIJ91] van Wijk, J.J., "Spot Noise - Texture Synthesis for Data Visualization", Computer Graphics, vol 25, n. 4, July, 1991.

[WIJ95] van Wijk, J.J., "Enhanced Spot Noise for Vector Field Visualization", Proceeding of Visualization'95, IEEE Press, pp. 233-239, 1995

[WIL83] Willians, L., "Piramidal parametrics”, Computer Graphics, Vol. 17, pp. 1-12, 1983. 


\section{Apêndice}




\section{A Método vtkImageLIC::Execute()}

O trecho de código mostrado abaixo pertence ao método Execute() da classe vtkImageLIC, e é usado na geração da imagem LIC para o plano XY. Para os demais planos, a implementação é análoga.

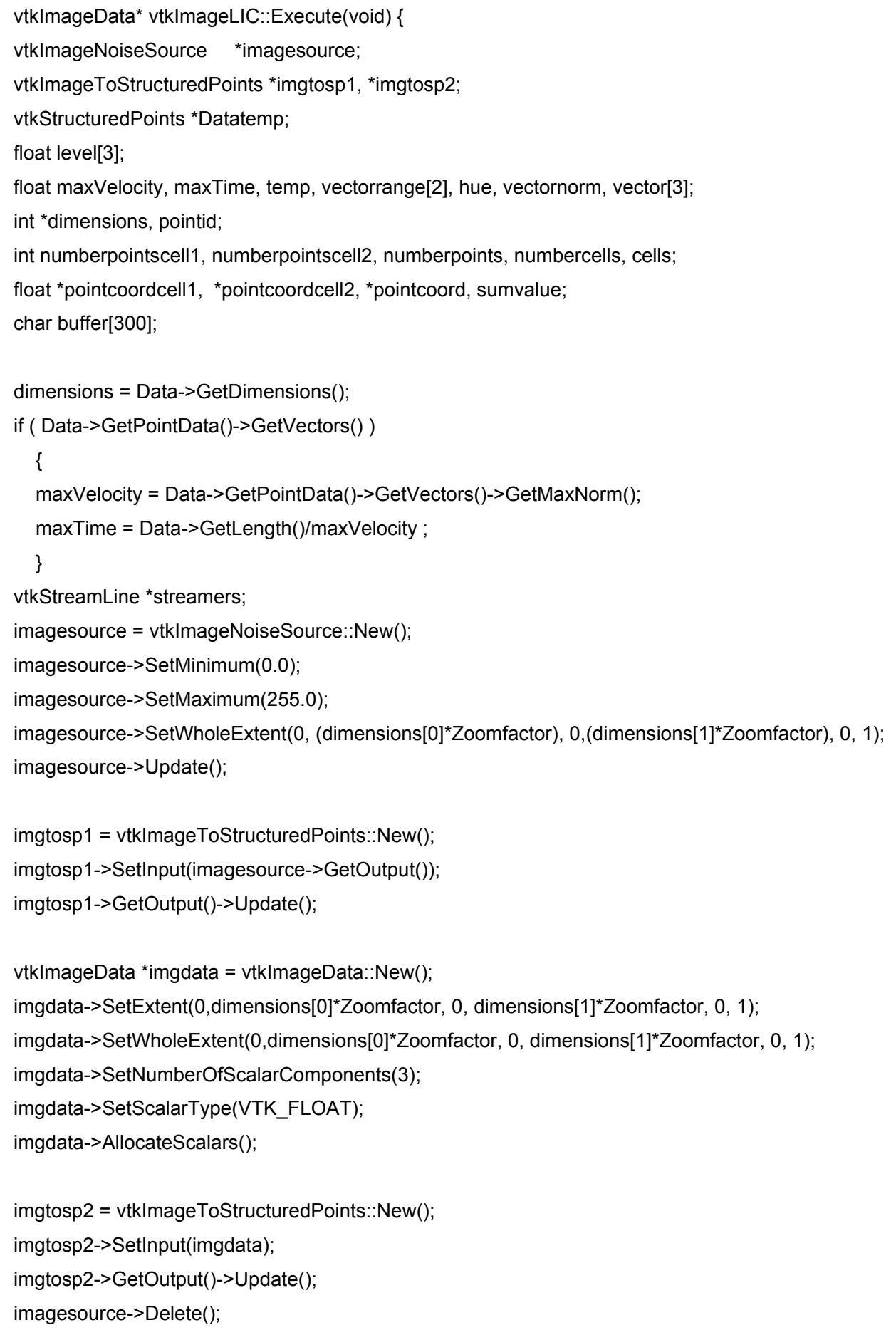


this-> GetVectorRange();

switch (ViewPlane) \{

// XY Plane

case 0:

Data $=$ this $->$ ToPlaneXY $($ Data $)$;

for (int $y=0 ; y<\left((\text { dimensions[1]-1 })^{\star}\right.$ Zoomfactor $\left.) ; y++\right)$

\{

for (int $x=0 ; x<\left((\text { dimensions }[0]-1)^{\star}\right.$ Zoomfactor $\left.) ; x++\right)$

\{

streamers= vtkStreamLine::New();

streamers->SetInput(Data);

streamers->SetStartPosition(x/Zoomfactor, y/Zoomfactor , Slice);

streamers->SetMaximumPropagationTime(maxTime/40);

streamers->SetStepLength(maxTime/200);

streamers->SetIntegrationDirectionTolntegrateBothDirections();

streamers->SetIntegrationStepLength(0.8);

streamers->Update();

numbercells=streamers->GetOutput()->GetNumberOfCells()-1;

cells $=0$;

for (int $\mathrm{j}=0$; cells $<$ numbercells; $j++$ )

\{

numberpointscell1 $=$ =streamers $>$ GetOutput()->GetCell(cells)- $>$ GetNumberOfPoints();

numberpointscell2=streamers $->$ GetOutput() $->$ GetCell(cells +1$)->$ GetNumberOfPoints();

pointcoordcell1 =streamers $>$ GetOutput() $->$ GetCell(cells) $->$ GetPoints() $->$ GetPoint( $(0)$;

pointcoordcell2=streamers $->$ GetOutput() $->$ GetCell(cells+1)->GetPoints()->GetPoint(0);

sumvalue $=0.0$;

numberpoints $=0$;

pointcoordcell1[2] $=0$;

pointcoordcell2[2] $=0$;

if $(($ pointcoordcell1[0] $==$ pointcoordcell2[0]) \&\& (pointcoordcell1[1] == pointcoordcell2[1]) $)$

\{

pointid $=$ imgtosp1->GetOutput()->FindPoint(pointcoordcell1[0] $]^{\star}$ Zoomfactor, pointcoordcell1[1 $]^{\star}$ Zoomfactor,

0/*pointcoordcell1[2]*/);

imgtosp1->GetOutput()->GetPointData()->GetScalars()->GetData()->GetTuple(pointid,level);

sumvalue = level[0];

pointid=imgtosp1->GetOutput()->FindPoint(pointcoordcell2[0]*Zoomfactor, pointcoordcell2[1] $]^{\star}$ Zoomfactor,0);

imgtosp1->GetOutput()->GetPointData()->GetScalars()->GetData()->GetTuple(pointid,level);

sumvalue = sumvalue + level[0];

numberpoints $=2$;

for (int $\mathrm{i}=1 ; \mathrm{i}<$ numberpointscell $1 ; \mathrm{i}++$ )

\{

pointcoord $=$ streamers $->$ GetOutput() $->$ GetCell(cells) $->$ GetPoints() $->$ GetPoint(i);

pointcoord[2] = 0 ;

if $(($ pointcoord $[0]>=0) \& \&$ (pointcoord $[0]<($ dimensions[0]-1)) \&\& (pointcoord[1] $>=0) \& \&$ (pointcoord[1] $<$ (dimensions[1]-1)))

\{

pointid=imgtosp1->GetOutput()->FindPoint(pointcoord[0]*Zoomfactor, pointcoord[1]Zoomfactor,0); 


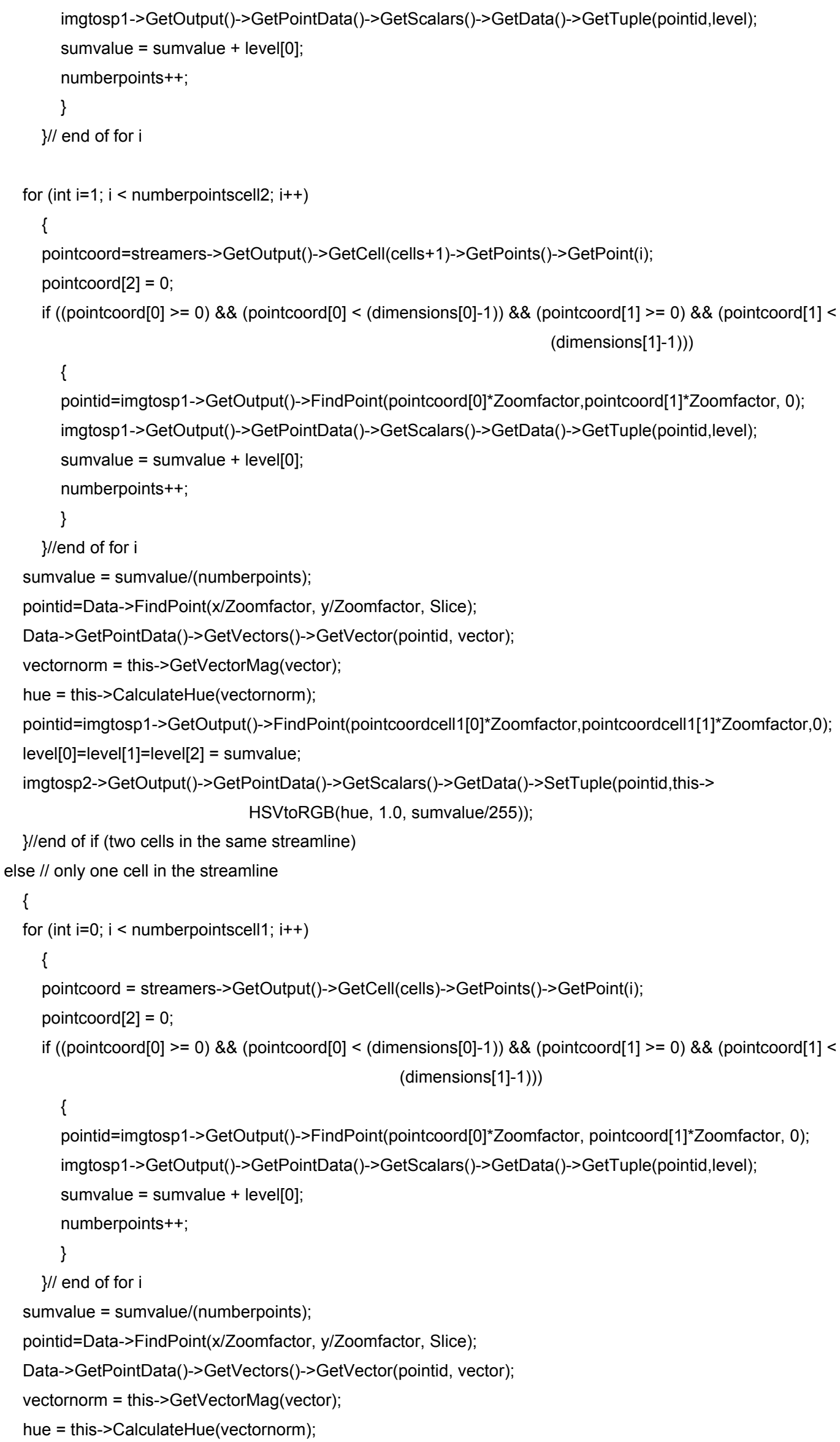


pointid=imgtosp1->GetOutput()->FindPoint(pointcoordcell1[0]Zoomfactor,pointcoordcell1[1] Zoomfactor,0); level[0]=level[1]=level[2] = sumvalue;

imgtosp2->GetOutput()->GetPointData()->GetScalars()->GetData()->SetTuple(pointid,this-> HSVtoRGB(hue, 100.0, sumvalue/2.55));

\} // end of else (only one cell in the streamline)

cells++;

\} // end of for $\mathrm{j}$

streamers->Delete();

\}//end of for $x$

\}// end of for $Y$

break; // end of Plane XY 